Aus der Klinik für Kardiologie und Pneumologie

(Prof. Dr. med. G. Hasenfuß)

der Medizinischen Fakultät der Universität Göttingen

\title{
Der Transkriptionsfaktor GATA4 und seine Rolle in der Entwicklung kardialer Hypertrophie
}

\author{
INAUGURAL-DISSERTATION \\ zur Erlangung des Doktorgrades \\ der Medizinischen Fakultät der \\ Georg-August-Universität zu Göttingen
}

vorgelegt von

André Wilken

aus Damme

Göttingen 2016 
Dekan:

Referent:

Korreferent:

Drittreferent:

Datum der mündlichen Prüfung:
Prof. Dr. rer. nat. H. K. Kroemer

Prof. Dr. Rolf Wachter

Prof. Dr. Markus Bohnsack

Prof. Dr. Martin Oppermann

29.11.2016 
Hiermit erkläre ich, die Dissertation mit dem Titel "Der Transkriptionsfaktor GATA4 und seine Rolle in der Entwicklung kardialer Hypertrophie" eigenständig angefertigt und keine anderen als die von mir angegebenen Quellen und Hilfsmittel verwendet zu haben.

Göttingen, den

(Unterschrift) 


\section{Teilpublikationen der Dissertationsarbeit}

Diese Dissertationsarbeit wurde betreut durch

Prof. Dr. med. Rolf Wachter, Leitender Oberarzt der Klinik für Kardiologie und Pneumologie, Medizinische Fakultät der Universität Göttingen, und

Ass.Prof. Priv.-Doz. Dr. med. Egbert Bisping, Oberarzt der Abteilung für Kardiologie, Medizinische Universität Graz.

Anteile dieser Arbeit wurden in Form von Vortrag, Poster und Abstract publiziert:

1. Bisping E, Wilken A, Dörge H, Pieske B: „Load dependent regulation of Gata4 in human myocardium.“

Poster auf den Kardiovaskulären Forschungstagen in Weissensee, 18.- 20. Januar 2007 in Weissensee, Österreich.

2. Bisping E, Wilken A, Pieske B (2007): ,Regulation des Transkriptionsfaktors GATA4 bei akuter und chronischer Last im humanen Myokard“.

Vortrag und Abstract auf der 73. Jahrestagung der Deutschen Gesellschaft für Kardiologie, 12.-14.April 2007 in Mannheim, Germany.

3. Bisping E, Wilken A, Pieske B: „GATA4 regulation in human myocardium in chronic and acute overload.“

Poster auf dem ESC Kongress, 1.-5. September 2007 in Wien, Österreich. 


\section{Inhaltsverzeichnis}

I. Einleitung........................................................................................................................................ 1

I.1 Hypertrophie und Last im menschlichen Herzen .............................................. 2

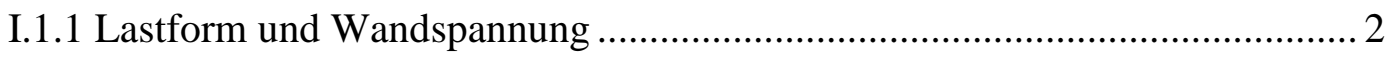

I.1.2 Hypertrophie und Herzinsuffizienz........................................................ 2

I.1.3 Hypertrophe Signaltransduktion ............................................................. 3

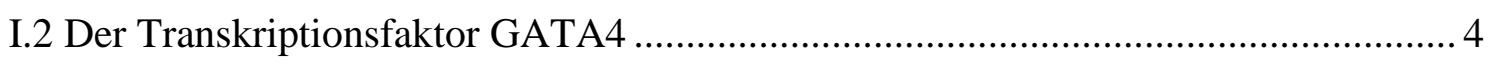

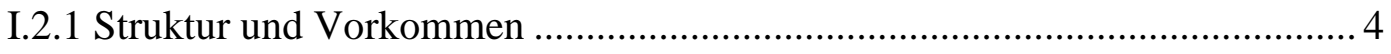

I.2.2 Subzelluläre Regulation von GATA4 ….................................................. 5

I.2.3 Rolle von GATA4 für die kardiale Hypertrophie ..................................... 7

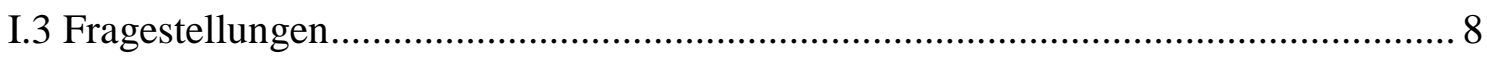

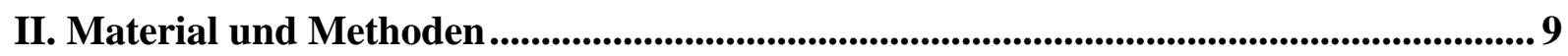

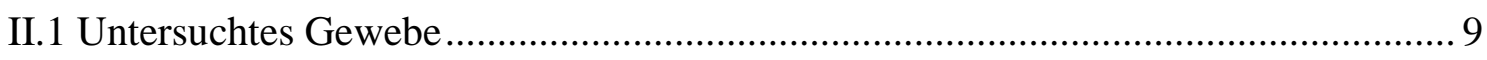

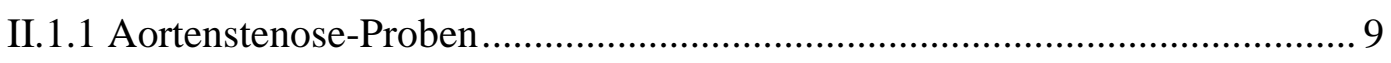

II.1.2 Nicht-insuffizientes ventrikuläres Myokard ............................................. 9

II.1.3 Insuffizientes ventrikuläres Myokard ….................................................. 10

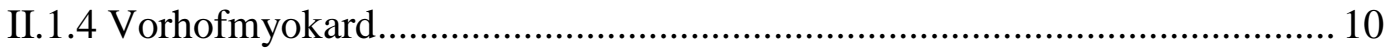

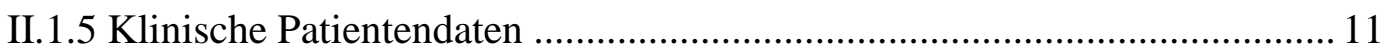

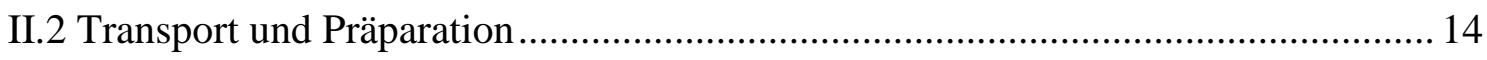

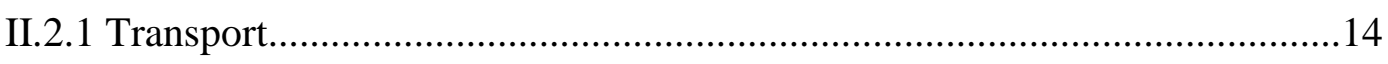

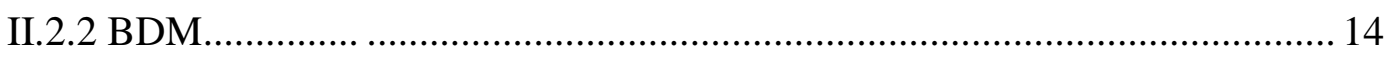

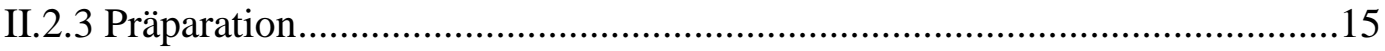

II.3 Langzeit-Messanlage zur Untersuchung akuter Last ............................................ 16

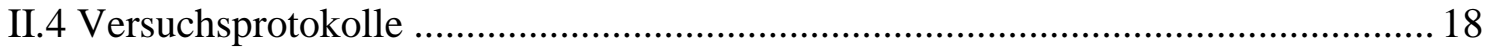

II.4.1 Dehnungsexperimente zur Generierung akuter Last ................................ 18

II.4.2 Zeitabhängige Degeneration von GATA4 .............................................. 20

II.4.3 Experimente zum Einfluss der Ubiquitin Isopeptidase ............................ 20

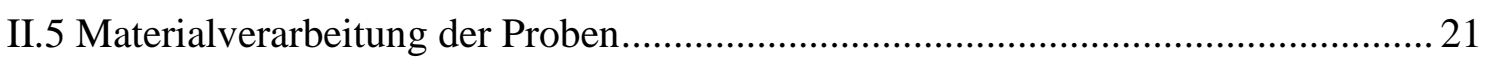

II.5.1 RNA-Isolation mittels RNeasy Kit ........................................................ 21

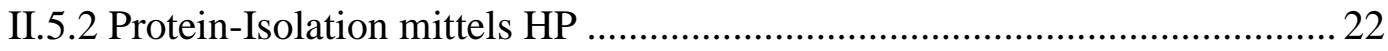

II.6 Messverfahren zur RNA- und Proteinexpression .................................................... 25

II.6.1 Messungen zur RNA-Expression ......................................................... 25

II.6.2 Western Blot................................................................................ 28

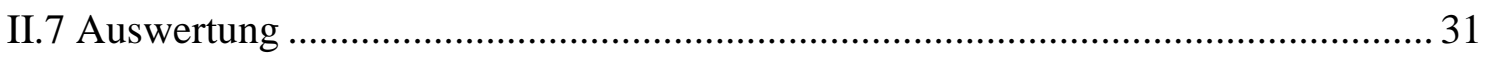




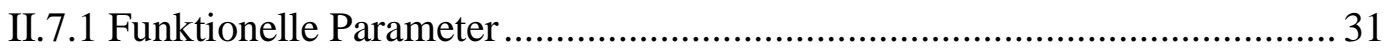

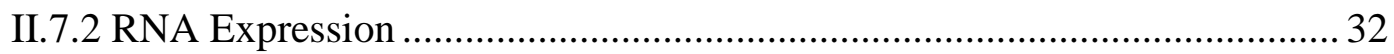

II.7.3 Protein Expression und Phosphorylierung................................................. 32

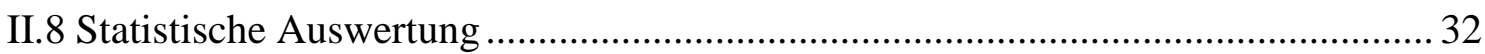

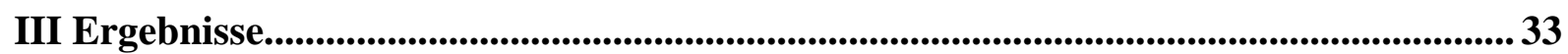

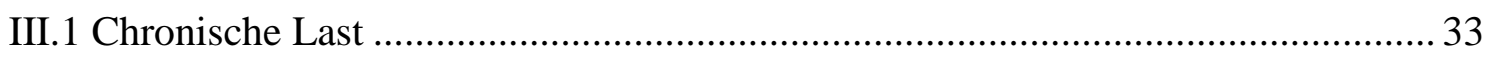

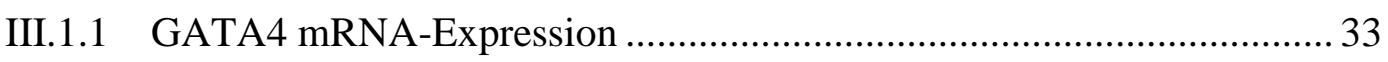

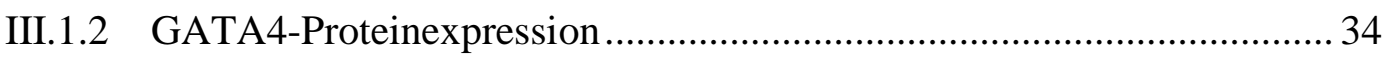

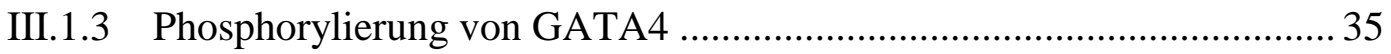

III.1.4 Korrelation mit klinischen Funktionsparametern ............................... 37

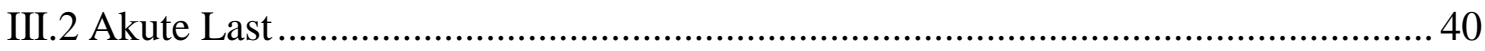

III.2.1 mRNA-Expression (Atriales Myokard) ......................................... 41

III.2.2 mRNA-Expression (Insuffizientes ventrikuläres Myokard) ................... 42

III.2.3 Proteinexpression (Atriales Myokard) ............................................... 43

III.2.4 Proteinexpression (Ventrikuläres Myokard) ….................................... 45

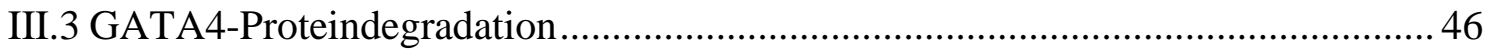

III.3.1 GATA4-Proteindegradation (ventrikuläres und atriales Myokard) ........ 46

III.3.2 Abhängigkeit der GATA4-Proteindegradation von der Ubiquitin-

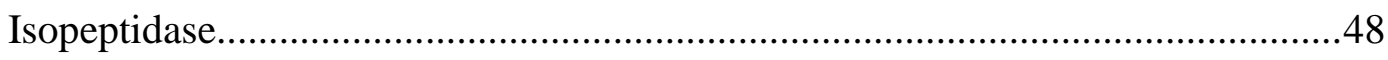

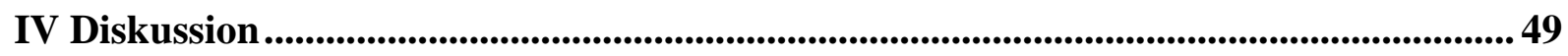

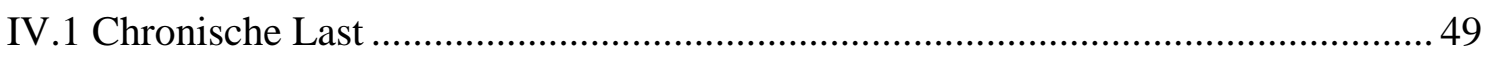

IV.1.1 Chronische Nachlasterhöhung durch eine Aortenstenose......................... 49

IV.1.2 Expression von GATA4 …............................................................... 49

IV.1.3 Phosphorylierung von GATA4 …...................................................... 51

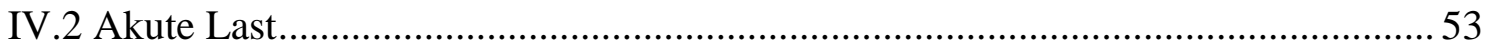

IV.2.1 Lastmodell und verwendete Materialien .................................................. 53

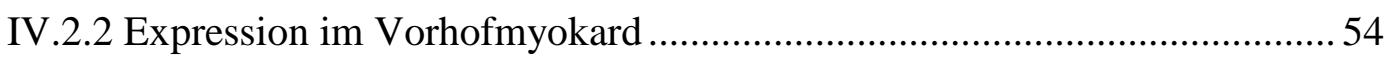

IV.2.3 Expression im ventrikulären Myokard ................................................. 54

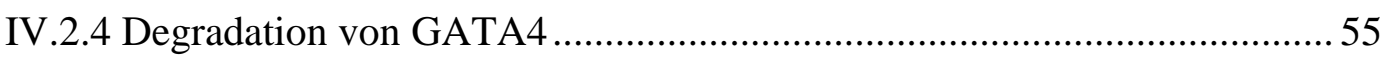

IV.2.5 Einfluss der Ubiquitin-Isopeptidase ...................................................... 56

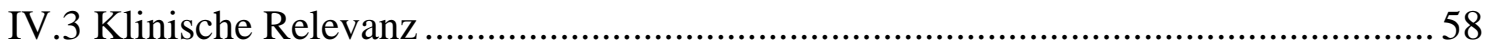

V Zusammenfassung ................................................................................................................5 59

VI Literaturverzeichnis ....................................................................................................60 


\section{Einleitung}

Die chronische Herzinsuffizienz ist mit einer Prävalenz von $1,5-2 \%$ in der europäischen Gesamtbevölkerung eine der häufigsten internistischen Erkrankungen. Die Herzmuskelhypertrophie stellt für die Herzinsuffizienz einen prognostisch relevanten, unabhängigen Risikofaktor dar. Kommt es aufgrund einer kardialen Erkrankung, z.B. einem Aortenvitium, zu einer gesteigerten ventrikulären Belastung, reagiert das Myokard mittels Hypertrophie.

Im Tiermodell wurden diverse Signalkaskaden identifiziert, die im Rahmen der ventrikulären Anpassung an veränderte Druck- und Lastzustände, die Hypertrophieentwicklung des Myokards einleiten und unterhalten. Diese Signalwege konvergieren auf einige wenige Proteine wie z.B. GATA4, einem Protein, das durch Bindung an DNA die Transkription verschiedenster Gene regulieren kann. Dieser Transkriptionsfaktor ist im Myokard hoch exprimiert und reguliert synergistisch mit anderen Faktoren wie SRF, NKX 2.5, NFAT oder MEF-2 die Expression multipler hypertrophie-relevanter Proteine. Die gesteigerte Aktivität von GATA4 durch Reize wie Dehnung, Druckbelastung oder sympathische Stimulation ist im Tiermodell bewiesen. Jedoch sind diese Zusammenhänge im menschlichen Herzen bislang nicht gezielt untersucht worden.

Die vorliegende Arbeit sollte untersuchen, wie biomechanische Last im menschlichen Herzen die Expression von GATA4 und seine Aktivität reguliert. Hierfür wurde der Einfluss eines chronischen Lastzustandes, hervorgerufen durch eine Aortenstenose, ebenso wie der eines akuten Lastzustandes durch Steigerung der Vor- und Nachlast von Muskelstreifen im Organbad auf die Expression von GATA4 untersucht. Die Muskelstreifen stammten dabei sowohl aus gesundem Myokard (Vorhofmyokard bei normaler Pumpfunktion) als auch aus vorgeschädigtem Myokard (insuffizientes Ventrikelmyokard).

Auf den folgenden Seiten sollen zunächst die zum Verständnis der Arbeit notwendigen Hintergrundinformationen und die Fragestellungen im Detail veranschaulicht werden. 


\section{I.1 Hypertrophie und Last im menschlichen Herzen}

\subsubsection{Lastform und Wandspannung}

Wird das menschliche Herz chronisch einer erhöhten Last durch gesteigerte Pumpdrücke oder einer vermehrten Ventrikelfüllung ausgesetzt, kommt es zu strukturellen Veränderungen des Myokards. Der Ventrikel nimmt an Dicke zu oder vergrößert sein Volumen. Zelluläre Hypertrophie beschreibt die adaptative Zunahme der Einzelzelle in Dicke oder Länge, einhergehend mit gesteigerter Proteinsynthese (Sugden und Clerk 1998). Die muskuläre Hypertrophie kompensiert die höheren Füllungs- bzw. Pumpdrücke durch die vermehrte Rekrutierung von Sarkomeren, um die ventrikuläre Wandspannung aufrechtzuerhalten. Nach dem Laplace'schen Gesetz bleibt so die Kraft pro Muskelquerschnitt gleich. Mit der Druckund der Volumenbelastung werden zwei Arten der erhöhten Arbeitsbelastung unterschieden. Vermehrte Druckbelastung, z.B. im Rahmen einer Aortenklappenstenose, zwingt das Myokard, höhere Pumpdrücke zu realisieren. Der Herzmuskel verstärkt sich durch konzentrische Hypertrophie und vermehrte, parallele Anordnung der Sarkomere, sodass die Wanddicke bei gleichbleibendem oder sogar reduziertem linksventrikulärem Volumen zunimmt. Das Verhältnis von Wanddicke zu Ventrikelvolumen (h/R-Ratio) steigt (Grossman et al. 1975). Eine erhöhte Volumenbelastung, z.B. bei Aortenklappeninsuffizienz, führt hingegen zu einer exzentrischen Myokardhypertrophie mit Anordnung der Sarkomere in linearer Richtung. Das Ventrikelvolumen nimmt bei gesteigerter Muskelfaserlänge ebenso wie die linksventrikuläre Masse zu. Die h/R-Ratio bleibt konstant (Grossman et al. 1975). Die Myokardhypertrophie kompensiert somit die vermehrte Wandspannung und erhält damit das Herzzeitvolumen trotz erhöhter Belastung.

\subsubsection{Hypertrophie und Herzinsuffizienz}

Kommt es durch die Hypertrophie zu einem Wachstum des Myokards über $500 \mathrm{~g}$, so ist das sogenannte „kritische Herzgewicht“ erreicht (Linzbach 1948). Aufgrund verdickter Herzwände verlängern sich die Perfusionswege in der diastolischen Füllungsphase, und das Herz kann in Belastungssituationen nicht mehr ausreichend mit Nährstoffen versorgt werden (Cannon 1987). Mit zunehmender Hypertrophie entwickelt sich eine relative Insuffizienz des Myokards, die sich zur dauerhaften manifesten Insuffizienz mit eingeschränkter Ventrikelfunktion entwickeln kann. Hypertrophie ist somit ein prognostisch relevanter, unabhängiger Risikofaktor für die Entwicklung einer Herzinsuffizienz (Levy et al. 1990). Das Syndrom der chronischen Herzinsuffizienz ist in Europa eine der häufigsten chronischen internistischen Erkrankungen überhaupt. Die Prävalenz liegt bei ca. $1,5-2 \%$ der 
Gesamtbevölkerung, was mehr als 10 Millionen Menschen in Europa entspricht. Die jährliche Letalität der Herzinsuffizienz beträgt trotz Forschung und Verbesserung der Therapie auf diesem Gebiet je nach Schwere der Symptomatik 7 - 40 \% (Hummel et al. 2015). Aufgrund dieser Tatsachen kommt dem Verständnis der dazugehörigen Signalwege eine große Bedeutung zu, um künftig noch gezielter und bereits bei der Entstehung einer Hypertrophie und nicht erst nach dem Auftreten einer Dysfunktion therapeutisch eingreifen zu können.

\subsubsection{Hypertrophe Signaltransduktion}

$\mathrm{Zu}$ Beginn der Hypertrophieentwicklung steht die Induktion von Signalwegen, die durch direkte myokardiale oder neurohumerale Aktivierung erfolgen kann und immer an zellmembrangebundene Rezeptoren gebunden ist. Integrine, heterodimere transmembranöse Rezeptoren, können mechanischen Stress von der extrazellulären Matrix auf das Zytoskelett übertragen und so direkt z.B. GTPasen wie Ras und Rho aktivieren (Ross und Borg 2001). Einige Hormone, z.B. Angiotensin II, oder Katecholamine besetzen hingegen spezifische, membrangebundene, mit heterotrimeren Gq-Proteinen gekoppelte Rezeptoren (Rockman et al. 2002). Eine wichtige Gruppe von Signalproteinen, deren Einflüsse sowohl in Tiermodellen als auch beim Menschen nachgewiesen worden sind, sind die mitogen activated protein kinases (MAPK). Die MAPK-Signalwege beschreiben Aktivierungssequenzen mehrerer Kinasen, deren Aktivierung in der Phosphorylierung von p38, c-jun-n-terminal kinases (JNK) und ERKs resultiert. Diese regulieren wiederum diverse andere Faktoren, die letztlich auf Transkriptionsfaktoren wie z.B. GATA4 abzielen (Garrington und Johnson 1999; Liang et al. 2001b). Bueno et al. zeigten im Tierversuch, dass Überaktivierung von ERK1/2 im Herzen die Entwicklung einer konzentrischen Hypertrophie bei kompensierter Funktion fördert (Bueno et al. 2000). Haq et al. konnten im dekompensierten hypertrophen Herzen eine Aktivitätssteigerung der MAPK-Signalwege nachweisen, jedoch nicht bei Patienten mit einer kompensierten ventrikulären Hypertrophie (Haq et al. 2001). Das verdeutlicht die Komplexität dieser Signalwege, denn die Rolle der MAP-Kinasen in der Entwicklung kardialer Hypertrophie konnte eindeutig nachgewiesen werden. Sowohl in kultivierten Myozyten als auch in vivo führt direkter mechanischer Stress durch Dehnung zu einer gesteigerten Aktivierung von MAP-Kinasen wie z.B. ERK1/2 (Yamazaki et al. 1999). Wird hingegen der mechanische Stress eines terminal-insuffizienten Herzens durch ein linksventrikuläres Assist Device (LVAD) deutlich reduziert, sinkt die Aktivität der MAPKinasen um ca. $80 \%$ (Baba et al. 2003). Aufgrund dessen ist anzunehmen, dass diese Signalwege auch beim Menschen an der Entstehung einer Last-induzierten Hypertrophie beteiligt sind. 


\section{I.2 Der Transkriptionsfaktor GATA4}

\subsubsection{Struktur und Vorkommen}

Innerhalb einer Zelle konvergieren viele Signalwege wie auch die MAPK-Signalwege auf einige Zielproteine, die die Expression anderer Proteine regulieren. Die Familie der GATATranskriptionsfaktoren stellt eine Gruppe von sechs Proteinen dar, die an DNA binden und dadurch die Transkription verschiedenster Gene regulieren können. Die Isoformen GATA-12-3 werden im hämatopoetischen System exprimiert. Sie regulieren dort den Zellzyklus, die Proliferation sowie die Differenzierung hämatopoetischer Vorläuferzellen (Ho et al. 1991; Joulin et al. 1991; Ko et al. 1991; Yamamoto et al. 1990; Zon et al. 1991). GATA4-5-6 hingegen werden in meso- und endodermalen Geweben wie z.B. der Leber, dem MagenDarm-Trakt und auch dem Herzen von Wirbeltieren exprimiert, so auch beim Menschen (Arceci et al. 1993; Kelley et al. 1993; Laverriere et al. 1994; Liang et al. 2001a; Morrisey et al. 1996; Morrisey et al. 1997; Suzuki et al. 1996). Die GATA-Faktoren verdanken ihren Namen der Konsensus-DNA-Sequenz 5'-(A/T)GATA(A/G)-3', an die sie mittels zweier Zinkfinger-Domänen binden. Abbildung 1 stellt die Proteinstruktur von GATA4 dar.

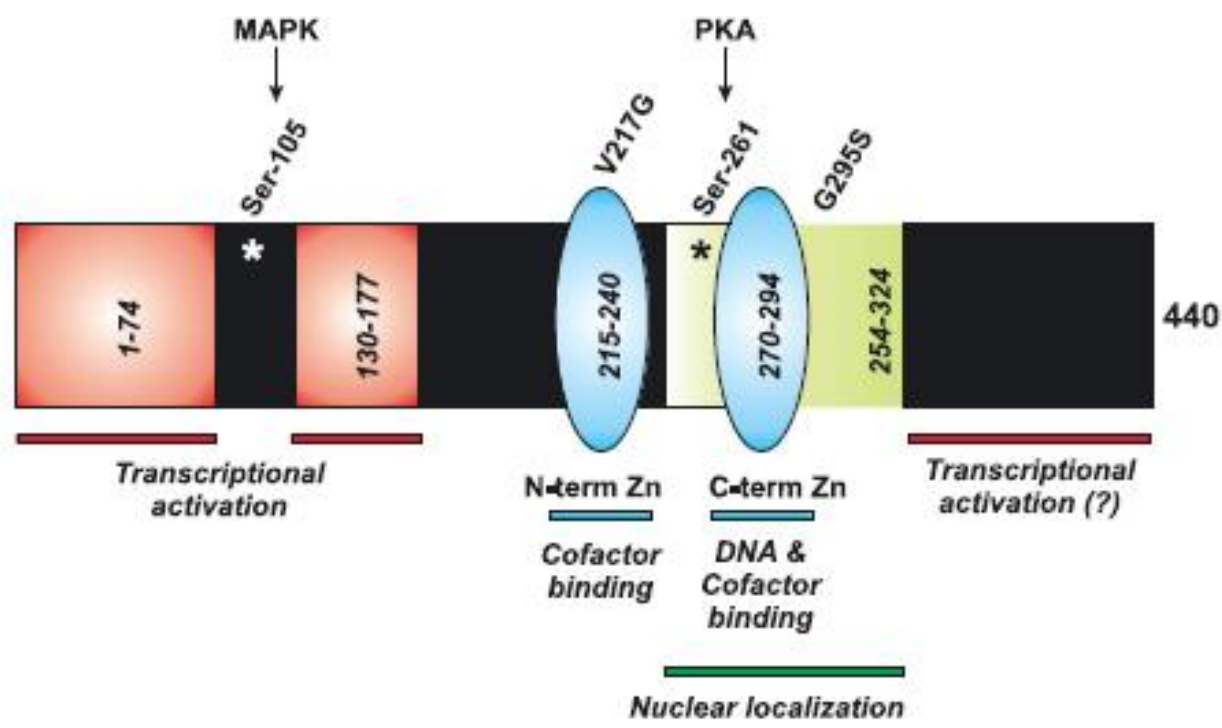

Abb. 1: Proteinstruktur von GATA4. Die DNA-bindenden Zinkfingerdomänen sind in blau, das Kernerkennungssignal in grün dargestellt. Ser-105 und Ser-261 sind Aminosäuren, über deren Phosphorylierung die Aktivität von GATA4 gesteuert werden kann. (Abbildung aus Pikkarainen et al. 2004, S. 197)

GATA4 besitzt innerhalb des Herzens die höchste Expression und reguliert eine Vielzahl kardialer Gene, die als Marker und Vermittler einer Hypertrophiereaktion bekannt sind (z.B. $\alpha$-MHC, $\beta$-MHC, Nkx-2.5, ANF, BNP) (Akazawa und Komuro 2003). Die Domäne 254 - 324 vermittelt hierbei das Signal zum nukleären Transport. Über die C-terminale Zinkfinger- 
Domäne erfolgt die Bindung an die DNA (Morrisey et al. 1997). Die N-terminale-Domäne hingegen kann nicht binden, beeinflusst aber Stabilität und Spezifität der DNA-Bindung (Yang und Evans 1992).

Von Bedeutung für die Regulation der Aktivität von GATA4 sind mehrere Phosphorylierungsstellen. Serin-105 wird von den MAP-Kinasen p38-MAPK (Charron et al. 2001) und extracellular-signal-regulated kinase (ERK) phosphoryliert (Liang et al. 2001b). Die Protein Kinase A (PKA) reguliert die Aktivität von GATA4 durch Phosphorylierung an Serin-261, das direkt zwischen den beiden Zinkfinger-Domänen liegt (Tremblay und Viger 2003). GSK-3- $\beta$ phosphoryliert GATA4 an seiner N-terminalen Domäne im Bereich der Aminosäuren 2 - 205 (Morisco et al. 2001).

\subsubsection{Subzelluläre Regulation von GATA4}

Verschiedene Studien konnten zeigen, dass die DNA-Bindungsaktivität von GATA4 durch verschiedene Mechanismen reguliert wird, die neben der oben bereits genannten Phosphorylierung die Acetylierung durch Kofaktoren und die Interaktion mit anderen Transkriptionsfaktoren umfassen. Hypertrophiestimuli wie mechanische Last oder Agonisten wie Endothelin-1, Angiotensin II, Phenylephrin oder Isoprenalin aktivieren in Kardiomyozyten den Gq- und Rho-Signalweg (Charron et al. 2001; Kerkela et al. 2002; Liang und Molkentin 2002; Morimoto et al. 2000; Morisco et al. 2001; Suzuki et al. 1999). Im Verlauf dieses Signalweges phosphorylieren die Kinasen p38-MAPK und ERK GATA4 an Serin-105 und steigern damit seine Aktivität (Charron et al. 2001; Liang et al. 2001b). GATA4 kann zudem durch den Kofaktor p300 durch Acetylierung aktiviert werden. Nach Aktivierung interagiert GATA4 synergistisch mit Transkriptionsfaktoren wie SRF, NKX 2.5, NFAT oder MEF-2, die die Expression hypertrophierelevanter Gene vermitteln (Durocher et al. 1997; Lee et al. 1998; Molkentin et al. 1998; Morin et al. 2000; Shiojima et al. 1999). Erfolgt hingegen eine Phosphorylierung am N-terminalen Ende von GATA4 durch die Glykogen-Synthase-Kinase GSK-3- $\beta$ fördert dies den nukleären Export von GATA4 und hemmt damit seine Aktivität (Morisco et al. 2001). Diese Signalwege sind in Abbildung 2 zusammengefasst. 


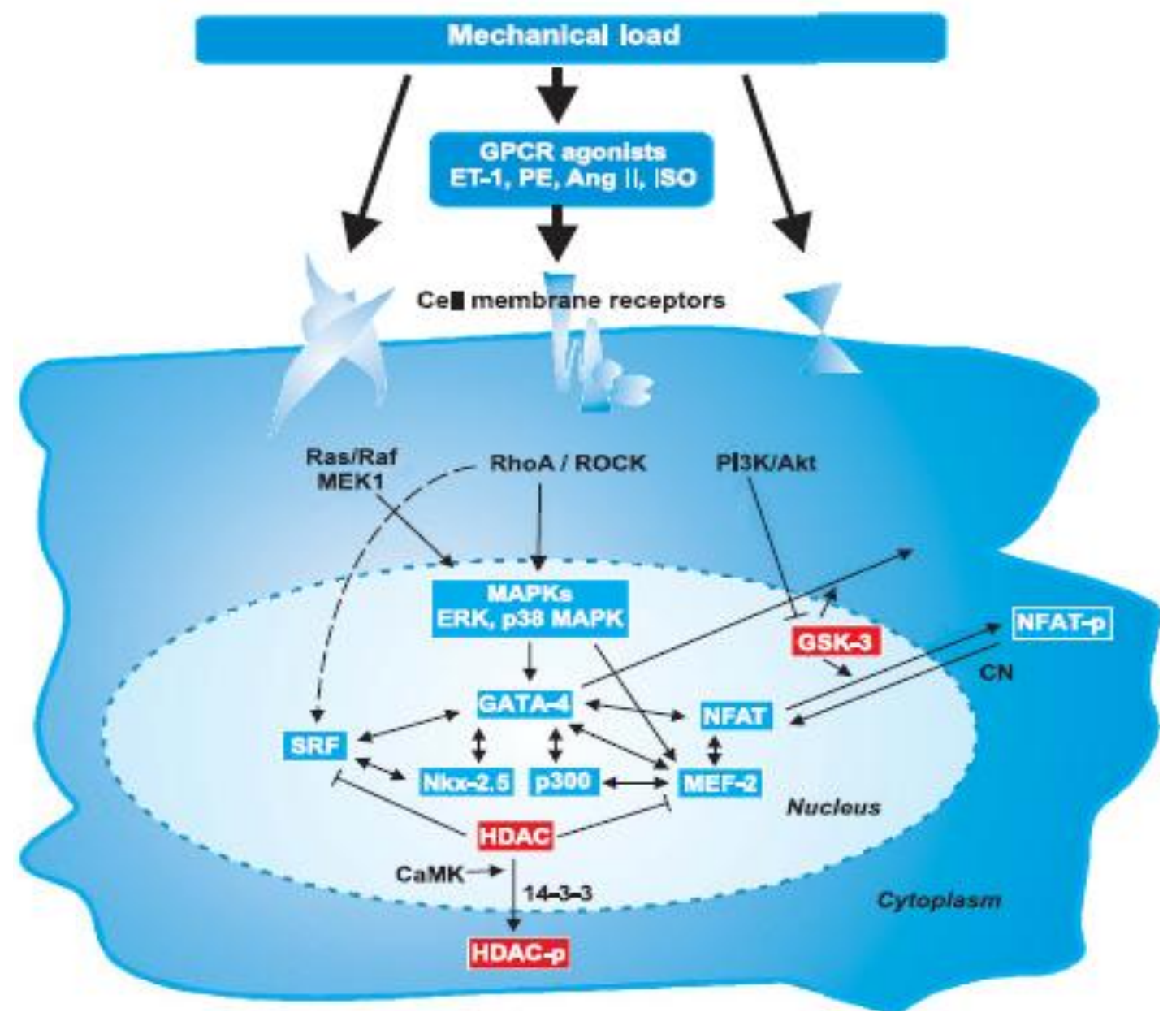

Abb. 2: Signalkaskade. Diverse Signalwege innerhalb der Zelle konvergieren auf GATA4. Eine komplexe Interaktion mit Ko- und anderen Transkriptionsfaktoren vermittelt die gesteigerte Aktivität von GATA4. (Abbildung aus Pikkarainen et al. 2004, S. 200)

Die Abbildung verdeutlicht die Komplexität dieser Signalkaskaden und deren Bedeutung für die Regulation der transkriptionalen Aktivität von GATA4. Neben diesen Mechanismen kann GATA4 zudem auch durch seine Expression reguliert werden, wobei dessen Bedeutung beim Menschen und im Tiermodell unterschiedlich zu sein scheint. So beschreiben die meisten Autoren in Tiermodellen mit pathologischer Nachlasterhöhung eine unveränderte Expression bei gesteigerter Aktivität von GATA4 (Hautala et al. 2001; Liang et al. 2001a; Liang et al. 2001b; Morimoto et al. 2000), lediglich Colston et al. fanden in Mäusen neben einer Aktivitätssteigerung auch eine Hochregulation der GATA4 Expression (Colston et al. 2007). Beim Menschen hingegen sind die Befunde einheitlich. Diedrichs et al. wiesen einen Anstieg der Expression von GATA4 in Herzen von Patienten mit dilatativer Kardiomyopathie nach (Diedrichs et al. 2004). Passend hierzu fanden Hall et al. eine Herabregulation von GATA4 nach Entlastung insuffizienter Herzen durch eine mechanisches Unterstützungssystem (LVAD) (Hall et al. 2004). 


\section{I.2.3 Rolle von GATA4 für die kardiale Hypertrophie}

Die Steigerung der DNA-Bindungsaktivität von GATA4 durch verschiedene pathologische Hypertrophiestimuli wie Dehnung, Druckbelastung oder sympathische Stimulation legt nahe, dass GATA4 an der Hypertrophieentwicklung beteiligt ist. So konnten Liang et al. in kultivierten Kardiomyozyten zeigen, dass eine Überexpression von GATA4 zu einer Aktivierung hypertrophierelevanter Gene und einer zellulären Hypertrophie führt (Liang et al. 2001b). Zudem wiesen diese Autoren nach, dass GATA4 für den hypertrophen Agonisten Phenylephrin ein essentieller Faktor ist und nach Knockdown von GATA4 Phenylephrin seine hypertrophe Wirkung verliert (Liang et al. 2001b). Phenylephrin ist ein Agonist an alpha-Rezeptoren, die an ein Gq-Protein gekoppelt sind (LaMorte et al. 1994). Diese Kaskade wird auch bei Last und zellulärer Dehnung aktiviert (Wettschureck et al. 2001). Passend hierzu konnten daher Pikkarainen et al. in kultivierten Kardiomyozyten, die über eine FlexMembran gedehnt wurden, nachweisen, dass GATA4 auch für die Hypertrophiereaktion nach direkter Dehnung ausschlaggebend ist (Pikkarainen et al. 2003).

Die genannten in vitro Befunde zeigen bereits deutlich, welche Bedeutung GATA4 für die strukturelle Hypertrophiereaktion hat. In Mausmodellen in vivo konnten darüber hinaus die funktionellen Konsequenzen veränderter GATA4 Aktivität untersucht werden. Liang et al. zeigten im Mausmodell, dass eine zweifache Überexpression von GATA4 zu einer pathologischen Hypertrophie führt, die im Verlauf mit Fibrose, Dilatation und eingeschränkter Myokardfunktion einhergeht (Liang et al. 2001a). Bisping et al. hingegen beschrieben im Modell mit heterozygoten Knockout-Mäusen, die 50 \% GATA4 Protein exprimierten, eine gestörte Hypertrophiereaktion auf Druckbelastung. Es zeigte sich ein exzentrisches statt konzentrisches Hypertrophiemuster und die Entwicklung einer Herzinsuffizienz, basierend auf einer gesteigerten Apoptose und dadurch verminderten Anzahl von Kardiomyozyten (Bisping et al. 2006). Oka et al. konnten in einem anderen GATA4 Knockout Modell (aMHCCre/GATA4 ${ }^{\text {flox }}$ Mäuse) ähnliche qualitative Befunde erheben und darüber hinaus auch eine quantitative Einschränkung der Hypertrophiereaktion unter Druckbelastung nachweisen (Oka et al. 2006).

Insgesamt lässt sich ableiten, dass GATA4 in vitro und in vivo essentiell an der durch pathologische Stimuli induzierten Entstehung einer Hypertrophie beteiligt ist. Bereits relativ geringe Schwankungen der Expression (0,5-fach bis 2-fach) führen zu erheblichen Störungen sowohl struktureller als auch funktioneller Art. 


\section{I.3 Fragestellungen}

Die Rolle von GATA4 für die Hypertrophieentwicklung und seine Regulation in Abhängigkeit von der Last sind im menschlichen Herzen im Gegensatz zu den zahlreichen tierexperimentellen Ansätzen bislang nicht gezielt untersucht worden. Einen wegweisenden Befund lieferten jedoch Hall et al., welche die Expression von GATA4 bei herzinsuffizienten Patienten analysierten, deren Herz durch einen LVAD mechanisch entlastet wurde (Hall et al. 2004). Sie stellten dar, dass die durch die Herzinsuffizienz gesteigerte Proteinexpression von GATA4 nach der mechanischen Entlastung auf Normalniveau zurückging. Damit lieferten sie einen analogen Befund zu Baba et al., die eine Reduktion der ERK-Aktivität nach Entlastung durch einen LVAD nachwiesen (Baba et al. 2003).

Unklar ist allerdings der Grund für diesen Rückgang. Es stellt sich die Frage, ob die GATA4 Spiegel allein aufgrund der Senkung der Last durch das LVAD-System sanken. Oder sanken sie, weil das hypertrophierte insuffiziente Herz einem gegenläufigen Remodeling unterzogen wurde, das zu einer deutlichen Funktionsverbesserung führte?

Um der Frage gezielt nachzugehen, ob Last oder die Pumpfunktion den entscheidenden Trigger für Expressionsänderungen von GATA4 darstellt, sollte die vorliegende Arbeit untersuchen, wie biomechanische Last im menschlichen Herzen die Expression von GATA4 und seine Phosphorylierung an einer aktivierenden Phosphorylierungsstelle (Serin-105) reguliert. Dabei sollte zudem die myokardiale Pumpfunktion als Einflussgröße eruiert werden.

Die Fragestellungen waren im Einzelnen:

1. Führt eine chronische Nachlasterhöhung durch eine Aortenstenose $\mathrm{zu}$ einer Expressionsänderung von GATA4?

2. Kommt es bei einer Aortenstenose zu einer veränderten Phosphorylierung von GATA4 an Serin-105?

3. Wie beeinflusst eine myokardiale Dysfunktion bei Aortenstenose die oben genannten Parameter?

4. Bestehen Korrelationen $\mathrm{zu}$ klinischen lastabhängigen oder funktionsabhängigen Parametern?

5. Führt akute Last in vitro durch kombinierte Vor- und Nachlast zu einer Expressionsänderung von GATA4?

6. Lassen sich akute lastabhängige Veränderungen sowohl im gesunden Myokard (Vorhofgewebe) als auch im insuffizienten Myokard (Ventrikelgewebe) nachweisen? 


\section{Material und Methoden}

\section{II.1 Untersuchtes Gewebe}

In der vorliegenden Arbeit wurde im ersten Teil die Auswirkung chronischer Last, hervorgerufen durch eine Aortenstenose, auf die Expression und Phosphorylierung von GATA4 untersucht. Im zweiten Teil wurde die Auswirkung akuter Last in isolierten Herzmuskelstreifen untersucht. Hierzu wurden Präparate aus humanem atrialem und ventrikulärem Myokard verwendet.

\section{II.1.1 Aortenstenose-Proben}

Bei Patienten mit einer hochgradigen symptomatischen Aortenstenose wurde im Rahmen eines operativen Aortenklappenersatzes (AKE) eine Morrow-Resektion durchgeführt. Diese Resektion besteht aus der Entnahme eines kleinen Stücks septalen Myokards in Höhe des linksventrikulären Ausflusstrakts, wo sich das Myokard aufgrund der Druckbelastung so verdickt haben kann, dass es zu einer Obstruktion führt. Das entnommene Myokardstück wurde umgehend in gekühlter und Carbogen-vorbegaster kardiopleger Lösung (Bretschneider Lösung, Custodiol@) von Blutresten gewaschen. Dann wurde es nach kurzer Trocknung in ein Aluminiumdöschen überführt, in welchem es verschlossen und in flüssigem Stickstoff schockgefroren wurde. Für die Verwendung der Proben lag unter (AZ 21/10/00) ein Ethikvotum vor, die Patienten mussten mittels eines standardisierten Aufklärungsbogens einwilligen. Die klinischen Charakteristika der zwanzig untersuchten Patienten sind in Tabelle 1 unter II.1.5 aufgeführt.

\section{II.1.2 Nicht-insuffizientes ventrikuläres Myokard}

Das nicht-insuffiziente Myokard (NF) stammte von herzgesunden Organspendern, deren Herzen aus technischen Gründen nicht transplantiert werden konnten. Für die Verwendung zu wissenschaftlichen Untersuchungen bestand unter AZ 31/9/00 ein Ethikvotum der Universität Göttingen. Die linksventrikuläre Funktion dieser Herzen war normal. Für die Untersuchungen der chronischen Last durch eine Aortenstenose wurden 10 Proben nicht-insuffizienten Myokards als Referenzproben zum Vergleich verwendet. Zur Gewinnung von Trabekeln für die Untersuchungen zur akuten Last stand beim nicht-insuffizienten Myokard jedoch leider nicht hinreichend Material zur Verfügung. 


\section{II.1.3 Insuffizientes ventrikuläres Myokard}

Für die Experimente zur akuten Last wurden daher Präparate aus insuffizienten Herzen verwendet, die von Patienten stammten, die sich einer orthotopen Herztransplantation unterziehen mussten. Operationsorte waren die Chirurgische Universitätsklinik Göttingen und das Herzzentrum NRW in Bad Oeynhausen (Ethikvotum AZ 31/9/00). Alle Patienten wurden dem Insuffizienzgrad NYHA IV gemäß der Klassifizierung der New York Heart Association zugeteilt. Hinsichtlich der Genese konnten die Patienten in eine Gruppe mit ischämischer Kardiomyopathie (ICM) und eine Gruppe mit dilatativer Kardiomyopathie (DCM) eingeteilt werden: Bei 4 Patienten war eine ICM, bei 8 Patienten eine DCM die zu Grunde liegende Erkrankung. Die Ejektionsfraktion (EF) betrug 25,25 \pm 3,33 \% für die ICM-Gruppe und $23 \pm$ 1,63 \% für die DCM-Gruppe. Weitere klinische Parameter sind in Tabelle 2 unter II.1.4 aufgeführt.

\section{II.1.4 Vorhofmyokard}

Zum Vergleich wurden zudem Experimente zur aktuen Last an Trabekeln aus Vorhofmyokard durchgeführt. Das untersuchte Vorhofmyokard stammte von Patienten, die sich einer Herzoperation unterziehen mussten, in deren Rahmen die Kreislauffunktion durch die HerzLungen-Maschine (HLM) übernommen wurde. Im Verlauf dieser Operationen wird in der Regel der rechte Vorhof zum Anschluss an die HLM kanüliert, sodass ein kleines Stück des Vorhofs abgetrennt werden muss, um einen suffizienten Anschluss der Kanüle zu garantieren.

Das entnommene Vorhofpräparat wurde in Carbogen-vorbegaster Tyrodelösung (Zusammensetzung s. unten) aufbewahrt und zur Präparation isolierter atrialer Trabekel ins Labor transportiert. Auch für die Verwendung dieser Proben lag unter AZ 21/10/00 ein Ethikvotum vor, die Patienten wurden seitens der Operateure über die mögliche wissenschaftliche Verwendung des Materials aufgeklärt und willigten mittels eines standardisierten Aufklärungsbogens ein.

Die klinischen Charakteristika der untersuchten Patienten werden in Tabelle 3 unter II.1.4 aufgeführt. 


\section{II.1.5 Klinische Patientendaten}

\section{Aortenstenose - Patientendaten}

Die folgende Tabellen gibt für die Experimente dieser Arbeit die folgenden Daten wieder:

Probennummer, Geschlecht, Alter [Jahre], Ejektionsfraktion (EF [\%]), aortale Öffnungsfläche (AÖF $\left[\mathrm{cm}^{2}\right]$ ), maximaler Druckgradient über der Aortenklappe (dPmax $[\mathrm{mmHg}]$ ), pulmonalkapillärer Verschlußdruck (PCW [mmHg]), Herzzeitvolumen (HZV [1/min] $)$, Cardiac Index (CI $\left.\left[(1 / \mathrm{min}) / \mathrm{m}^{2}\right]\right)$.

Tabelle 1

\begin{tabular}{|l|l|l|l|l|l|l|l|l|}
\hline Proben & Geschlecht & Alter & EF & AÖF & dPmax & PCW & HZV & CI \\
\hline 7 & m & 65 & 50 & 0,99 & - & 14 & 6,5 & 3,87 \\
\hline 10 & w & 67 & 45 & - & - & - & - & - \\
\hline 12 & m & 79 & 26,25 & 0,7 & - & - & 5 & - \\
\hline 13 & w & 81 & 52,5 & 0,4 & 85 & - & - & - \\
\hline 15 & m & 63 & 31 & 0,7 & - & 29 & 4,4 & 2,32 \\
\hline 27 & m & 70 & 70 & 0,7 & 118 & - & - & - \\
\hline 28 & w & 69 & 47,5 & - & 41 & - & - & - \\
\hline 31 & w & 75 & 65 & 0,6 & 70 & - & - & - \\
\hline 32 & w & 68 & 64 & 0,5 & 91 & - & - & - \\
\hline 33 & w & 67 & 65 & - & 60 & - & - & - \\
\hline 34 & w & 79 & 61,25 & - & - & - & - & - \\
\hline 35 & m & 74 & 47,5 & 0,9 & - & - & - & - \\
\hline 36 & w & 82 & 65 & 0,6 & 92 & - & - & - \\
\hline 37 & m & 64 & 65 & - & - & - & 3 & 1,5 \\
\hline 38 & m & 72 & 51,25 & 0,6 & - & - & - & - \\
\hline 166 & m & 63 & 50 & 0,6 & 95 & - & - & - \\
\hline 175 & m & 67 & 30 & 0,5 & 60 & - & 2,9 & 1,5 \\
\hline 177 & m & 76 & 37,5 & 0,91 & 40 & - & - & - \\
\hline 181 & m & 70 & 45 & 1,2 & 35 & - & - & - \\
\hline 232 & w & 78 & 89 & 0,42 & 55 & - & 3,6 & 2,1 \\
\hline
\end{tabular}




\section{Insuffizientes ventrikuläres Myokard - Patientendaten}

Die folgende Tabelle gibt für die Experimente dieser Arbeit die folgenden Daten wieder: Probennummer, Geschlecht, Alter [Jahre], Ejektionsfraktion (EF [\%]), zentralvenöser Druck (ZVD [mmHg]), Cardiac Index (CI [(1/min)/m²]), pulmonalkapillärer Verschlußdruck (PCW $[\mathrm{mmHg}])$, Rhythmus mit SR = Sinusrhythmus oder Vhf = Vorhofflimmern.

Tabelle 2

\begin{tabular}{|l|l|l|l|l|l|l|l|l|}
\hline Proben & Geschlecht & Alter & Diagnose & EF & ZVD & CI & PCW & Rhythmus \\
\hline aw110906 & w & 67 & DCM & 20 & - & - & 16 & SR \\
\hline aw130906 & m & 57 & ICM & 35 & & - & & SR \\
\hline aw051006 & m & 45 & DCM & 25 & 8 & 2,07 & 23 & SR \\
\hline aw211106 & m & 62 & DCM & 30 & 2 & 2,1 & 16 & SR mit SM \\
\hline aw301106 & m & 35 & DCM & 20 & 8 & 2,44 & 21 & - \\
\hline aw151206 & m & 20 & DCM & 20 & 10 & 3,1 & 14 & SR \\
\hline aw160207 & m & 57 & ICM & 23 & 18 & 2,77 & 28 & SR \\
\hline aw030407 & m & 49 & DCM & 27 & 7 & 2,63 & 26 & SR \\
\hline aw040407 & m & 58 & DCM & 19 & 7 & 2,49 & 14 & SR \\
\hline aw190407 & m & 43 & DCM & 20 & 11 & 1,31 & 32 & SR \\
\hline aw270407 & m & 54 & ICM & 23 & 7 & 2,6 & 10 & SR \\
\hline aw210607 & m & 55 & ICM & - & 13 & 2,49 & 29 & SR \\
\hline
\end{tabular}




\section{Vorhofmyokard- Patientendaten}

Die folgenden Tabelle gibt für die Experimente dieser Arbeit die folgenden Daten wieder: Probennummer, Geschlecht, Alter [Jahre], Ejektionsfraktion (EF [\%]), Art der durchgeführten Operation, Rhythmus im EKG, Größe des linksventrikulären enddiastolischen Durchmessers (LVEDD [cm]), Größe des linken Vorhofs in der M-Mode-Echokardiograpfie [cm]. Bei den Patienten, die einen Aorteklappenersatz (AKE) erhielten, betrug die Aortenöffnungsfläche im Mittel 0,67 $\pm 0,18 \mathrm{~cm}^{2}$

Tabelle 3

\begin{tabular}{|c|c|c|c|c|c|c|c|}
\hline $\begin{array}{l}\text { Proben } \\
\text { nummer }\end{array}$ & Geschlecht & Alter & $\mathbf{E F}$ & OP-Art & Rhythmus & LVEDD & $\begin{array}{l}\text { Vorhof- } \\
\text { Größe }\end{array}$ \\
\hline aw010806 & $\mathrm{m}$ & 72 & 70 & AKE & SR & - & - \\
\hline aw020806 & $\mathrm{m}$ & 60 & 33 & AKE & SR & - & - \\
\hline aw040806 & $\mathrm{m}$ & 67 & 65 & ACVB & SR & - & - \\
\hline aw230806 & $\mathrm{W}$ & 46 & 50 & ACVB & SR & - & - \\
\hline aw040906 & $\mathrm{m}$ & 71 & 25 & ACVB & SR & - & - \\
\hline aw060906 & $\mathrm{m}$ & 52 & 70 & ACVB & SR & 4,6 & - \\
\hline aw280906 & $\mathrm{w}$ & 80 & 65 & ACVB & SR & 3,7 & 4,1 \\
\hline aw181006 & $\mathrm{W}$ & 86 & 50 & ACVB & SR & - & - \\
\hline aw241006 & $\mathrm{m}$ & 73 & 30 & ACVB & SR & - & - \\
\hline aw271006 & $\mathrm{w}$ & 72 & 83 & ACVB & SR & 3,7 & 3,5 \\
\hline aw011106 & $\mathrm{m}$ & 70 & 60 & ACVB & SR & - & 3 \\
\hline aw091106 & $\mathrm{m}$ & 68 & 32 & AKE & SR & - & 5,5 \\
\hline aw231106 & $\mathrm{m}$ & 52 & 54 & $\mathrm{ACVB}+\mathrm{AKE}$ & SR & 6 & 5,3 \\
\hline aw030107 & $\mathrm{m}$ & 62 & 35 & ACVB & SR & - & - \\
\hline aw050107 & $\mathrm{m}$ & 63 & 63 & ACVB & SR & - & - \\
\hline aw150107 & $\mathrm{m}$ & 70 & 55 & ACVB & SR & 5,1 & 4,1 \\
\hline aw190207 & $\mathrm{W}$ & 78 & 54 & ACVB & SR & - & - \\
\hline aw280207 & $\mathrm{m}$ & 63 & 64 & ACVB & SR & 3,8 & 3,6 \\
\hline aw080307 & $\mathrm{m}$ & 59 & 60 & ACVB & SR & - & - \\
\hline aw150307 & $\mathrm{W}$ & 64 & 60 & ACVB & SR mit SM & 4,3 & 3,7 \\
\hline aw120407 & $\mathrm{w}$ & 78 & 36 & $\mathrm{AKE}$ & SR & 4,9 & 4,1 \\
\hline aw140607 & $\mathrm{m}$ & & 56 & ACB & SR & - & - \\
\hline aw141207 & $\mathrm{m}$ & & 55 & $\mathrm{AKE}$ & SR & - & - \\
\hline aw100108 & $\mathrm{m}$ & 47 & 60 & AKE & SR & 44 & - \\
\hline
\end{tabular}




\section{II.2 Transport und Präparation}

\section{II.2.1 Transport}

Die Myokardproben von Aortenstenosepatienten wurden noch im OP-Bereich in flüssigem Stickstoff schockgefroren und darauf in einem Stickstoff-Transportbehälter ins Labor gebracht und nachfolgend in einem $-80^{\circ} \mathrm{C}$-Gefrierschrank gelagert.

Vorhofmyokard wurde in Carbogen-oxygenierte Tyrodelösung überführt und zur Präparation ins Labor gebracht und ggf. kurzzeitig in präoxygenierter Tyrodelösung im Kühlschrank aufbewahrt.

Das aus Bad Oeynhausen stammende insuffiziente und nicht-insuffiziente Myokard musste in einem mehrstündigen Bahntransport in die Göttinger Labore gebracht werden. Hierzu diente ein Temperatur-isolierter Transportkoffer, der über Kühl-Akkus eine Temperatur von etwa $4^{\circ} \mathrm{C}$ konstant hielt. Das Herz befand sich dabei in Carbogen-oxygenierter BDM-Tyrodelösung in einem luftdichten Glasgefäß. Diese Lösung war durch Carbogen $\left(95 \% \mathrm{O}_{2} ; 5 \% \mathrm{CO}_{2}\right)$ präoxygeniert, gekühlt und enthielt als kardioplegen Wirkstoff 2,3-Butan-Dion-Monoxim (BDM; s.u.). Die weitere Aufbewahrung erfolgte in einer gleichartigen Lösung in einem auf ca. $4^{\circ} \mathrm{C}$ gekühlten Behälter, der fortwährend mit Carbogen durchperlt wurde. Im Abstand von vier Stunden wurde die BDM-Tyrodelösung ausgetauscht.

\section{II.2.2 BDM}

Für den Transport sowie die Präparation von Proben für die Untersuchung von akuter Last in Muskelstreifen wurde eine Tyrodelösung, versetzt mit $30 \mathrm{mmol} / \mathrm{L}$ BDM, verwendet:

\begin{tabular}{|l|l|}
\hline Stoff & Konzentration \\
\hline $\mathrm{BDM}$ & $30 \mathrm{mM}$ \\
\hline $\mathrm{Na}^{+}$ & $152 \mathrm{mM}$ \\
\hline $\mathrm{Cl}^{-}$ & $135 \mathrm{mM}$ \\
\hline $\mathrm{NaHCO}_{3}{ }^{-}$ & $25 \mathrm{mM}$ \\
\hline $\mathrm{Mg}^{2+}$ & $0,6 \mathrm{mM}$ \\
\hline $\mathrm{H}_{2} \mathrm{PO}_{4}^{-}$ & $1,3 \mathrm{mM}$ \\
\hline $\mathrm{SO}_{4}{ }^{2-}$ & $0,6 \mathrm{mM}$ \\
\hline $\mathrm{Ca}^{2+}$ & $2,5 \mathrm{mM}$ \\
\hline Glukose & $11,2 \mathrm{mM}$ \\
\hline Altinsulin (H-Insulin, Hoechst) & $10 \mathrm{IE} / \mathrm{l}$ \\
\hline
\end{tabular}


BDM (2,3-Butan-Dion-Monoxim) diente als kardioplege Substanz, die in ihren Effekten vollständig reversibel ist. Folgende Sachverhalte machen diesen Schutz des Myokards notwendig: Vor allem während der Präparation wird durch die zahlreich gesetzten Gewebedefekte massiv Kalzium aus geschädigten Zellen freigesetzt, welches unweigerlich zur Kontraktur des Präparates führen würde. Auch während des Transportes ist der Gefahr einer Kontraktur daher vorzubeugen. Die Wirkungsweise von BDM läßt sich folgendermaßen darstellen:

Als Phosphatase hemmt BDM die Querbrückeninteraktion reversibel (Blanchard et al. 1990; Mulieri 1984). In der verwendeten Konzentration von $30 \mathrm{mM}$ wird eine vollständige Hemmung der Querbrückeninteraktion (Perreault et al. 1992) erreicht, die allerdings durch Auswaschen komplett reversibel ist.

Die Kalziumsensitivität von Troponin C (Gwathmey et al. 1991), die Aufnahme von $\mathrm{Ca}^{2+}$ in das sarkoplasmatische Retikulum (Phillips und Altschuld 1996) und der Verlauf von Membran- und Aktionspotentialen (Fryer et al. 1988) bleiben hingegen unbeeinflusst.

Diese Voraussetzungen machen BDM zur idealen kardioplegen und kardioprotektiven Substanz, um Präparationsschäden zu verhindern (Mulieri et al. 1989).

\section{II.2.3 Präparation}

Für die Messungen zur chronischen Last wurden die Biopsie-Proben der Aortenstenosepatienten und die Proben aus nicht-insuffizienten Herzen in gefrorenem Zustand zerkleinert, um einen Anteil für RNA-Messungen und einen Teil zur Proteingewinnung zu erhalten. Zum Zerkleinern wurden die Proben in Aluminiumfolie eingewickelt, die zuvor mit RNase-Zap ${ }^{\circledR}$ zur Inaktivierung von RNasen abgewischt worden war. Durch einen gezielten Hammerschlag wurden die Proben in mehrere Bröckel zerteilt, umgehend aus der Alufolie befreit und dann in beschrifteten und vorgekühlten EppendorfRöhrchen in Stickstoff eingefroren. Ein Auftauen der Proben musste hierbei durch sehr rasches Arbeiten (ca. 5 Sekunden) unbedingt vermieden werden, ggf. aufgetaute Anteile wurden entsorgt und nicht weiterverarbeitet.

Für die Untersuchungen zur akuten Last wurden aus dem erhaltenen Vorhofmyokard oder insuffizienten Ventrikelmyokard Trabekel präpariert. Unter Sicht eines Stereomikroskops (VMT; Olympus) mit 10-facher Vergrößerung wurde das Gewebe zunächst gründlich nach geeigneten trabeculae carneae durchsucht. Im Rahmen des Versuchsprotokolls wurde auf Durchmesser um 800 bis $1000 \mu \mathrm{m}$ geachtet. Dies erlaubte einerseits eine noch hinreichende Oxygenierung des Kerns des Muskelstreifens und andererseits die Gewinnung von möglichst 
viel Material für die nachgeschalteten Expressionsanalysen. Die Trabekel wurden möglichst langstreckig unter Vermeidung von Dehnung mit Hilfe mikrochirurgischer Scheren aus der Wand herausgetrennt. Falls erforderlich, wurden bei der Präparation des ventrikulären Gewebes zur besseren Zugänglichkeit störende Papillarmuskeln mobilisiert oder größere Trabekel weggeschnitten. Nur wenn z.B. aufgrund zu starker Fibrose im linken Ventrikel kein geeigneter Trabekel aufzufinden war, wurden auch rechtsventrikuläre Präparate verwendet.

\section{II.3 Langzeit-Messanlage zur Untersuchung akuter Last}

Alle Experimente zur akuten Last wurden an der unten dargestellten Langzeit-Messanlage „Long Term Muscle Culture System“ der Firma Scientific Instruments Heidelberg (SIH LTMT Muscle Tester) durchgeführt. Mittels der Anlage ist es möglich, Muskelstreifen unter kontrollierten Bedingungen über bis zu 24 Stunden im Organbad stimuliert isometrisch kontrahieren zu lassen und dabei äußere Störfaktoren zu minimieren.

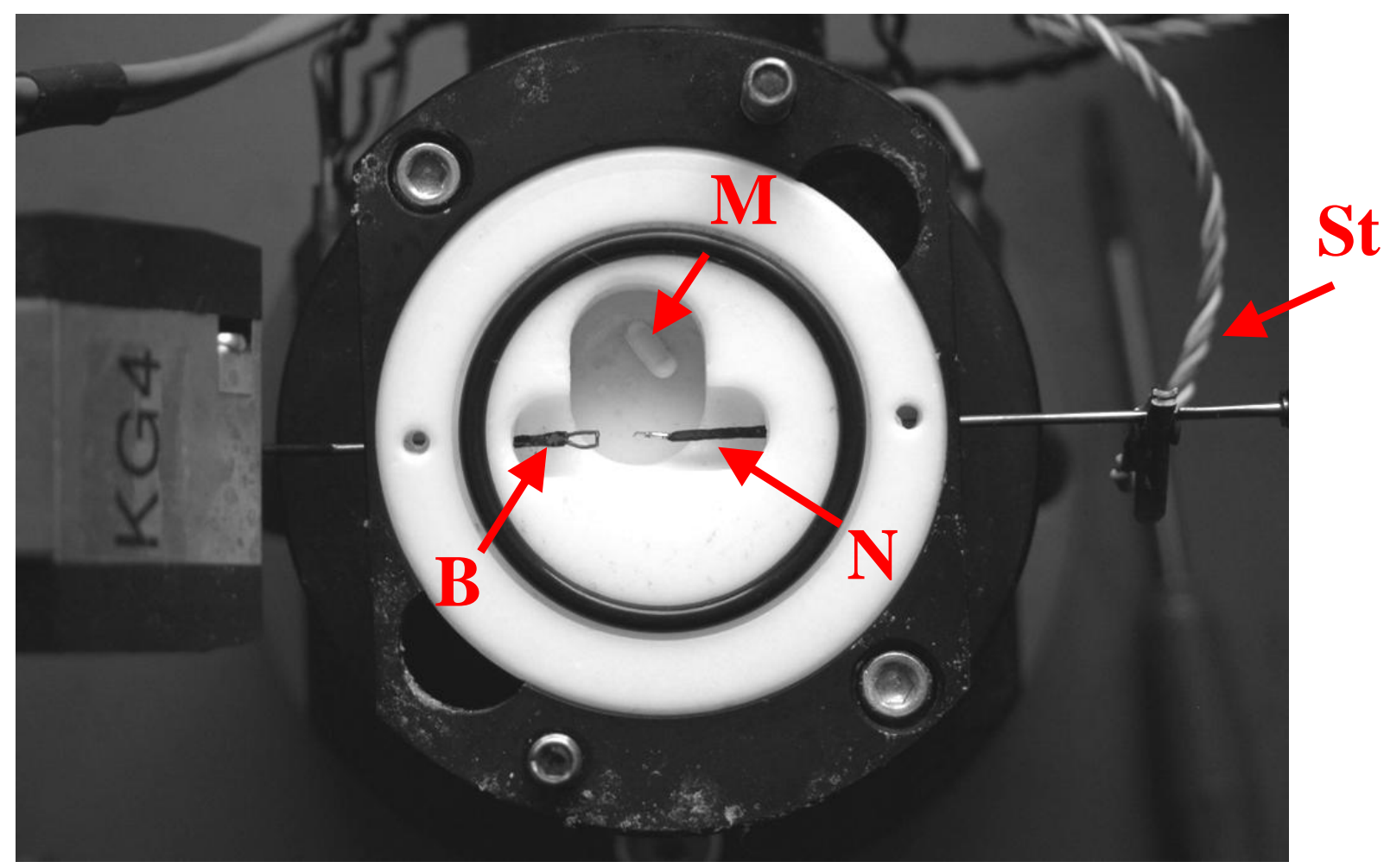

Abb. 3: Organbad mit Drahtschlaufe / Basket (B) und Nadel (N) zur Aufhängung eines Muskels. M = Magnetrührer, St = Stimulationskabel.

Zentrales Element dieser Anlage ist das Organbad, dargestellt in Abb. 3. Dort wird der Muskel eingehängt. Auf der rechten Seite befindet sich eine Nadel („N“), die mit dem elektrischen Stimulationskabel (,St“) verbunden ist. Auf der linken Seite befindet sich eine 
Drahtschlaufe, auch Körbchen oder Basket („B“) genannt, in das der Muskel dehnungsarm eingelegt werden kann. Diese Aufhängung ist mit dem Kraftaufnehmer KG4 verbunden, der die gemessenen Kräfte an den Computer überträgt. Zur optimalen Aufhängungsmöglichkeit wurden bei der Präparation der Trabekel ein dickeres und ein dünneres Ende zugeschnitten, sodass der Muskelstreifen mit seinem dünnen Ende durch den Basket („,B“) durchgefädelt werden kann und mit seinem dickeren Ende festklemmt. Zur homogenen Durchmischung des Langzeitmediums und gleichmäßigen Oxygenierung des Muskelstreifens enthält das Organbad einen Magnetrührer (,M“).

Über Mikrometerschrauben kann die Position der Muskelklemmen zueinander verändert werden und damit der Dehnungszustand des eingelegten Muskels entsprechend dem Versuchsprotokoll angepasst werden. Sowohl Basket als auch Nadel durchlaufen einen Kanal, der Organbad und Äußeres voneinander trennt. Um einen Abfluss der verwendeten Lösungen im Organbad zu vermeiden, sind die Kanäle mit niedrig-viskösem Silikongel abgedichtet.

Auf das Bad wird nach dem Einspannen der Muskeln ein Deckel aufgesetzt, der mit zwei Schrauben fixiert wird. Mittels der beiden Schlauchanschlüsse, in Abbildung 4 mit „S“ bezeichnet, kann kontinuierlich eine Begasung des Bades durch eine Schlauchpumpe erfolgen, die hier nicht $\mathrm{zu}$ sehen ist. Über den Kanal „, $\mathrm{K}^{“}$ erfolgt im Rahmen des Versuchsprotokolls ein Austausch der Lösungen.

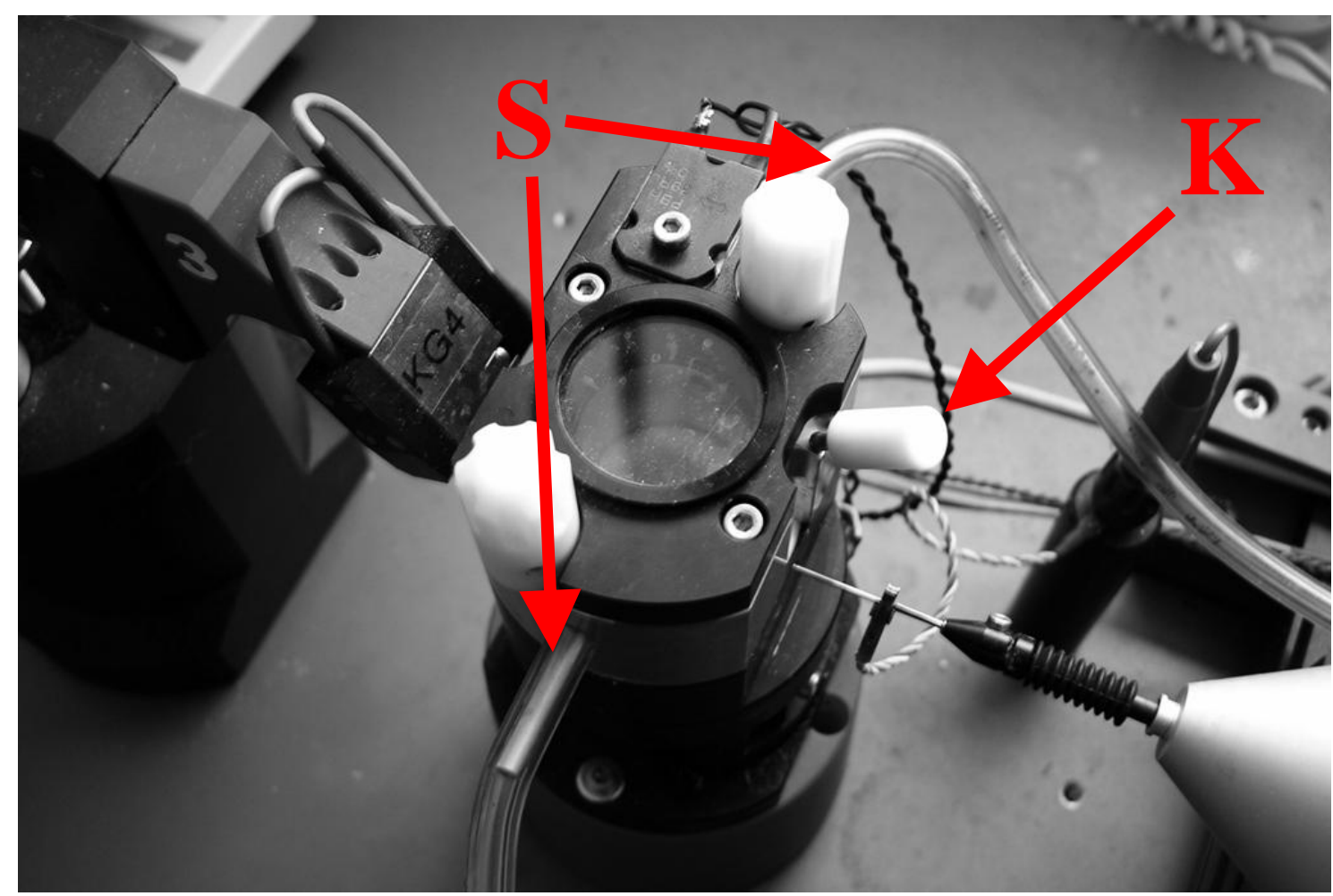

Abb. 4: Aufsicht auf die Anlage mit geschlossenem Deckel mit Schlauchanschlüssen (S) und Zuführungskanal (K) 


\section{II.4 Versuchsprotokolle}

\section{II.4.1 Dehnungsexperimente zur Generierung akuter Last}

\section{Einspannen:}

$\mathrm{Zu}$ Beginn des Experiments wurde das Organbad mit 1,5 ml Tyrodelösung, die eine Kalziumkonzentration von 0,2 mM hat, befüllt und dann der Muskel mittels einer Pipette in das Bad gegeben. Mit Hilfe mikrochirurgischer Pinzetten wurde der Muskel spannungsfrei auf der einen Seite in das Drahtkörbchen (Basket) eingehängt und dann auf der anderen Seite auf dem Nadellhaken aufgespießt. Nun wurde der Deckel auf das Organbad gesetzt. Jetzt wurde nochmals $4 \mathrm{ml}$ Tyrode-Lösung in das geschlossene Bad gefüllt und das Bad auf Dichtigkeit geprüft. Das Gesamtvolumen der Lösung in einem Bad beträgt somit 5,5 ml. Zur Konstanthaltung des $\mathrm{pH}$-Wertes wurde das Organbad mit Carbogen $\left(95 \% \mathrm{O}_{2} ; 5 \% \mathrm{CO}_{2}\right)$ begast. Nach fünfminütiger Wartezeit wurde mit dem Aufbau der zur Durchführung des Experiments benötigten Kalzium-Konzentration begonnen.

\section{Kalziumaufbau:}

Im ersten Durchgang wurde die Tyrodelösung im Bad in zwei Schritten gegen eine Tyrodelösung mit 0,5 $\mathrm{mM} \mathrm{Ca}^{2}+$ ausgetauscht, indem je $4 \mathrm{ml}$ der vorhandenen Lösung gegen 4 ml Tyrode mit 0,5 $\mathrm{mM} \mathrm{Ca}{ }^{2}+$ ersetzt wurden. Im zweiten Durchgang erfolgt das gleiche Procedere mit einer Tyrode-Lösung, die eine Kalziumkonzentration von $1 \mathrm{mM}$ hat. Zwischen den beiden Durchgängen war eine Wartezeit von 10 Minuten erforderlich, um eine Stabilisierung des Muskels zu gewährleisten.

\section{Elektrische Stimulation und Wechsel auf LZ-Medium:}

Nun wurde das Präparat über die Muskelklemmen stimuliert (Rechteckimpulse; End-zu-End; Impulsdauer $5 \mathrm{~ms}$; Frequenz $1 \mathrm{~Hz}$ ). Die Impulsspannung wurde bis zur ersten sichtbaren Kontraktion erhöht. Als endgültige Spannung wurde der Wert $40 \%$ über dieser Schwellenspannung gewählt. Nach Stabilisierung der Kontraktionskraft wurde die Lösung nochmals durch das mit Sauerstoff präoxygenierte Langzeitmedium ausgetauscht und 10 Minuten zur Stabilisierung abgewartet. Um den pH-Wert im Bad konstant halten zu können und der Kontamination mit Bakterien vorzubeugen, wurde hierzu ein HEPES-gepuffertes Langzeit-Medium verwendet, das mit einer Kombination von Penicillin und Streptomycin versehen war. Zusätzlich wurde das Organbad mit Sauerstoff begast. Im Genauen hatte es folgende Zusammensetzung: 


\begin{tabular}{|l|l|}
\hline LZ Medium Bestandteil & Konzentration \\
\hline L-Carnitine & $2 \mathrm{mmol} / \mathrm{L}$ \\
\hline Creatine & $5 \mathrm{mmol} / \mathrm{L}$ \\
\hline Taurine & $5 \mathrm{mmol} / \mathrm{L}$ \\
\hline DL-Glutamic-Acid & $2 \mathrm{mmol} / \mathrm{L}$ \\
\hline Bovine Serum Albumine & $0,2 \%$ \\
\hline Penicillin & $100 \mathrm{IU} / \mathrm{ml}$ \\
\hline Streptomycin & $0,1 \mathrm{mg} / \mathrm{ml}$ \\
\hline Kalzium & $1,8 \mathrm{mmol} / \mathrm{L}$ \\
\hline Insulin & $20 \mathrm{IU} / \mathrm{L}$ \\
\hline
\end{tabular}

\section{Dehnung (akute Last):}

Anschließend wurde der Muskel entweder ungedehnt belassen oder über die beiden Mikrometerschrauben in Schritten von $50 \mu \mathrm{m}$ vorgedehnt, bis die aktive Kontraktionskraft durch weitere Vordehnung nicht mehr oder nur noch minimal zunahm. Diese Länge wurde als $\mathrm{L}_{\max }$ definiert. Abb. 5 zeigt eine typische Vordehnung. Nach Beendigung des Vordehnens wurde das Experiment gestartet und ein Muskel als unbehandelte Kontrolle direkt eingefroren. Zur Kontrolle wurde $\mathrm{zu}$ jedem gedehnten Muskel ein ungedehnter Muskel gepaart, der ohne Vordehnung einen deutlich unterschiedlichen Dehnungszustand zum gedehnten Muskel aufwies und sich zudem isotonisch verkürzen konnte. Die gedehnten Präparate hingegen kontrahierten isometrisch. Somit ermöglichte der Versuchsaufbau einen Paarvergleich zwischen einem gänzlich lastfreien Zustand und einem maximalen Level an Vor- und Nachlast. Die Kontraktionen wurden mittels eines 4-Kanal-Schreibers und am Computer kontinuierlich aufgezeichnet.

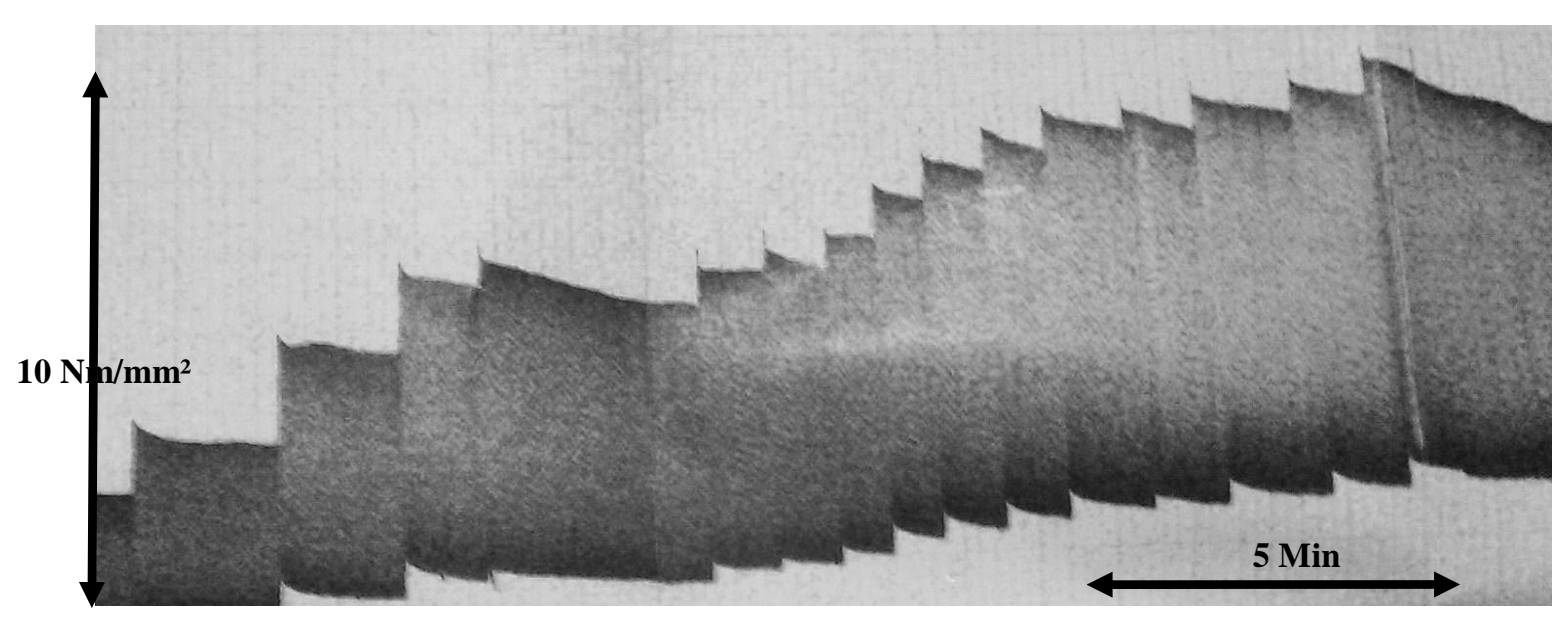

Abb. 5 Vordehnung eines Muskelstreifenpräparates (Originalregistrierung) 


\section{II.4.2 Zeitabhängige Degeneration von GATA4}

In Vorversuchen zeigte sich, dass die Expressionssignale von GATA4 in unbehandelten Muskeln abnahmen. Um dies gezielt zu untersuchen, wurde daher wie folgt verfahren: Die Muskeln wurden nicht, wie vorher beschrieben, gedehnt, sondern in einem $37^{\circ} \mathrm{C}$ warmen Wasserbad für einen Zeitraum von bis zu sechs Stunden ohne jegliche Manipulation inkubiert. Nach Präparation wurden sie in ein mit $10 \mathrm{ml}$ Tyrode befüllten Behälter überführt und ins Wasserbad gegeben. Es erfolgten ein schrittweiser Kalziumaufbau auf $1,8 \mathrm{mM} \mathrm{Ca}^{2+}$ und anschließend ein Austausch der Tyrode gegen das mit Sauerstoff präoxygenierte LangzeitMedium mit einem Calciumgehalt von 2,5 mM.

Kurz nach dem Mediumwechsel begann die Zeitzählung und die „Nullprobe“ (Zeitpunkt 0) wurde aus dem Behälter entnommen und in flüssigem Stickstoff eingefroren. Diese diente als Referenz für alle weiteren Proben, die dann nach einer, drei und sechs Stunden Inkubation entnommen und eingefroren wurden.

\section{II.4.3 Experimente zum Einfluss der Ubiquitin Isopeptidase}

Um die Abhängigkeit der zeitabhängigen Degeneration von GATA4 vom UbiquitinProteasom-System zu testen wurden die oben beschriebenen Versuche wiederholt in der Anwesenheit des Prostaglandins $\Delta 12-\mathrm{PGJ} 2$. Dieses Prostaglandin ist ein Inhibitor der Ubiquitin-Isopeptidase, die die Ubiquitin-Ketten von Proteinen entfernt (Mullally et al. 2001). Es wurden $5 \mathrm{ml}$ des Langzeitmediums mit 100 $\mu 1 \Delta 12-\mathrm{PGJ} 2$ der Firma Cayman Chemicals (Katalognummer 18850, CAS 87893-54-7) versetzt, um im Medium eine Zielkonzentration von $60 \mu \mathrm{M}$ zu erreichen. Der Versuchsaufbau erfolgte wie unter II.3 beschrieben, jedoch wurden 7 Muskelstücke präpariert. Nach Kalziumaufbau und Wechsel auf Langzeitmedium wurde wieder eine Nullprobe entnommen und eingefroren. Drei Muskelstücke wurden dann sofort in ein mit $\Delta 12-\mathrm{PGJ} 2$ versetztes Langzeitmedium überführt, die anderen drei verblieben im unbehandelten Medium. Nach simultaner Inkubation wurden zu einer, drei und sechs Stunden Proben entnommen und in Stickstoff eingefroren. Um den direkten Vergleich zu ermöglichen und Expressionsunterschiede $\mathrm{zu}$ verdeutlichen, wurden die Proben eines Inkubationsversuches im nachfolgenden Western Blot auf einem Gel verarbeitet. 


\section{II.5 Materialverarbeitung der Proben}

\section{II.5.1 RNA-Isolation mittels RNeasy Kit}

Zur Untersuchung der RNA-Expression wurden die Myokardproben (Biopsate oder Trabekel aus den Akutversuchen) mittels des RNeasy RNA Isolations Kit von Qiagen (Bestellnr. 74104, Qiagen, 40724 Hilden) verarbeitet. Das Kit erlaubt die Aufreinigung der Gesamt-RNA aus sehr kleinen Gewebemengen wie z.B. Trabekeln.

Im ersten Schritt wurden die Muskeln zusammen mit $300 \mu$ l eines mit 1\% Mercaptoethanol versetzten Guanidin-Thiocyanat-Lyse-Puffer (RLT-Puffer) in ein Eppendorf-Röhrchen überführt. Dieser Puffer inaktiviert umgehend alle als Kontamination enthaltenen RNasen und ermöglicht so eine hohe Stabilität des Lysats.

Mittels eines Rotor-Stator Homogenisierers wurden die Muskeln im Röhrchen verarbeitet. Die kleinen Messer des Rotor-Stator drehen bei sehr hoher Geschwindigkeit, sodass die Proben sowohl durch Flüssigkeitsturbulenzen im Eppendorf-Röhrchen als auch durch direkte mechanische Einwirkung zerkleinert und homogenisert werden. Im Regelfall war nach ca. 40 Sekunden eine ausreichende Homogeniserung erreicht.

Zur Präzipitation wurden den $300 \mu$ l Lysat $300 \mu 1$ 70\% Ethanol hinzugegeben. Das durch Auf- und Abpipettieren durchmischte Gesamtvolumen wurde nun auf die zentrale Membran der dem Kit beiliegenden RNeasy Mini Spin Säulen gegeben und in 2-ml-Röhrchen gestellt. Nach einer Zentrifugation von 15 Sekunden bei 10.000 Umdrehungen pro Minute (Rpm) wurde das in den 2-ml-Röhrchen durchflossene Material verworfen.

Nun wurde die auf der Membran fixierte RNA durch Zugabe von $350 \mu$ l RW1-Puffer gewaschen und 15 Sekunden bei 10.000 Rpm zentrifugiert. Der Durchfluss wurde wiederum verworfen.

Anschliessend wurde die nun auf der Mebran des Röhrchens fixierte RNA von Kontaminationen mit genomischer DNA gereinigt und hierzu wie folgt mit einer DNase (RNase-free DNase kit, Qiagen, Bestell-Nr. 79254) behandelt: Die DNase-Stammlösung wurde mit dem Puffer RDD, welcher dem Kit beiliegt, gemischt. Pro zu verarbeitender Probe wurden $10 \mu \mathrm{l}$ des DNase-Stamm mit $70 \mu \mathrm{l}$ RDD-Puffer angesetzt und auf jede Membran 80 $\mu 1$ des DNase-Gemischs gegeben. Nach 15 Minuten Inkubation wurden nochmals $350 \mu 1$ des RW1-Puffers hinzugegeben und bei 10.000 Rpm für 15 Sekunden zentrifugiert.

Anschließend wurden die Säulen in neue 2 ml-Röhrchen überführt. Es folgte ein Waschschritt mit RPE-Lösung. $500 \mu 1$ wurden auf die Membran gegeben und nach 2 Minuten Inkubation wiederum für 15 Sekunden bei 10.000 Rpm zentrifugiert. Nach Ausleerung des Röhrchens 
wurde dieser Schritt wiederholt. Anschließend wurde die leere Säule in einem neuen 2-mlRöhrchen zur Trocknung der Membran für 1 Minute bei Maximalgeschwindigkeit zentrifugiert.

Im letzten Schritt erfolgte die Elution der an die Membran gebundenen RNA in RNase freies Wasser. Dazu wurden $55 \mu 1$ RNase freies Wasser auf die Membran pipettiert, die Säule in ein frisches 1,5-ml-Röhrchen gestellt und für 2 Minuten inkubiert. Die abschließende einminütige Zentrifugation bei $10.000 \mathrm{Rpm}$ ergab ein RNA-Eluat von $55 \mu \mathrm{l}$, das bei $-80^{\circ} \mathrm{C}$ gelagert werden konnte.

\section{RNA-Konzentrationsbestimmung:}

Anschließend wurde am Spectrophotometer (Biophotometer 6131, Eppendorf, Hamburg) der RNA-Gehalt der Eluate gemessen. Zuerst erfolgte eine Eichung des Photometers, die sogenannte Blankmessung, mit RNase freiem Wasser in einer sterilen Küvette. Die Messung der Extinktion OD260 der RNA-Eluate erfolgte bei $260 \mathrm{~nm}$. Die Konzentrationsberechnung erfolgte nach folgender Formel: OD260 $* 40=$ Konzentration in ng/ $\mu 1$. Es ergab sich im Schnitt eine RNA-Konzentration von $15,1 \pm 1,43 \mathrm{ng} / \mu 1$.

Durch eine weitere Extinktionsmessung bei $280 \mathrm{~nm}$ und die Bildung des OD260/OD280Quotienten konnte auf die Reinheit der vorliegenden RNA-Probe geschlossen werden. Die RNA wurde als hinreichend rein bewertet, wenn der Quotient zwischen 1,8 und 2,0 lag.

\section{II.5.2 Protein-Isolation mittels HP}

Zur Gewinnung von Protein wurde durch manuelle Homogenisierung ein Komplett-Lysat der Muskeln erzeugt. Dazu wurde zu Beginn der Homogenisierungspuffer (HP-Puffer) mit der unten angegebenen Zusammensetzung angesetzt. Dann wurden die Mikrostößel mit destilliertem Wasser gereinigt und eine Styroporbox mit Eis befüllt, da alle Schritte unter Kühlung stattfinden mussten. In die Glaszylinder der Mikrostößel wurde nun $30 \mu 1$ HP-Puffer gefüllt. Dann wurde der gefrorene Muskel umgehend aus dem in flüssigem Stickstoff gekühlten Eppendorf-Röhrchen in den Glaszylinder überführt, sodass sichergestellt war, dass der Muskel im HP-Puffer auftaut. Für ca. zwei bis drei Minuten wurde der Muskel dann durch Auf- und Ab-Bewegungen des Stempels zerkleinert und die Probe so mechanisch lysiert. Abhängig von der Materialmenge wurde in Schritten von 30 ul die Puffermenge erhöht bis eine suffiziente Lyse eintrat. Für kleine Muskeln waren insgesamt ca. $60 \mu 1$ nötig, größere Muskeln erforderten bis zu $150 \mu$ l. Es galt, das Lysat auf keinen Fall zu stark zu verdünnen, um für den nachfolgenden Western Blot eine hinreichend hohe 
Proteinkonzentration zu erhalten. Das Lysat aus dem Glaszylinder wurde dann in ein 2-mlEppendorf-Röhrchen gegeben und dieses für 3 Minuten bei $8.000 \mathrm{Rpm}$ in einer gekühlten Zentrifuge aufgetrennt. Der Überstand wurde in ein frisches 1,5-ml-Röhrchen überführt und der Restmuskel im Zylinder erneut in einer dem Muskel angepassten Menge HP für zwei bis drei Minuten zerstoßen. Bei diesem Schritt galt es wiederum, das Lysat nicht zu hoch zu verdünnen. Der Restmuskel sowie das Lysat wurden nun zum Überstand im 1,5-ml-Röhrchen hinzugegeben und für fünf Minuten bei $14.000 \mathrm{Rpm}$ zentrifugiert.

Der gesamte Überstand wurde dann in ein frisches 1,5-ml-Röhrchen und $10 \mu 1$ in ein ExtraRöhrchen für die Proteinbestimmung überführt.

\begin{tabular}{|c|c|c|c|}
\hline \multirow{2}{*}{$\begin{array}{c}\text { Bestandteil Homogenisierugnspuffer } \\
1 \% \text { NP40 (EPEGAL CA-630) }\end{array}$} & \multicolumn{2}{|c|}{ Konzentration } & \multirow{2}{*}{\begin{tabular}{|l|} 
Menge für 10ml \\
$100 \mu l$
\end{tabular}} \\
\hline & 1 & $1: 100$ & \\
\hline $10 \%$ Glycerol & 1 & $1: 10$ & $1 \mathrm{ml}$ \\
\hline $137 \mathrm{mM} \mathrm{NaCl}(\mathrm{M}=58,44)$ & $1370 \mathrm{mM}$ & $1: 10$ & $1 \mathrm{ml}$ \\
\hline $20 \mathrm{mM}$ Tris- $\mathrm{HCl} \mathrm{pH}=7,4(\mathrm{M}=121,14)$ & $200 \mathrm{mM}$ & $1: 10$ & $1 \mathrm{ml}$ \\
\hline $20 \mathrm{mM} \mathrm{NaF}(\mathrm{M}=41,99)$ & $200 \mathrm{mM}$ & $1: 10$ & $1 \mathrm{ml}$ \\
\hline $1 \mathrm{mM}$ Sodium orthovanadat $(\mathrm{M}=183,9)$ & $100 \mathrm{mM}$ & $1: 100$ & $100 \mu 1$ \\
\hline $1 \mathrm{mM}$ Sodium pyrophosphat $(\mathrm{M}=446,1)$ & $100 \mathrm{mM}$ & $1: 100$ & $100 \mu 1$ \\
\hline $50 \mathrm{mM} \beta$-Glycerophosphat $(\mathrm{M}=216)$ & $500 \mathrm{mM}$ & $1: 10$ & $1 \mathrm{ml}$ \\
\hline $10 \mathrm{mM}$ EDTA $\mathrm{pH}=8(\mathrm{M}=372)$ & $100 \mathrm{mM}$ & $1: 10$ & $1 \mathrm{ml}$ \\
\hline $1 \mathrm{mM}$ EGTA pH=7 $(\mathrm{M}=380,4)$ & $10 \mathrm{mM}$ & $1: 10$ & $1 \mathrm{ml}$ \\
\hline $4 \mu \mathrm{g} / \mathrm{ml}$ Aprotinin $(\mathrm{M}=651,2)$ & $10 \mathrm{mg} / \mathrm{ml}$ & $1: 2500$ & $4 \mu 1$ \\
\hline $4 \mu \mathrm{g} / \mathrm{ml}$ Leupeptin $(\mathrm{M}=475,6)$ & $10 \mathrm{mg} / \mathrm{ml}$ & $1: 2500$ & $4 \mu 1$ \\
\hline $4 \mu \mathrm{g} / \mathrm{ml}$ Pepstatin A $(\mathrm{M}=685,9)$ & $0,5 \mathrm{mg} / \mathrm{ml}$ & $1: 25$ & $80 \mu 1$ \\
\hline $1 \mathrm{mM}$ PMSF $(\mathrm{M}=174,2)$ & $200 \mathrm{mM}$ & $1: 200$ & $50 \mu 1$ \\
\hline \multicolumn{3}{|l|}{ Mit $\mathrm{ddH}_{2} \mathrm{O}$ auf $10 \mathrm{ml}$ auffüllen } & $2,562 \mathrm{ml}$ \\
\hline
\end{tabular}




\section{Proteinkonzentrationsbestimmung (Bradford Test):}

Die Bestimmung der Proteinkonzentrationen der Lysate erfolgte photometrisch. Dazu wurde zu Beginn eine Standardreihe mit Rinder-Albumin (bovine serum albumin; BSA) erstellt. Zur Herstellung der BSA-Stammlösung mussten ca. 0,3 mg BSA abgewogen werden und mit der entsprechenden Menge HP-Puffer auf eine Zielkonzentration von $3 \mathrm{mg} / \mathrm{ml}$ gebracht werden. Nach folgendem Schema wurde nun eine Reihe mit standardisierten Konzentrationen von BSA pipettiert, mit dem Vortexer durchmischt und jeweils $10 \mu 1$ in ein Röhrchen überführt.

\begin{tabular}{|c|c|c|c|c|c|c|c|}
\hline & $\mathbf{L W}$ & $\mathbf{0 , 5}$ & $\mathbf{1}$ & $\mathbf{1 , 5}$ & $\mathbf{2}$ & $\mathbf{2 , 5}$ & $\mathbf{3}$ \\
\hline HP $[\boldsymbol{\mu l}]$ & 100 & 83,3 & 66,7 & 50 & 33,3 & 16,7 & 0 \\
\hline BSA $[\boldsymbol{\mu l}]$ & 0 & 16,7 & 33,3 & 50 & 66,7 & 83,3 & 100 \\
\hline
\end{tabular}

Dann wurde die BCA-Protein-Mischung angesetzt. In einem Verhältnis von 50:1 wurden die Reagenzien A und B vermischt. Zu den $10 \mu \mathrm{l}$ der Proben wurden $500 \mu \mathrm{l}$ des BCA-Reagenz gegeben und mittels Vortexer gemischt. Nach einer Inkubationszeit von 30 Minuten bei $37^{\circ} \mathrm{C}$ wurden die Proben in Küvetten überführt und anschließend deren Extinktion bei einer Wellenlänge von $562 \mathrm{~nm}$ gemessen. Anhand der Extinktionswerte der Standardreihe konnten die Extinktionswerte der Proben einer Regressionsanalyse unterzogen werden und so die Proteinkonzentrationen errechnet werden. Im Durchschnitt ergab sich eine Konzentration von $3 \mu \mathrm{g} / \mu \mathrm{l}$ 


\section{II.6 Messverfahren zur RNA- und Proteinexpression}

\section{II.6.1 Messungen zur RNA-Expression cDNA Synthese}

Um die RNA-Expression zu untersuchen, wurden die nach dem unter II.5.1 beschriebenen Verfahren hergestellten RNA-Eluate mit dem Reverse Transcription Kit von Qiagen (Bestellnr. 205311, Qiagen, 40724 Hilden) weiter verarbeitet. Das Kit erlaubt die Herstellung von cDNA, um im weiteren Verlauf mittels qRT-PCR die RNA-Expression in den untersuchten Muskeltrabekeln zu quantifizieren.

Dazu wurde eine definierte Menge RNA verwendet, die sich nach der per Spectrophotometer gemessenen Konzentration richtete, sodass alle zu untersuchenden Proben die gleiche RNAMenge enthielten. Beispiel: Bei einer Konzentration von $31 \mu \mathrm{g} / \mathrm{ml}$ in Probe $1,45,1 \mu \mathrm{g} / \mathrm{ml}$ in Probe 2 und einer Zieldosis von 72 ng entsprach dies 2,3 $\mu$ l reiner RNA für Probe 1 und 1,6 $\mu 1$ für Probe 2. Es wird deutlich, dass genaues Pipettieren essentiell für die Durchführung ist. Alle Schritte mussten auf Eis erfolgen, um die Degradation von RNA zu minimieren. Vor Beginn wurden alle Proben auf dem Vortexer durchmischt und dann 1 Minute bei 10.000 Rpm zentrifugiert. Dann wurde entsprechend der Berechnung die Menge RNA in ein frisches 1,5-ml-Röhrchen überführt. Allen Proben wurden $2 \mu$ gDNA-Wipeout-Buffer hinzugegeben und mit RNase-freiem Wasser auf eine Gesamtmenge von insgesamt $14 \mu$ l eluiert. Dann wurden sie für zwei Minuten bei $42^{\circ} \mathrm{C}$ inkubiert, sodass der gDNA-Wipeout-Buffer umgehend alle als Kontamination enthaltene genomische DNA inaktivierte. Damit wurde eine hohe Stabilität der Probe ermöglicht.

Dann wurden die Proben wieder auf Eis aufbewahrt und ein Reverse-TranskriptionMastermix angesetzt. Auf Eis wurde pro Probe $1 \mu 1$ Reverse-Transkriptase-Enzym mit $4 \mu 1$ RT-Buffer und je $1 \mu$ l RT-Primer-Mix hinzu pipettiert. Die reverse Transkriptase ist ein Enzym, das natürlicherweise in RNA-haltigen Retroviren wie z.B. dem HI-Virus vorkommt. Es ermöglicht die Synthese von DNA aus RNA mittels einer RNA-abhängigen DNAPolymerase. Die dem Kit beigelegten RT-Buffer und RT-Primer-Mix stellen die für die Polymerase notwendigen Primer und Nukleotide zur Verfügung. Dann wurden $6 \mu$ l dieses Mastermix mit den $14 \mu \mathrm{l}$ des auf Eis bewahrten Eluats versetzt und zur cDNA-Synthese für 15 Minuten bei $42^{\circ} \mathrm{C}$ inkubiert. Um die reverse Transkripase $\mathrm{zu}$ inaktivieren, folgte eine Inkubation für 3 Minuten bei $95^{\circ} \mathrm{C}$. Die so hergestellte cDNA konnte nun für die nachfolgende $\mathrm{qRT}-\mathrm{PCR}$ verwendet oder bei $-80^{\circ} \mathrm{C}$ gelagert werden. 


\section{Quantitative Real Time PCR (qRT-PCR)}

Die Polymerase-Ketten-Reaktion (PCR) wurde im Jahre 1987 von Kary Mullis entwickelt (Mullis und Faloona 1987). Basierend auf dem Einsatz von DNA-Polymerasen, z.B. der TaqPolymerase des hitzebeständigen Bakteriums Thermus aquaticus (Taq), kann die zu untersuchende DNA amplifiziert werden. Durch den zusätzlichen Einsatz von fluoreszierenden Farbstoffen wie dem SYBR-Green-I-Farbstoff kann die amplifizierte DNAMenge anhand von Fluoreszenz-Messungen quantifiziert werden. SYBR-Green ist ein asymmetrischer Cyanin-Farbstoff, der an doppelsträngige DNA bindet. Die Fluoreszenz des DNA-SYBR-Green-Komplex steigt dabei von PCR-Zyklus zu Zyklus an. Diese messbare Fluoreszenzzunahme korreliert mit der Menge an amplifizierter DNA.

Verwendet wurde das qPCR Core kit SYBR Green I der Firma Eurogentec (Bestellnr. RTSN10-05, Eurogentec, 50667 Köln). Da SYBR-Green lichtempfindlich ist, musste der Farbstoff lichtgeschützt gelagert werden. Alle Schritte wurden gekühlt auf Eis durchgeführt. $\mathrm{Zu}$ Beginn wurde das enthaltene SYBR-Green mit $1 \mathrm{ml}$ des Lösungsmittel DMSO versetzt und vorsichtig vermischt. Es folgte die Herstellung des Mastermix mit den im Kit enthaltenen Substanzen nach folgendem Schema:

\begin{tabular}{|l|l|}
\hline 10 x Reaktionspuffer & $2 \mathrm{ul}$ \\
\hline Magnesium & $1,4 \mathrm{ul}$ \\
\hline Nukleotide (dNTP) & $0,8 \mathrm{ul}$ \\
\hline Primer forward (2 uM) & $2 \mathrm{ul}$ \\
\hline Primer reverse (2 uM) & $2 \mathrm{ul}$ \\
\hline Goldstar DNA Polymerase & $0,1 \mathrm{ul}$ \\
\hline SYBR Green Farbstoff & $0,6 \mathrm{ul}$ \\
\hline Mastermix & $\mathbf{8 , 9} \boldsymbol{\mu l}$ \\
\hline Wasser & \\
\hline cDNA & $6,1 \mathrm{ul}$ \\
\hline Gesamt & $5 \mathrm{ul}$ \\
\hline
\end{tabular}

Magnesium ist für die Funktion der DNA-Polymerase essentiell. Die eingesetzten Primer definieren den Startpunkt der DNA-Synthese, für die Desoxyribonukleosidtriphosphate (dNTP) als Bausteine benötigt werden. Der erstellte Mastermix wurde vorsichtig gemischt und für 15 Sekunden bei 10.000 Rpm zentrifugiert.

$5 \mu 1$ der nach dem oben genannten Verfahren produzierten cDNA wurden auf eine Mikrotiter- 
Platte (384 well plate) überführt. Anschließend wurde die cDNA mit Wasser und Mastermix auf die Zielmenge von $20 \mu \mathrm{l}$ befüllt und vorsichtig per Pipette gemischt. Dabei durften keine Blasen im Probengefäß verbleiben. Es wurde eine Negativ-Probe mit $5 \mu 1$ RNase-freiem Wasser und eine Positiv-Probe mit dem Housekeeping-Gen GAPDH angelegt. Bei der Überführung der Proben auf die Mikrotiter-Platte war es sehr wichtig, die genaue Position einzuhalten, um die gemessenen Ergebnisse hinterher eindeutig zuordnen zu können.

Nun wurde die befüllte Mikrotiter-Platte in den Thermocycler ABI Prism 7900HT Real Time PCR System (Bestellnr. 4329001, Applied Biosystems, CA 94404 USA) überführt. Der PCRProzess bestand aus insgesamt 35 Zyklen mit speziellen Zeit- und Temperatur-anforderungen, auf die der Thermocycler eingestellt werden musste. $\mathrm{Zu}$ Beginn erfolgte die Aktivierung der Goldstar-Taq-Polymerase bei $95^{\circ} \mathrm{C}$ über 10 Minuten. Pro Zyklus erfolgten dann immer 3 Schritte.

1) Denaturierung: Denaturierung der DNA durch Aufbrechen der Wasserstoffbrückenbindungen bei $95^{\circ} \mathrm{C}$ über 15 Sekunden, sodass die zu untersuchende DNA als Einzelstränge ohne Primerbindung vorlag.

2) Annealing (Annäherung): Anlagerung der Primer an die Einzelstränge bei einer Temperatur von $60^{\circ} \mathrm{C}$ über 20 Sekunden.

3) Extension (Verlängerung): Polymerisation der fehlenden Stränge mit freien Nukleotiden durch die Taq-Polymerase bei $75^{\circ} \mathrm{C}$ über 40 Sekunden.

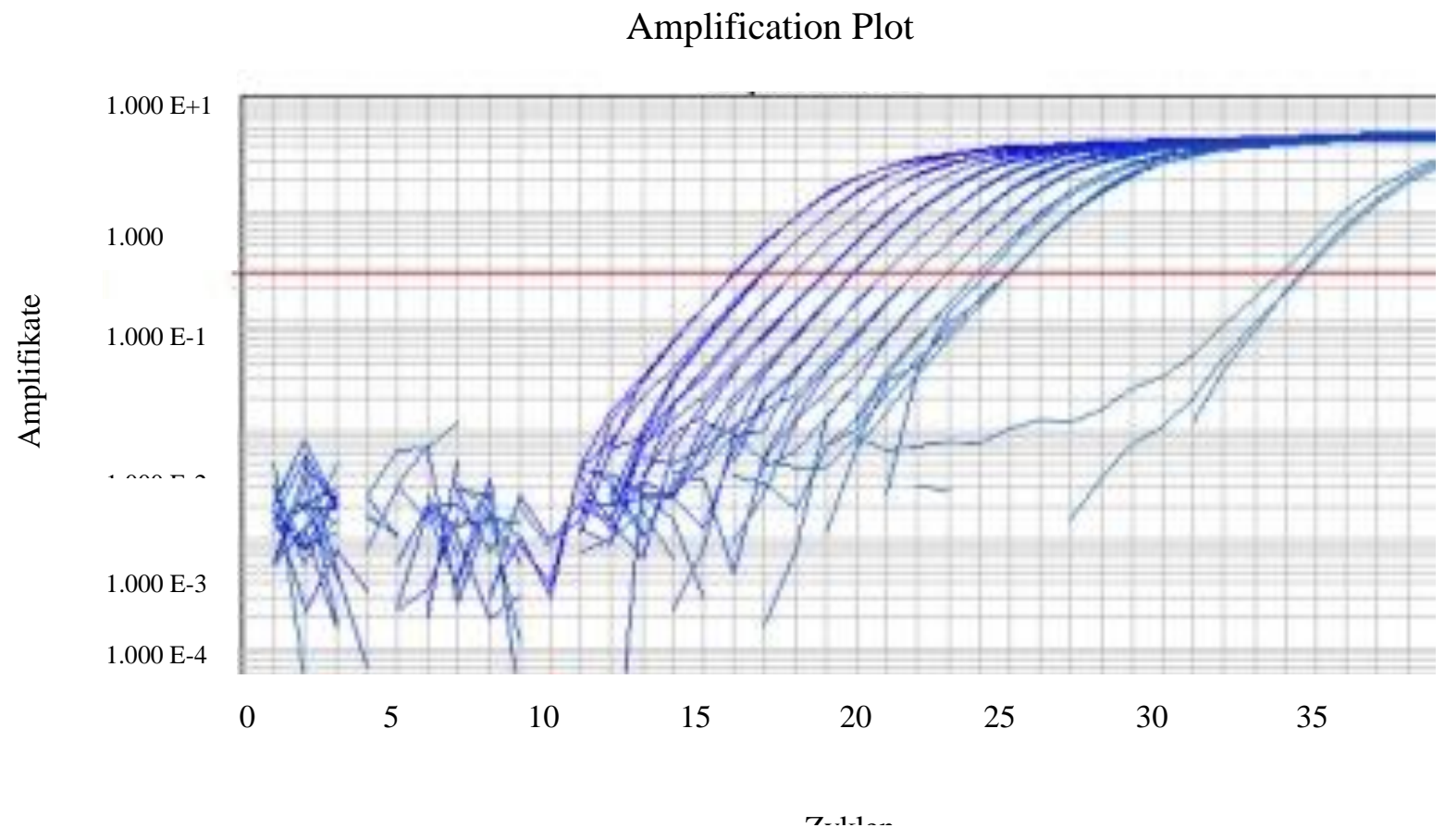




\section{II.6.2 Western Blot}

\section{Übersicht:}

Die zu untersuchenden Proteine wurden im ersten Schritt auf ein Gel aufgetragen und durch

Elektrophorese ihrer Größe nach aufgetrennt. Dann erfolgte die Übertragung der Proteine vom Gel auf eine Nitrozellulosemembran durch ein senkrecht zum Gel angelegtes elektrisches Feld. Anschließend wurden mit spezifischen Antikörpern, die an ein für sie spezifisches Epitop binden, Proteine auf der Membran gebunden. Zuvor mussten jedoch erst alle unspezifischen Bindungsstellen durch Albumin oder Milchpulver blockiert werden. Durch erneute Inkubation mit einem Sekundärantikörper, der an Peroxidase (HRP) gekoppelt ist, entstand ein Komplex, der durch eine Lichtreaktion als Bande sichtbar gemacht werden konnte (ECL Reaktion). Die Lichtemission wurde auf einem Fotofilm festgehalten und das Ausmaß der Schwärzung des Filmes densitometrisch ausgewertet.

\section{Giessen des Gels und Probenvorbereitung:}

Für das Gel und die nachfolgende Elektrophorese wurde ein System der Firma BioRad (MiniProtean Tetra Cell, Bestellnr. 5535, BioRad, 80939 München) verwendet. Zu Beginn wurden die grüne Halterung des Systems sowie die Spacer- und Frontplatten, in der die Gele polymerisieren und die Elektrophorese stattfindet, mit Ethanol $70 \%$ gereinigt und alles zusammengebaut. Die Inhaltsstoffe eines $10 \%$ Trenngels und eines Sammelgels wurden zusammen pipettiert und im Vortexer gemischt.

Die Zusammensetzung war:

\section{Trenngel $10 \%$}

\begin{tabular}{|l|c|}
\hline Stoff & Menge \\
\hline Acrylamid / Bisacrylamid & $7,5 \mathrm{ml}$ \\
\hline 4x Tris/SDS pH 8,8 & $5,63 \mathrm{ml}$ \\
\hline Aqua dest. & $9,38 \mathrm{ml}$ \\
\hline $10 \%$ APS & $75 \mu \mathrm{l}$ \\
\hline TEMED & $15 \mu \mathrm{l}$ \\
\hline
\end{tabular}

\section{Sammelgel}

\begin{tabular}{|l|c|}
\hline Stoff & Menge \\
\hline Acrylamid / Bisacrylamid & $1 \mathrm{ml}$ \\
\hline $4 x$ Tris/SDS pH 8,8 & $1,88 \mathrm{ml}$ \\
\hline Aqua dest. & $4,62 \mathrm{ml}$ \\
\hline $10 \%$ APS & $37,5 \mu \mathrm{l}$ \\
\hline TEMED & $15 \mu \mathrm{l}$ \\
\hline
\end{tabular}

TEMED und APS durften erst unmittelbar vor dem Gießen des Gels hinzugegeben werden. Das Trenngel wurde nun zwischen die gereinigten Glasplatten gegossen und zur Polymerisierung $1 \mathrm{ml}$ Butanol darübergegeben. Es musste gewartet werden, bis sich eine Wasserphase über dem Gel ausgebildet hat. Dann wurde das Butanol abgegossen, mit destilliertem Wasser gespült und die Geloberfläche mit Filterpapier getrocknet. Jetzt konnte 
das Sammelgel luftblasenfrei darüber gegossen werden. Ein auf die Halterung aufgesetzter Kamm erreichte die Bildung von Taschen, in die später die Proteinproben pipettiert werden konnten. Nach einer Stunde Wartezeit war auch das Sammelgel polymerisiert und konnte entweder sofort verwendet oder in feuchten Tüchern über Nacht gelagert werden.

Zwischenzeitlich wurden die Proben vorbereitet. Dazu wurden sie so verdünnt, dass gleiche Mengen an Protein von verschiedenen Proben untersucht werden konnten. Neben den Experimentproben wurden bei jedem Western Blot drei Proben einer Standardreihe aus PoolHomogenaten aufgetragen. Die Proben mussten bei $95^{\circ} \mathrm{C}$ für fünf Minuten gekocht und dann zwei Minuten auf Eis gestellt werden. Anschließend wurden sie für zwei Minuten bei 14.000 Rpm zentrifugiert und wieder bis zum Auftragen auf Eis gestellt.

\section{Gel-Elektrophorese:}

Dann konnten die polymerisierten Gele mit ihrer Halterung in eine Apparatur eingesetzt werden, die durch Stromfluss die Elektrophorese ermöglichte. Die Apparatur wurde bis zur Oberkante der Halterung mit Laufpuffer befüllt und die Geltaschen damit ausgespült, nachdem der Kamm entfernt worden war. Nun konnten die Taschen mit den Proben und einem Marker vorsichtig beschickt und die Apparatur geschlossen werden. Bei $100 \mathrm{~V}$ erfolgte die elektrophoretische Auftrennung der Proteine in Banden.

\section{Membran-Transfer:}

Nachdem die Proteine aufgetrennt worden waren, wurde das Gel aus seiner Halterung entnommen und auf eine Nitrozellulosemembran übertragen. In einer Art Sandwich wurden Gel und Membran luftblasenfrei zwischen jeweils zwei Filterpapiere, einem Schwämmchen und einem Plastikrahmen gelegt. Die Schwämmchen waren vorher in Transferpuffer eingeweicht worden.

Das Gel im Sandwich wurde nun zum eigentlichen Blotten in eine Apparatur eingesetzt. Diese wurde mit Transferpuffer befüllt und in einer mit Eis gefüllten Styroporbox gekühlt. Nun wurde senkrecht zum Gel ein elektrisches Feld mit einer konstanten Stromstärke von 150 mA angelegt, sodass über Nacht der Transfer der Proteine aus dem Gel auf die Membran erfolgte, wo diese aufgrund hydrophober Wechselwirkungen haften blieben.

\begin{tabular}{|l|l|}
\hline \multicolumn{2}{|l|}{ Transferpuffer 1x (2 Liter) } \\
\hline Tris-Base & $39,4 \mathrm{~g}$ \\
\hline Glycine & $144 \mathrm{~g}$ \\
\hline Mit Methanol 20\% auf 2 Liter Gesamtmenge auffüllen \\
\hline
\end{tabular}




\section{Blocken:}

Nach Beendigung des Transfers wurden die Banden der entnommenen Membran für fünf Minuten mit Ponceau S Lösung (P7170-1L, Sigma-Aldrich) angefärbt, um zu überprüfen, ob Protein übertragen worden war. Die Membran wurde nun bei einer Höhe von ca. 35 kDa eingeschnitten, um die abgetrennten Teile der Membran separat mit verschiedenen Antikörpern behandeln zu können. Nach der Färbung wurde die Membran mit einer $5 \%$ Mischung aus $100 \mathrm{ml}$ einfach konzentrierter TBST-Lösung (Tris-Buffered Saline Tween-20) und $5 \mathrm{~g}$ Milchpulver für eine Stunde bei Raumtemperatur geblockt, um unspezifische Bindungsreaktionen von Proteinen an der Membran im weiteren Ablauf zu verhindern.

\begin{tabular}{|l|l|}
\hline 10x TBST-Puffer (2 Liter) \\
\hline $\mathrm{NaCl}$ & $198,2 \mathrm{~g}$ \\
\hline Tris-Base & $24,2 \mathrm{~g}$ \\
\hline diesen Ansatz in $1600 \mathrm{ml}$ doppelt destilliertem & Wasser $\left(\mathrm{dd}_{2} \mathrm{O}\right)$ lösen, dann pH einstellen. \\
\hline Tween $200,1 \%$ & $20 \mathrm{ml}$ \\
\hline danach mit dd $\mathrm{H}_{2} \mathrm{O}$ auf 2 Liter auffüllen, bei Bedarf 1:10 verdünnen für 1x TBST \\
\hline
\end{tabular}

\section{Antikörper-Inkubation:}

Nun erfolgte die Behandlung der Membran mit spezifischen Antikörpern zur Identifizierung der Proteinbanden. Vor Hinzugabe der Antikörper musste allerdings der Blockpuffer zweimal für zehn Minuten mit TBST ausgewaschen werden. Folgende Antikörper kamen zur Verwendung: GATA4-AK 1:200 (Sigma Aldrich, Kat. Nr. G8794) in 1x TBST, PhosphoGATA4-AK 1:200 (Abcam, Kat. Nr. 5245) in 1x TBST und GAPDH-AK 1:60000 (Bio Trend, Kat. Nr. 4699-9555) in 0,5 \% MP/TBST. Die beiden erstgenannten Antikörper inkubierten über Nacht auf der Membran, wohingegen der GAPDH-AK lediglich 30 Minuten inkubieren musste.

Nach erfolgter Inkubation wurde ungebundener Antikörper dreimal jeweils zehn Minuten mit TBST ausgewaschen, bevor die Inkubation mit dem enzymmarkierten Zweitantikörper erfolgte, der den gebundenen Erstantikörper sichtbar machen sollte. Folgende Antikörper wurden verwendet: HRP2-Rabbit-AK 1:3000 (GE Healthcare, NA934V) in 0,5 \% MP/TBST für die GATA4-behandelten Membranen und HRP2-Mouse-AK 1:10000 (GE Healthcare, NA931V) in 0,5\% MP/TBST für die GAPDH-behandelten Membranen. Wiederum erfolgte nach einer Inkubationszeit von 30 Minuten die Auswaschung ungebundener Antikörper viermal für je zehn Minuten mit TBST. 


\section{ECL-Reaktion (Enhanced Chemi-Luminescence):}

Im nächsten Schritt wurde die Membran mit $5 \mathrm{ml}$ eines Gemisches aus Luminol und H2O2 behandelt, das in Anwesenheit von katalysierenden Proteinen reagiert und chemolumineszent Licht ausgibt. Die Membran und ein Röntgenfilm wurden in eine Filmkassette gelegt, sodass die Proteinbanden, die die Lichtreaktion katalysieren, den eingelegten Film schwärzten.

\section{Filmentwicklung:}

In der Dunkelkammer wurde der Film für eine definierte Zeit belichtet. Wir begannen mit einer Minute. Nach Ablauf der Zeit wurde der nun teils geschwärzte Film aus der Kassette entnommen und in den Entwickler (SRX-101A, Konica Minolta Medical Imaging, 81829 München) eingelegt. Anhand des entwickelten Bildes wurden je nach Belichtungsstärke mehrere Bilder mit längerer oder kürzerer Belichtungszeit angefertigt.

\section{Densitometrie:}

Zur Auswertung wurde der Film durch eine rechnergestützte Kamera (Multiimage Light Cabinet, Alpha-Innotech Corporation, 94577 San Leandro, USA) abfotografiert. Am Computer erfolgte mittels einer dazugehörigen Software (Alpha Imager, Alpha-Innotech Corporation, 94577 San Leandro, USA) eine densitometrische Messung der Schwärzung der Western Blot Banden. Dieses Messverfahren beruht auf der Linearität zwischen Intensität der Schwärzung und dem Licht, das durch die ECL-Reaktion ausgegeben wird.

Dazu wurden an die Blot-Banden jeweils gleich große Rechtecke angepasst, um deren Farbdichte als optische Dichtewerte (OD) miteinander vergleichen zu können. Zusätzlich wurde mittels eines gleich großen Rechtecks die Farbinformation des Hintergrunds als Grundlage für die vergleichende Berechnung ausgewählt.

\section{II.7 Auswertung}

\section{II.7.1 Funktionelle Parameter}

Bei den Experimenten zur Untersuchung akuter Last wurde der Verlauf der Kontraktionskraftamplitude in $\mathrm{mN}$ auf die Querschnittsfläche des Muskelstreifens normiert $\left(\mathrm{mN} / \mathrm{mm}^{2}\right)$ und der prozentuale Verlauf ausgewertet. Zur Beurteilung des Lastzustandes wurde die diastolische Spannung mit den gleichen Maßeinheiten ausgewertet. 


\section{II.7.2 RNA Expression}

Für die quantitative Real Time PCR wurde für jede Probe eines Laufes der CT-Wert ermittelt. Dieser Wert beschreibt den Zyklus der Amplifikationen, an dem die Fluoreszenz der Produkte erstmals signifikant die Hintergrundfluoreszenz übertrifft. Der CT-Wert stellt damit den Beginn der Phase der exponentiellen Vermehrung dar. Eine relative Quantifizierung erfolgte durch Normierung auf das Housekeeping-Gen GAPDH, um Variationen in der eingesetzten RNA-Menge ausgleichen zu können $\left(\triangle \mathrm{CT}=\mathrm{CT}_{\text {Probe }}-\mathrm{CT}_{\mathrm{GAPDH}}\right)$. Weitere Normierung auf eine Referenzgruppe ergab den $\triangle \triangle \mathrm{CT}$-Wert $\left(\triangle \triangle \mathrm{CT}=\triangle \mathrm{CT}-\triangle \mathrm{CT}_{\text {Referenz }}\right)$. Der relative Expressionsunterschied der Probe zur Referenzgruppe ergab sich aus der Potenz $2^{\triangle} \triangle \mathrm{CT}$.

\section{II.7.3 Protein Expression und Phosphorylierung}

Die densitometrisch gemessenen Dichte-Werte der Western Blot Banden wurden am Computer ausgemessen und zur Kontrolle der eingesetzten Proteinmengen auf das Housekeeping-Gen GAPDH normiert. Die Werte eines Versuches wurden auf die bei Versuchsbeginn entnommene Nullprobe normiert. Beim Vergleich mehrerer Blots untereinander, z.B. Daten zur Aortenstenose, erfolgte eine zusätzliche Normierung auf eine Standardreihe. Bei Blots, die sowohl phosphoryliertes als auch gesamtes Protein erfassten, wurde die Phospho-Ratio als dazugehöriger Quotient berechnet.

\section{II.8 Statistische Auswertung}

Alle in dieser Arbeit angegebenen Ergebnisse sind als Mittelwert \pm Standardfehler (SEM) angegeben. Die Testung auf Signifikanz wurde durch eine Varianzanalyse (Anova) und den Student-Newman-Keuls-Test durchgeführt. Je nach Anzahl der unabhängigen Variabeln wurde dabei der Ein- oder Zwei-Wege-Test benutzt. Unterschiede wurden bei einer Irrtumswahrscheinlichkeit von $\mathrm{p}<0,05$ als signifikant, bei $\mathrm{p}<0,01$ als hochsignifikant betrachtet. 


\section{Ergebnisse}

\section{III.1 Chronische Last}

Als Korrelat eines chronischen Lastzustandes wurden Myokard-Proben von 20 Patienten mit Aortenstenose (AS) untersucht und mit einer Kontrollgruppe von 10 Proben aus nichtinsuffizienten Herzen (Kontrolle) verglichen. Die Aortenstenosepatienten ließen sich anhand ihrer Ejektionsfraktion in zwei Gruppen einteilen: $\mathrm{n}=16$ mit kompensierter $\left(\mathrm{AS}_{\mathrm{komp}} \mathrm{EF}>40\right.$ $\%)$ und $\mathrm{n}=4$ mit dekompensierter linksventrikulärer Funktion $\left(\mathrm{AS}_{\text {dekomp }} \mathrm{EF}<40 \%\right)$.

\section{III.1.1 GATA4 mRNA-Expression}

Die RNA der Proben wurde nach dem im Methodenteil beschriebenen Protokoll isoliert, in cDNA umgeschrieben und die Expression von GATA4 und GAPDH mittes Realtime PCR quantifiziert. Aufgrund prozesstechnischer Probleme konnten 3 Aortenstenoseproben für die RNA-Expressionsmessung nicht verwendet werden.

Abbildung 7 zeigt die mRNA-Expression von GATA4 in Aortenstenoseproben im Vergleich zu Proben von nicht-insuffizientem Myokard nach Normierung auf das Referenz-Gen GAPDH. Es bestand eine signifikante Hochregulation der GATA4 mRNA-Expression, die sich auf $202 \pm 60 \%$ im Vergleich zur Kontrolle (jeweils p < 0,05) belief. Zwischen den oben genanneten Subgruppen $\mathrm{AS}_{\mathrm{komp}}$ und $\mathrm{AS}_{\text {dekomp }}$ bestand dabei kein signifikanter Unterschied.

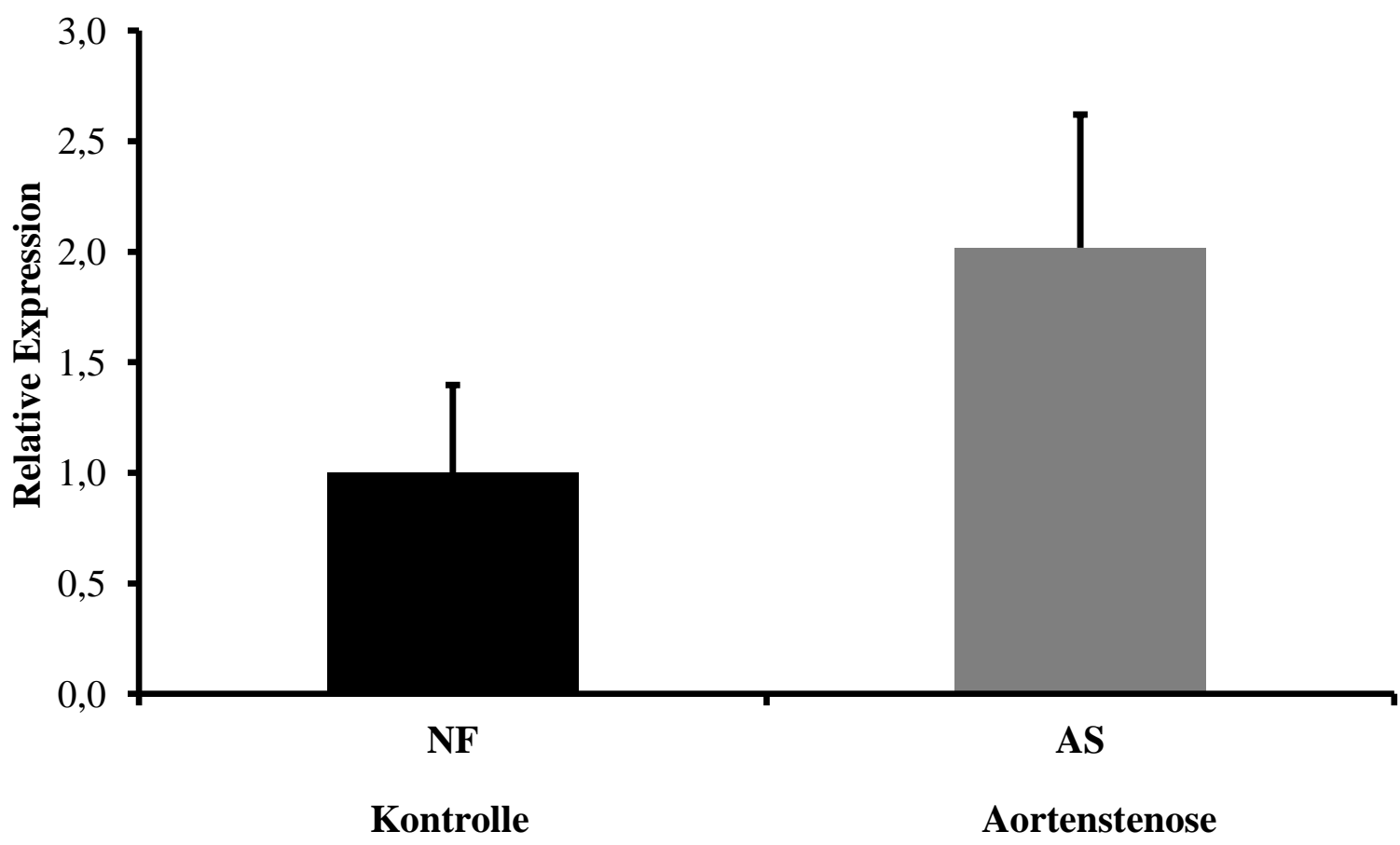

Abb. 7: mRNA-Expression von GATA4 bei Aortenstenose. 


\section{III.1.2 GATA4-Proteinexpression}

Die Proben wurden nach dem im Methodenteil dargestellten Protokoll homogenisiert und geblottet. Auch auf Proteinebene zeigte sich analog zur mRNA-Expression eine Hochregulation. In der Gruppe mit kompensierter Funktion lag diese bei $159 \pm 7 \%$, in der Gruppe mit dekompensierter Funktion bei $143 \pm 16 \%$ (jeweils $\mathrm{p}<0,05$, Abb. 8). Zwischen den Subgruppen ergaben sich dabei keine signifikanten Unterschiede.

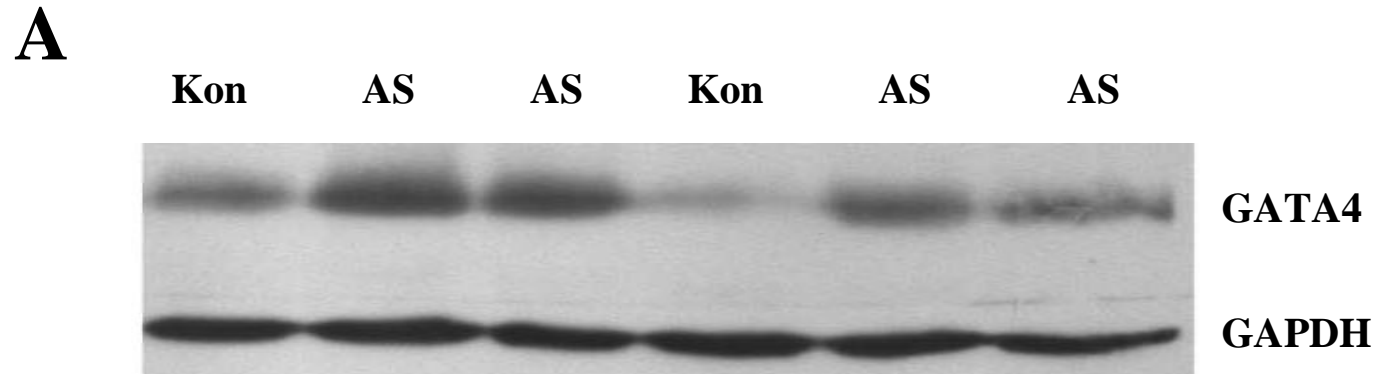

B

\section{Gesamt-Protein-Expression in Aortenstenoseproben}

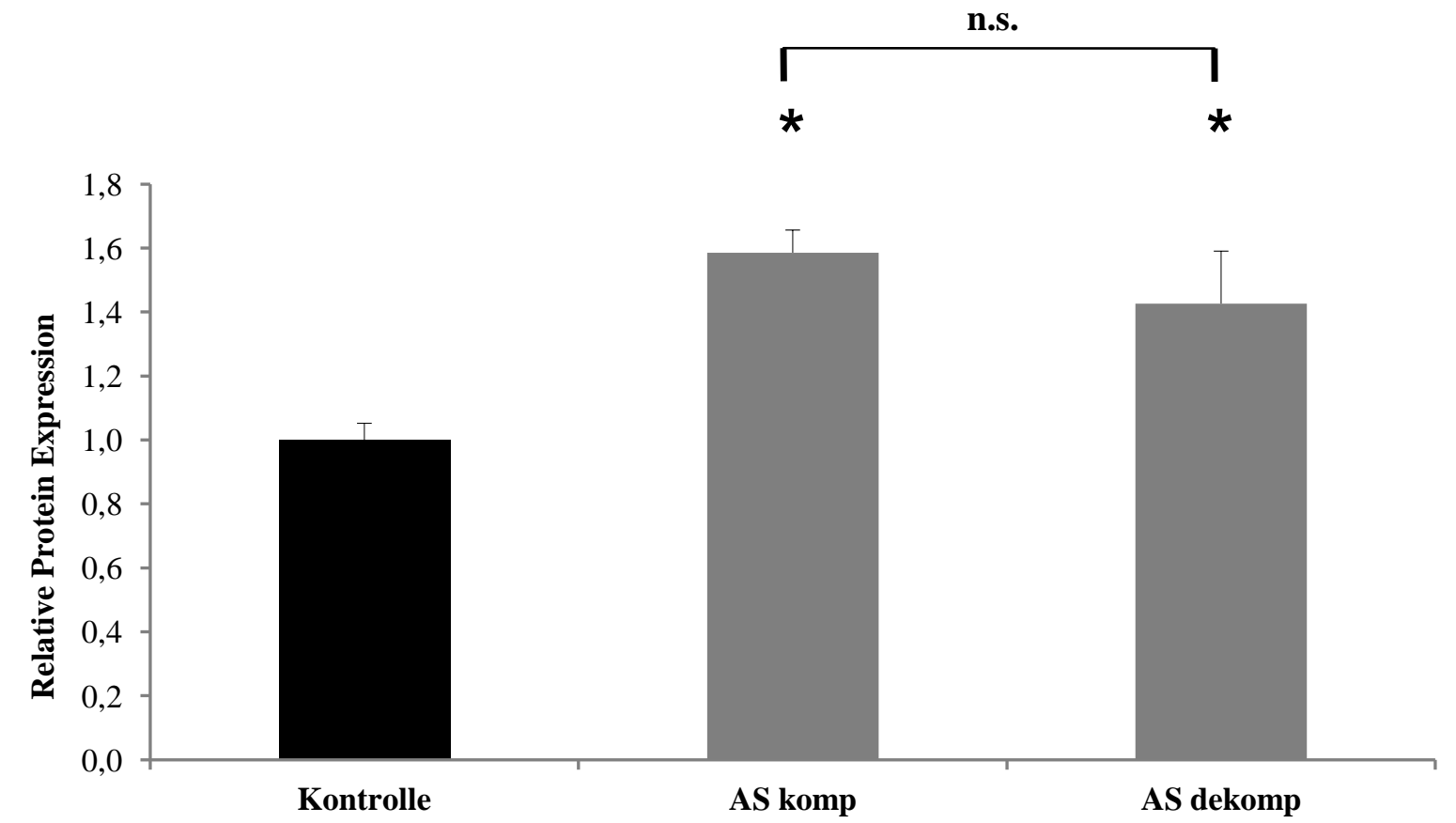

Abb. 8: Teil A zeigt einen exemplarischen Western Blot für GATA4 und das Referenz-Gen GAPDH. Teil B zeigt die statistische Zusammenfassung. Deutlich wird ein signifikanter Expressionsanstieg in den AS-Proben, deren Untergruppen sich nicht signifikant unterscheiden. $*=p<0,05$ versus Kontrolle. 


\section{III.1.3 Phosphorylierung von GATA4}

Anhand Western Blots mit phospho-spezifischen Antikörpern für die Bindungsstelle Serin 105 wurde der Phosphorylierungsstatus von GATA4 geprüft. Auch für die Phosphorylierung von GATA4 (pGATA4) zeigte sich eine Hochregulation. In der Gruppe mit kompensierter Funktion lag diese bei $165 \pm 12 \%$, in der Gruppe mit dekompensierter Funktion bei $208 \pm 8$ $\%$ (jeweils $\mathrm{p}<0,05$ gegenüber Kontrolle, Abb. 9). Zwischen den AS-Subgruppen ergaben sich auch hier keine signifikanten Unterschiede.

\section{GATA-4 Phosphorylierung in AS}

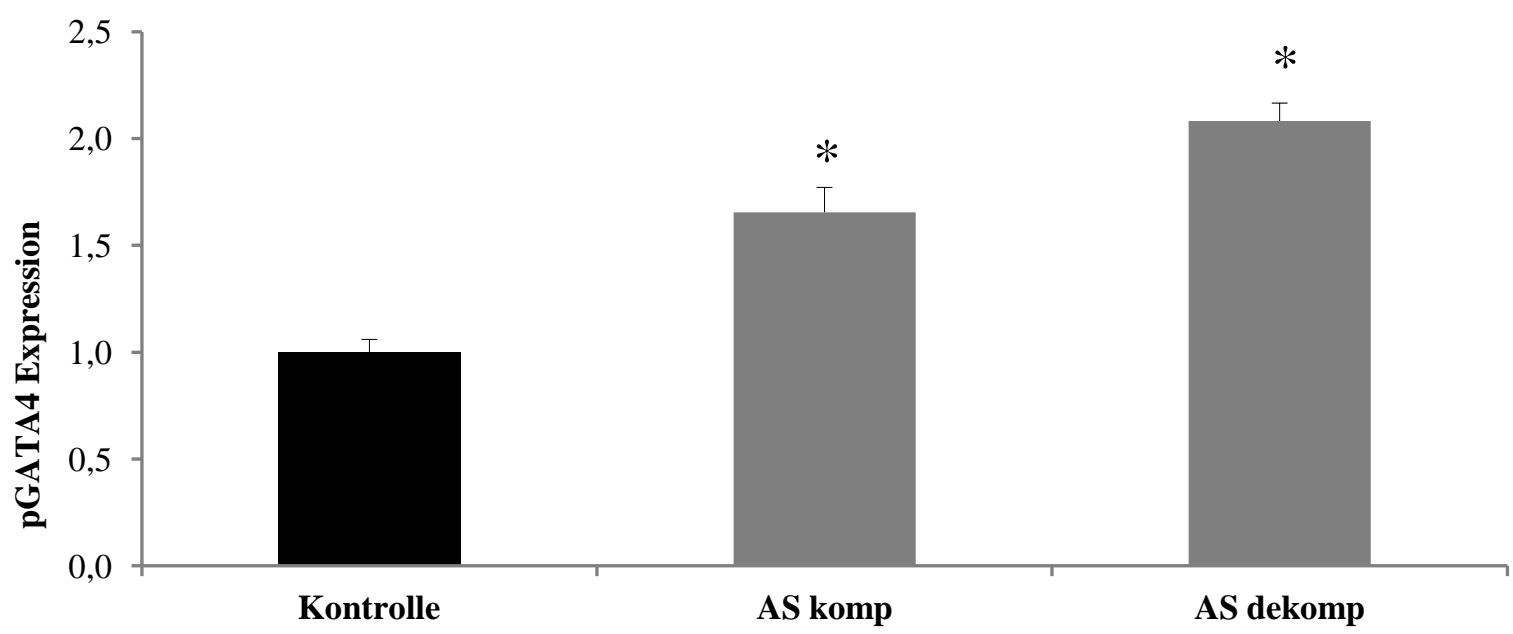

Abb. 9: Teil A zeigt einen exemplarischen Western Blot für pGATA4 und das Referenz-Gen GAPDH. Teil B zeigt die statistische Zusammenfassung. Wie bei der Gesamtexpression findet sich auch für die phosphorylierte Form von GATA4 ein Expressionsanstieg in den AS-Proben. * $=\mathrm{p}<0,05$ versus Kontrolle. 
Bei Normalisierung der Werte auf Gesamt GATA4 ergibt sich die relative Phosphorylierung, die sogenannte Phospho-Ratio (pGATA4 / Gesamt-GATA4). Es zeigte sich im Verhältnis zur Kontrollgruppe ein signifikanter Anstieg dieses Quotienten in der $\mathrm{AS}_{\text {dekomp}}$-Gruppe, während die Gruppe der Patienten mit kompensierter LV-Funktion eine fast ausgeglichene Ratio aufwies (Abb. 9). In der $\mathrm{AS}_{\mathrm{komp}}$-Gruppe lag der Quotient bei $109 \pm 9 \%$ (n.s.), in der Gruppe mit dekompensierter LV-Funktion bei $160 \pm 40 \%(\mathrm{p}<0,05)$.

\section{Relative Phosphorylierung in AS}

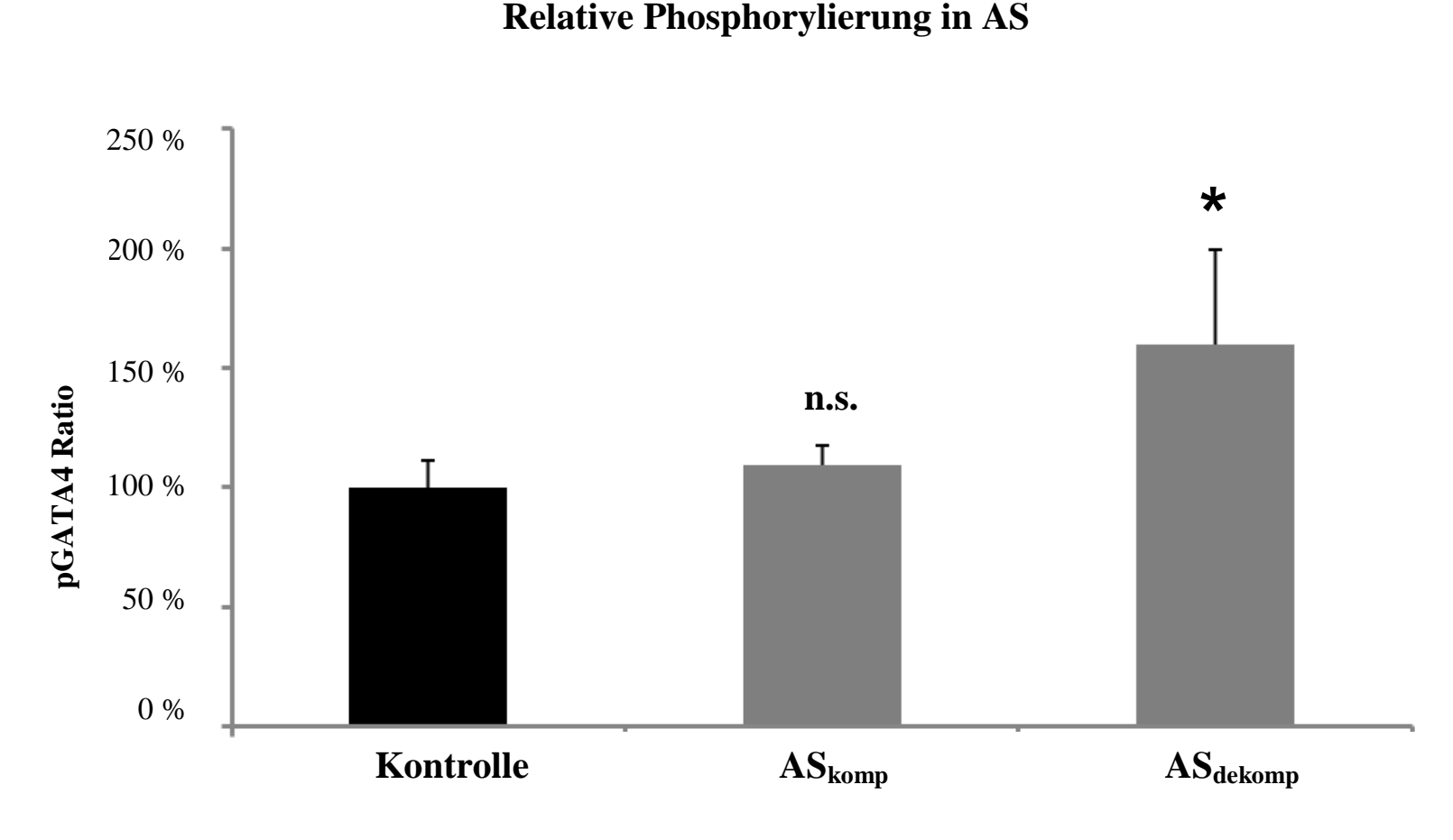

Abb. 9: Die pG4/GesG4-Ratio steigt lediglich in den AS-Proben mit dekompensierter Funktion an. $*=p<0,05$ versus Kontrolle. 


\section{III.1.4 Korrelation mit klinischen Funktionsparametern}

Die bisher gezeigten Daten legen nahe, dass die GATA4 Protein Expression lastabhängig und der Phosphorylierungsgrad von GATA4 in Abhängigkeit von der LV-Funktion reguliert werden. Um die Zusammenhänge noch besser zu verdeutlichen, wurden die genannten Messparameter mit drei klinischen Funktionsparametern korreliert, sofern diese bei den zugehörigen Patienten ermittelt worden waren:

1) Maximaler Druckgradient über der Aortenklappe (dPmax) vorliegend bei $n=11$.

2) Ejektionsfraktion $(\mathrm{EF})$ vorliegend bei $\mathrm{n}=16$.

3) Cardiac Index (CI) [EF/Körperoberfläche] vorliegend bei $n=5$.

Während der dPmax einen Surrogatparamter der Last darstellt, bilden die EF und der CI die Pumpfunktion des Herzens ab.

Abbildung 10 stellt die Korrelation der Proteinexpression von GATA4 mit dem Lastparameter dPmax dar. Deutlich wird, dass der maximale Druckgradient linear zu den gesteigerten Expressionswerten zunimmt. Somit besteht eine positive Korrelation mit einem Koeffizienten von $\mathrm{R}^{2}=0,499(\mathrm{p}<0,05)$. Im Gegensatz zur Gesamtexpression besteht bei phosphoryliertem GATA4 (pGATA4) keine signifikante Korrelation zum dPmax $\left(\mathrm{R}^{2}=-0,048\right)$.

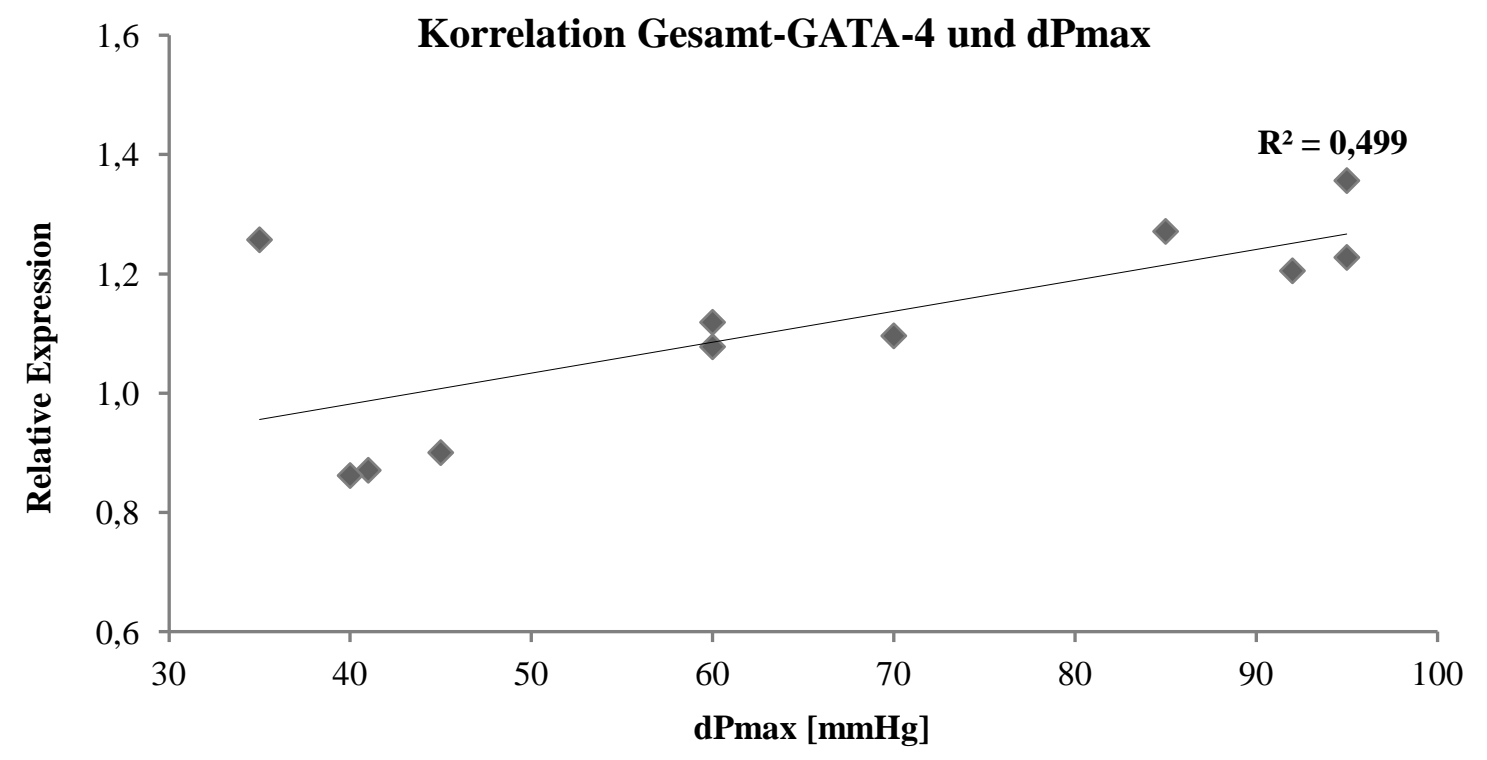

Abb. 10: Der maximale Druck dPmax korreliert positiv mit der Gesamtexpression von GATA4, p < 0,05. 
Für die linksventrikuläre Ejektionsfraktion EF fand sich hinsichtlich der Gesamtexpression von GATA4 keine signifikante Korrelation. Wie Abbildung 11 zeigt, besteht aber eine Korrelation von der phosphorylierten Form (pGATA4) mit der EF. Die Grafik zeigt, dass bei abnehmender ventrikulärer Pumpfunktion grundsätzlich die Expression von pGATA4 ansteigt. Es besteht insgesamt eine inverse Korrelation mit einem Koeffizienten von $\mathrm{R}^{2}=$ $0,2785(\mathrm{p}<0,05)$.

\section{Korrelation pGATA-4 und EF}

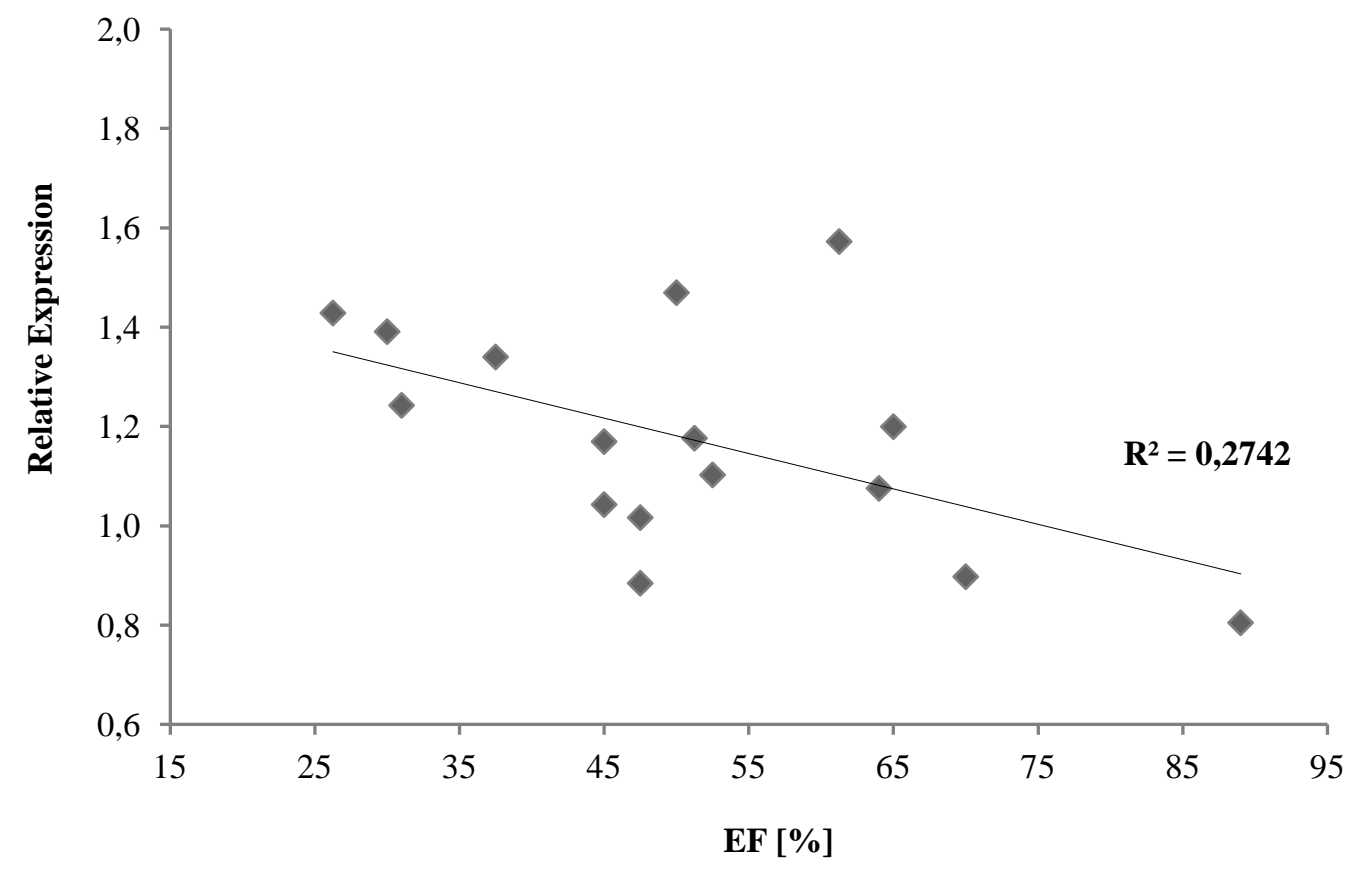

Abb. 11: Es besteht eine signifikante inverse Korrelation zwischen der Ejektionsfraktion und pGATA4, p < 0,05.

Auch im Verhältnis zum Cardiac Index besteht eine Korrelation mit phosphoryliertem GATA4, wobei hier sowohl die absolute (Abb. 12) als auch die relative Phosphorylierung (Abb. 13) invers mit diesem auf die Körperoberfläche normierten Parameter der Ventrikelfunktion korrelieren. Der invasiv gemessene Parameter lag nur bei 5 Patienten vor, was die Aussagekraft limitiert, allerdings weisen die Korrelationen jedoch ein hohes Bestimmtheitsmaß auf: pGATA4: $\mathrm{R}^{2}=0,81$; Phospho-Ratio: $\mathrm{R}^{2}=0,78$ (jeweils $\mathrm{p}<0,05$ ). 


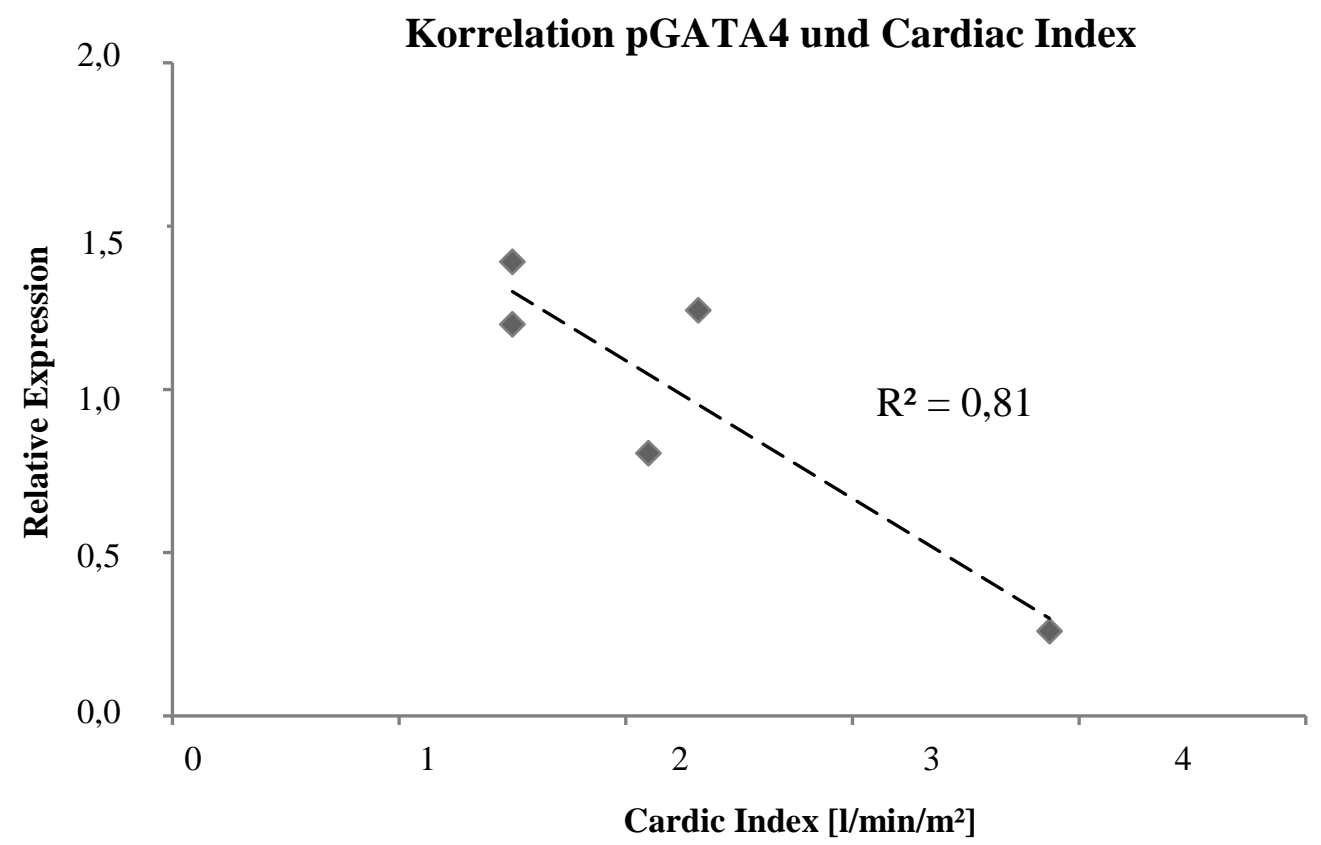

Abb. 12: pGATA4 zeigt eine negative Korrelationen mit dem Cardiac Index.

\section{Korrelation Phospho-Ratio und Cardiac Index}

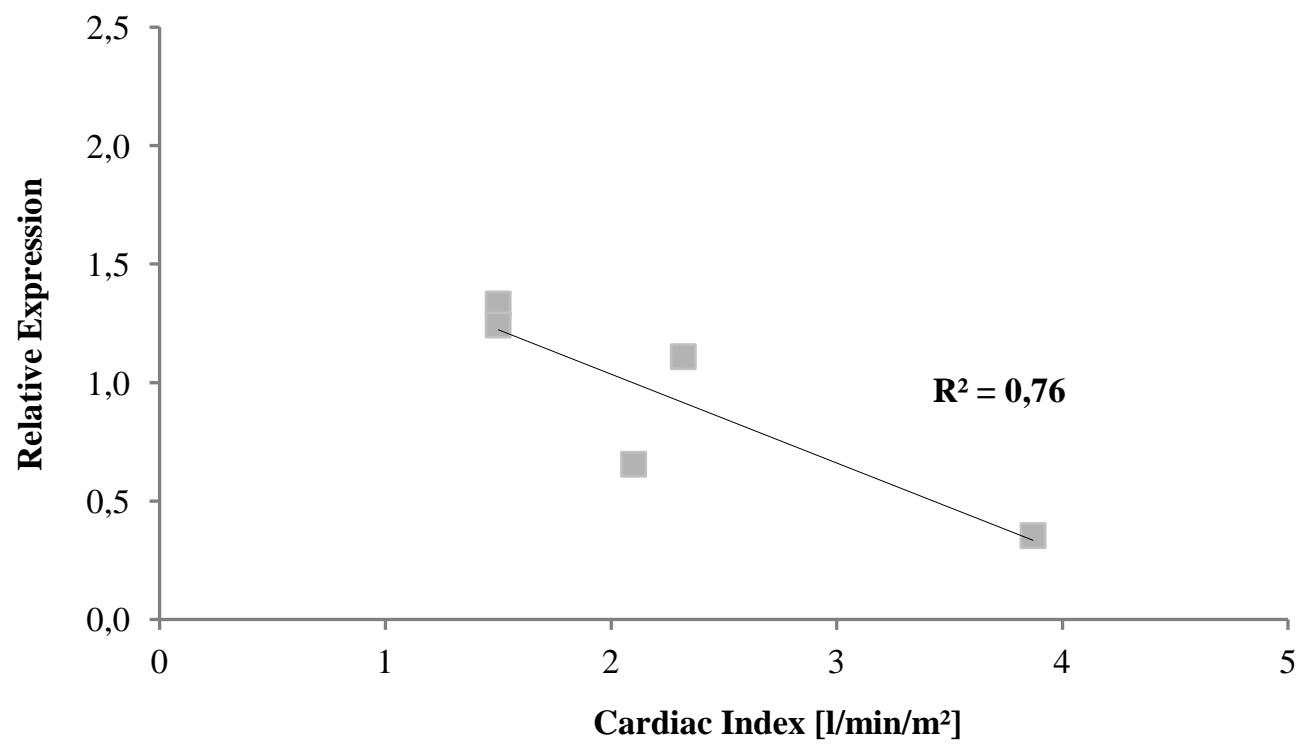

Abb. 13: Auch die Phospho-Ratio weist eine negative Korrelationen mit dem Cardiac Index auf. 
Insgesamt zeigen die dargestellten Korrelationen: Die Proteinexpression von GATA4 steigt mit zunehmendem Druckgradienten über der Aortenklappe deutlich an, während absolute und relative Phosphorylierung leicht abnehmen. Mit Verschlechterung der Ventrikelfunktion nehmen die Parameter der Phosphorylierung hingegen zu. Diese Korrelationen unterstützen die Hypothese, dass die Expression von GATA4 lastabhängig und der Phosphorylierungsgrad funktionsabhängig reguliert werden.

Die Ergebnisse der folgenden Experimente zur akuten Dehnung sollten zeigen, ob allein pathologisch gesteigerte Vor- und Nachlast als Stimuli für Expressionsveränderungen ausreichen oder ob die bei Aortenstenose zu beobachtenden Effekte eher sekundär als Folge komplexer Adaptationsvorgänge verursacht werden.

\section{III.2 Akute Last}

Für die folgenden Experimente wurden aus menschlichen Myokardproben Trabekel entnommen, die in Pärchen untersucht wurden. Ein Trabekel wurde maximal gedehnt und kontrahierte isometrisch, was einem maximalen Lastzustand hinsichtlich Vor- und Nachlast entspricht. Der zweite Trabekel wurde nicht gedehnt und kontrahierte isotonisch, entsprechend einem minimalen Lastzustand (siehe „Material und Methoden“ II.5.1). Nach 1 Stunde oder 6 Stunden wurden die Proben schockgefroren. Anschliessend folgte die Analyse der Proben per Real Time PCR oder Western Blot.

Messungen zur Phosporylierung wurden aus technischen Gründen aufgrund der geringen Materialmengen in Trabekeln nicht durchgeführt, da Vorexperimente folgende Befunde gezeigt hatten:

1. Das Phospho-Signal zeigte bei Trabekelen aus identischen Herzen bereits eine weitläufige Streuung.

2. Stimulation mit Phenylephrin erbrachte einen klaren positiv inotropen Effekt, aber keine Zunahme des Phospho-Signals bei der verwendeten Proteinmenge von ca. $30 \mu \mathrm{g}$.

3. Hingegen ließ sich in Zellkultur mit einer größeren Proteinmenge von ca. $100 \mu \mathrm{g}$ eine eindeutige Stimulierbarkeit der Phosphoylierung nachweisen. 


\section{III.2.1 GATA4 mRNA-Expression (Atriales Myokard)}

Die RNA der Proben wurde nach dem im Methodenteil beschriebenen Protokoll isoliert, in cDNA umgeschrieben und die Expression von GATA4 und GAPDH mittes Realtime PCR quantifiziert. Abb. 14 zeigt die auf das Referenz-Gen GAPDH normierte mRNA Expression von GATA4 in $\mathrm{n}=27$ Proben atrialen Myokards.

Zum Zeitpunkt $1 \mathrm{~h}$ war sowohl in den gedehnten $(110 \pm 10 \%)$ als auch ungedehnten Trabekeln $(129 \pm 12 \%)$ eine tendenzielle Steigerung (n.s.) der GATA4 mRNA-Expression gegenüber der Kontrolle nachzuweisen. Nach sechs Stunden hingegen zeigte sich wie beim ventrikulären Myokard für beide Dehnungszustände eine signifikante Expressionsabnahme auf $64 \pm 9 \%$ in den ungedehnten Muskeln und auf $49 \pm 7 \%$ in Trabekeln mit maximalem Lastzustand (jeweils $\mathrm{p}>0,05$ gegenüber dem Nullwert, Abb. 15). Hinsichtlich des Lastzustandes bestand in den Gruppen zu beiden Zeitpunkten kein signifikanter Unterschied.

\section{mRNA-Expression Vorhof}

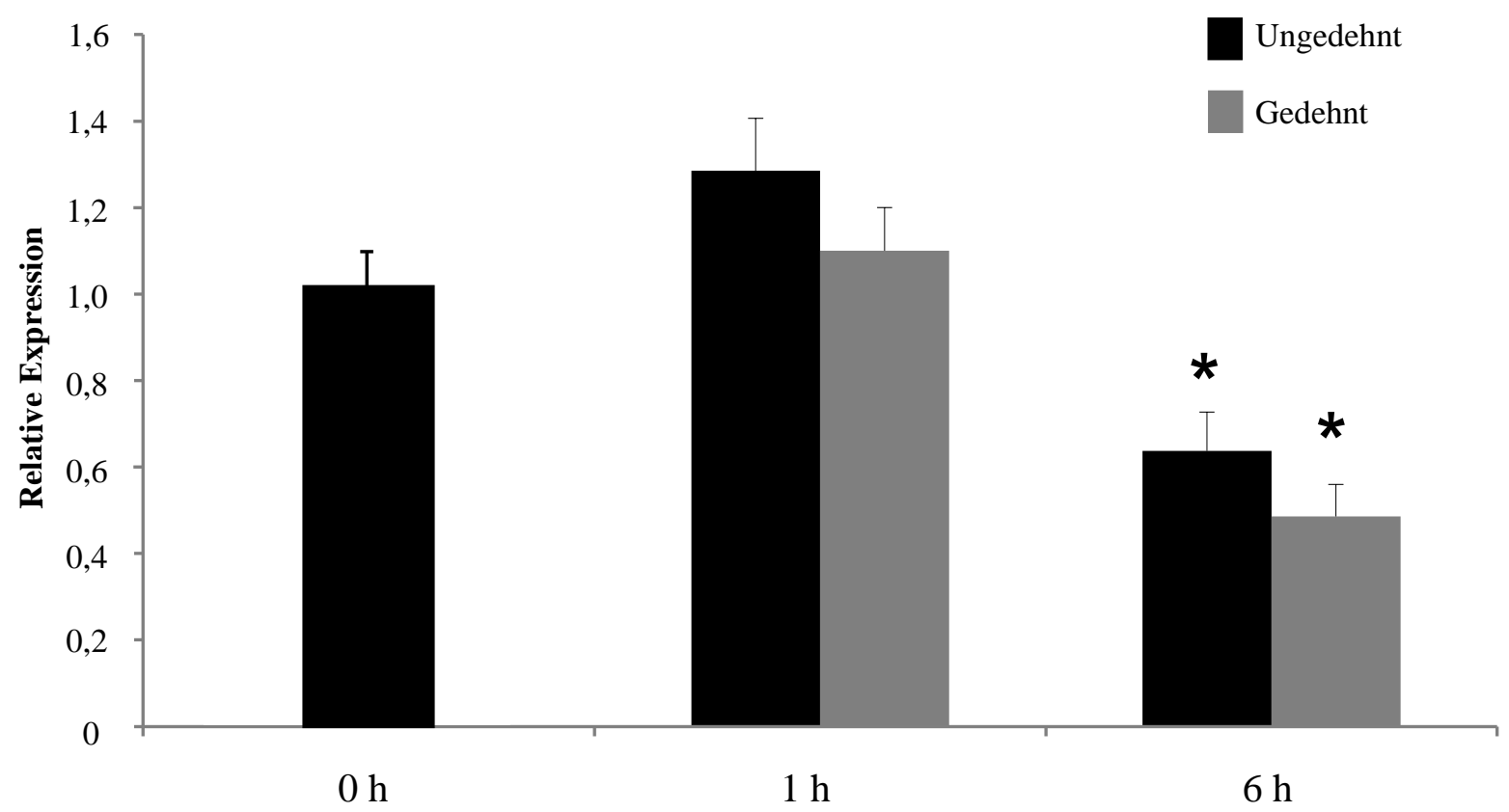

Abb. 14: Expression von GATA4-mRNA in atrialem Myokard. * $=\mathrm{p}<0,05$ versus Kontrolle $(0 \mathrm{~h})$. 


\section{III.2.2 GATA4 mRNA-Expression (Insuffizientes ventrikuläres Myokard)}

Die Auswertung erfolgte analog zum atrialen Myokard. Es gingen $n=17$ Proben insuffizienten ventrikulären Myokards in die Auswertung ein.

Sowohl nach einer als auch nach sechs Stunden Versuchsdauer war eine signifikante Abnahme der mRNA-Expression von GATA4 gegenüber der Kontrolle nachzuweisen. Nach einer Stunde sank die mRNA-Expression in den ungedehnten Muskelstreifen auf $66 \pm 20 \%$, in der Gruppe der gedehnten Trabekel auf $81 \pm 31 \%(\mathrm{p}>0,05)$. Nach sechs Stunden sank die Expression weiter ab auf $56 \pm 8 \%$ in den ungedehnten Muskeln und auf $51 \pm 6 \%$ in der Gruppe der gedehnten Trabekel ( $p>0,05)$. Hinsichtlich des Lastzustandes konnte zu beiden Zeitpunkten kein signifikanter Unterschied in den Gruppen nachgewiesen werden.

\section{mRNA-Expression Ventrikel}

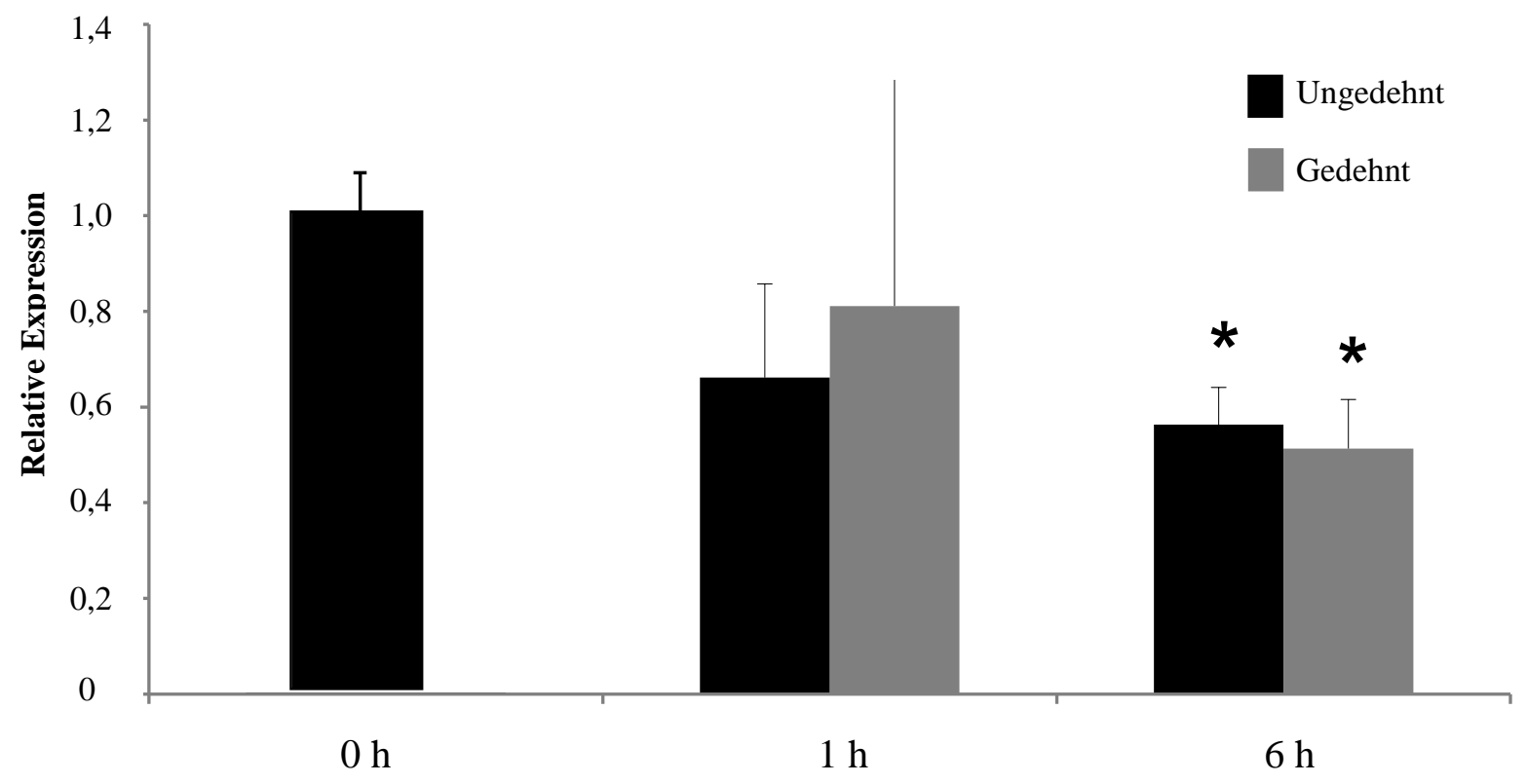

Abb. 15: Expression von GATA4 mRNA in Ventrikelmyokard. Vergleich der Kontrolle $(0 \mathrm{~h})$ mit Proben zu $1 \mathrm{~h}$ und 6 h sowie die Gegenüberstellung un- und gedehnter Muskeln. * $=p<0,05$ versus Kontrolle. 


\section{III.2.3 GATA4-Proteinexpression (Atriales Myokard)}

Die Proteinexpression von GATA4 wurde nach Homogenisierung und Western Blot gemäß dem im Methodenteil beschriebenen Protokoll bestimmt.

Abbildung 16 stellt den Zeitverlauf der Gesamtexpression von GATA4 in Vorhofmyokardproben $(\mathrm{N}=19)$ als optische Dichtewerte dar. Über den Versuchszeitraum von sechs Stunden konnte in den unbelasteten Muskeln ein stetiger Abfall der Expressionswerte ermittelt werden. Dieser Abfall war in den gedehnten Trabekeln auch vorhanden, aber deutlich schwächer ausgeprägt.

\section{Proteinexpression Vorhof}

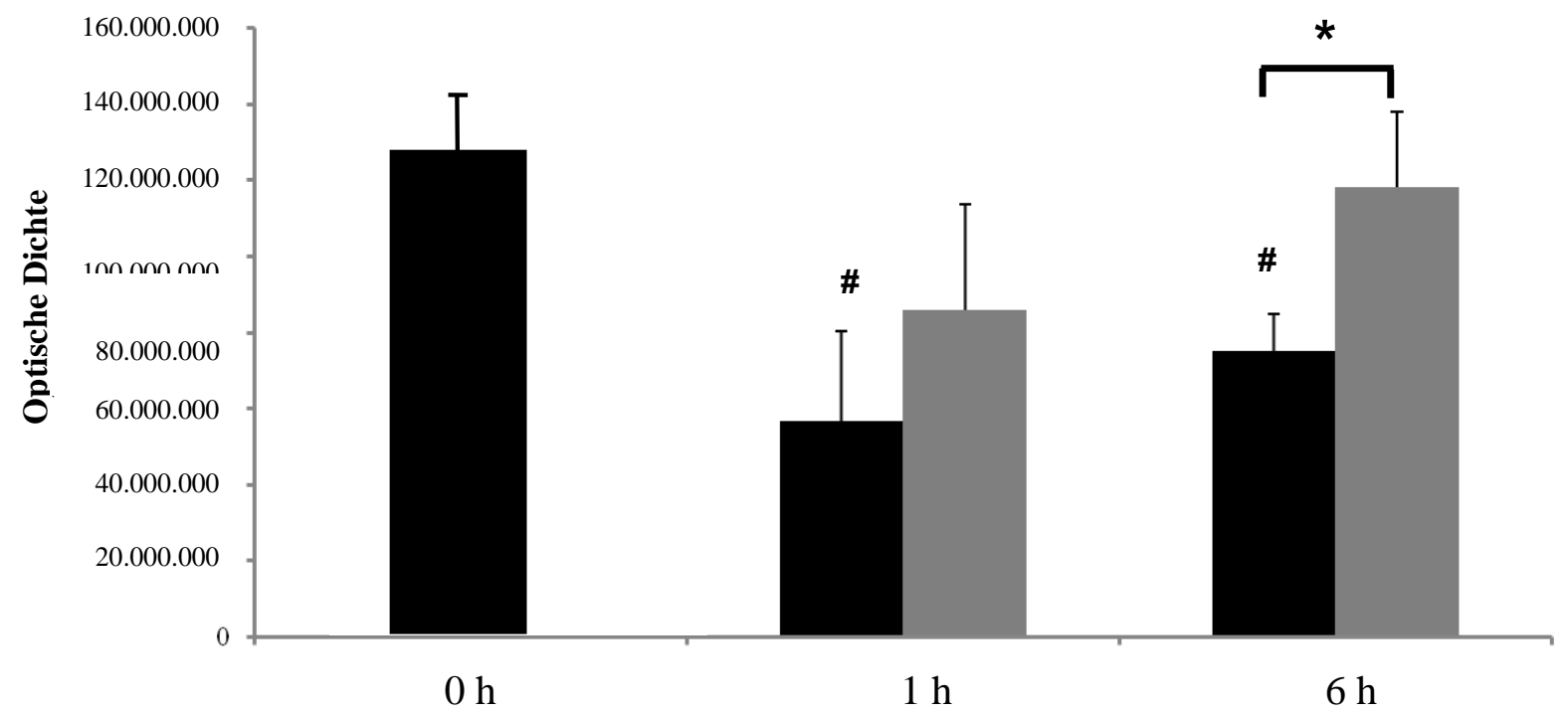

Abb. 16: Atriale Proteinexpression von GATA4, dargestellt in optischen Dichtewerten. $\#=p<0,05$ versus Kontrolle, $*=p<0,05$ im Paarvergleich. 
Abbildung 17 zeigt den Effekt der Dehnung jeweils im direkten Vergleich zum ungedehnten Präparat zu einem gegebenen Zeitpunkt ausgedrückt in Prozent. Es zeigt sich, dass Dehnung eine signifikant höhere Expression hervorruft: $151 \pm 36 \%(\mathrm{n}=10)$ nach einer Stunde und 158 $\pm 30 \%(\mathrm{n}=5)$ nach sechs Stunden, jeweils $\mathrm{p}<0,05 \mathrm{im}$ Vergleich $\mathrm{zu}$ den lastfrei kontrahierenden Muskeln.

\section{Proteinexpression Vorhof}

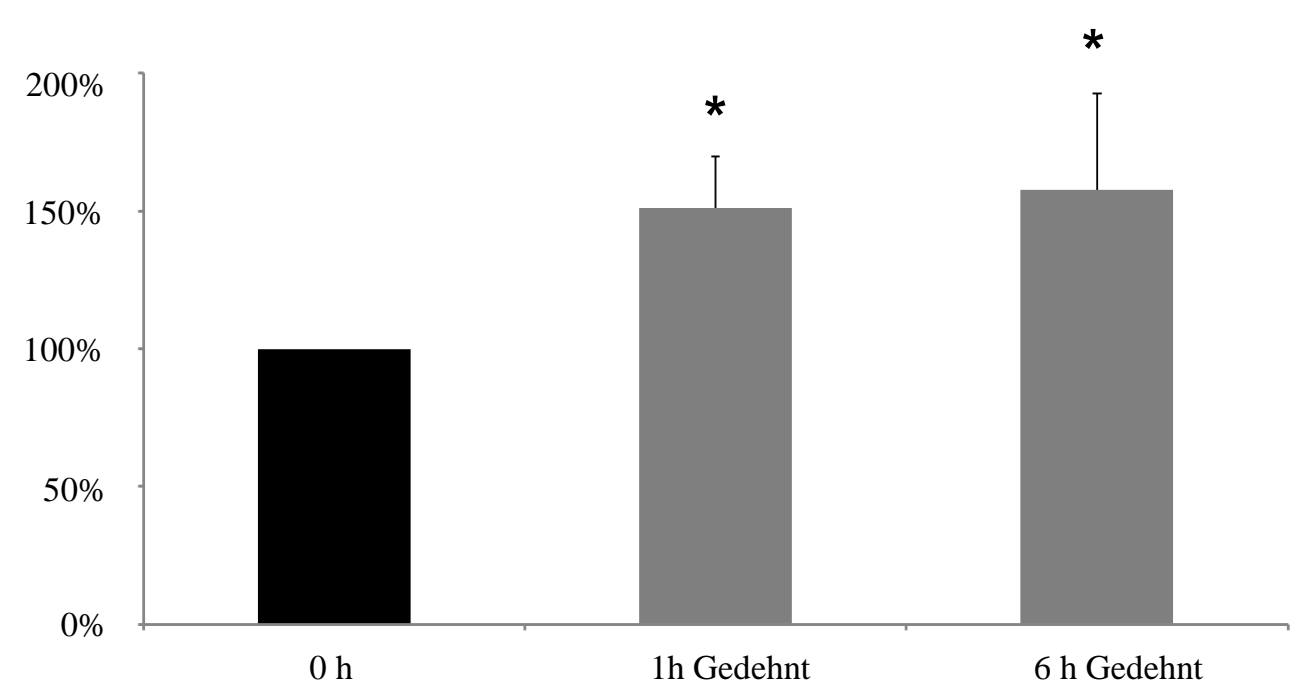

Abb. 17: Relative Expression der gedehnten Muskeln nach Normierung auf die ungedehnten Proben 


\section{III.2.4 GATA4-Proteinexpression (Ventrikuläres Myokard)}

Die Auswertung erfolgte analog zum atrialen Myokard.

Abb. 18 stellt den Zeitverlauf der Gesamtproteinexpression von GATA4 gemessen als optische Dichtewerte der Western Blots dar $(n=2)$. Über den Versuchszeitraum von sechs Stunden konnte ein stabiler Verlauf der Expressionswerte auf dem Ausgangsniveau der Nullprobe ermittelt werden. Es bestand kein signifikanter Unterschied zwischen den Gruppen. Für die Testung des Dehnungseffektes auf Proteinebene standen nicht ausreichend Proben zur Verfügung.

\section{Proteinexpression Ventrikel}

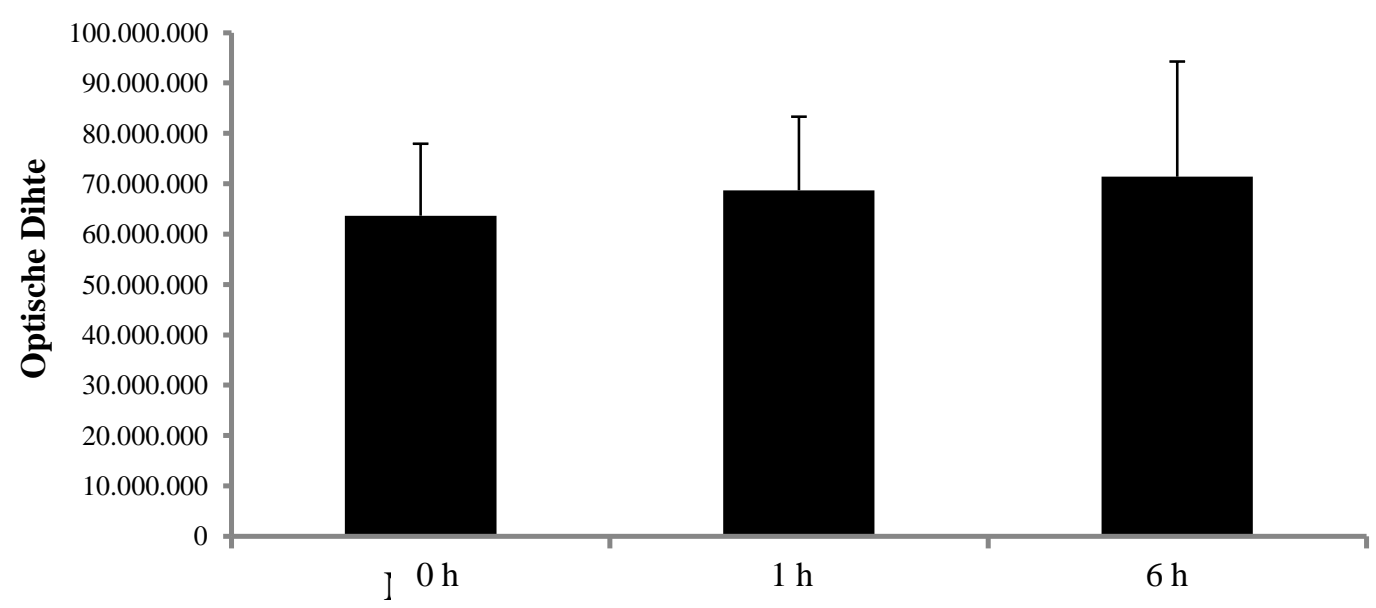

Abb. 18: Proteinexpression von GATA4 in ventrikulärem Myokard. 


\section{III.3 GATA4-Proteindegradation}

In den Versuchen zur akuten Last wurde deutlich, dass es in unbelasteten Muskeltrabekeln aus Vorhofmyokard bereits innerhalb kurzer Zeiträume nach Experimentbeginn zu einer Abnahme der Proteinexpression von GATA4 kommt, wohingegen die Expression des Referenzgens GAPDH stabil blieb und dies in gedehnten Präparaten schwächer ausgeprägt war. In den folgenden Experimenten wurde die Zeitabhängigkeit dieses Prozesses daher gezielt untersucht.

\section{III.3.1 GATA4-Proteindegradation (ventrikuläres und atriales Myokard)}

Die Trabekelproben wurden nach Protokoll homogenisiert und geblottet. Abb. 19 stellt den Zeitverlauf der Expression von GATA4 über einen Zeitraum von sechs Stunden im ventrikulären Myokard dar $(\mathrm{n}=2)$. Die Expression bleibt stabil auf einem Niveau: Nach einer Stunde bei $105 \pm 16 \%$, nach drei Stunden $105 \pm 6 \%$, weitere drei Stunden später bei $113 \pm 6$ $\%$ (alle n.s. gegenüber dem Kontrollwert).

\section{Proteindegradation Ventrikel}

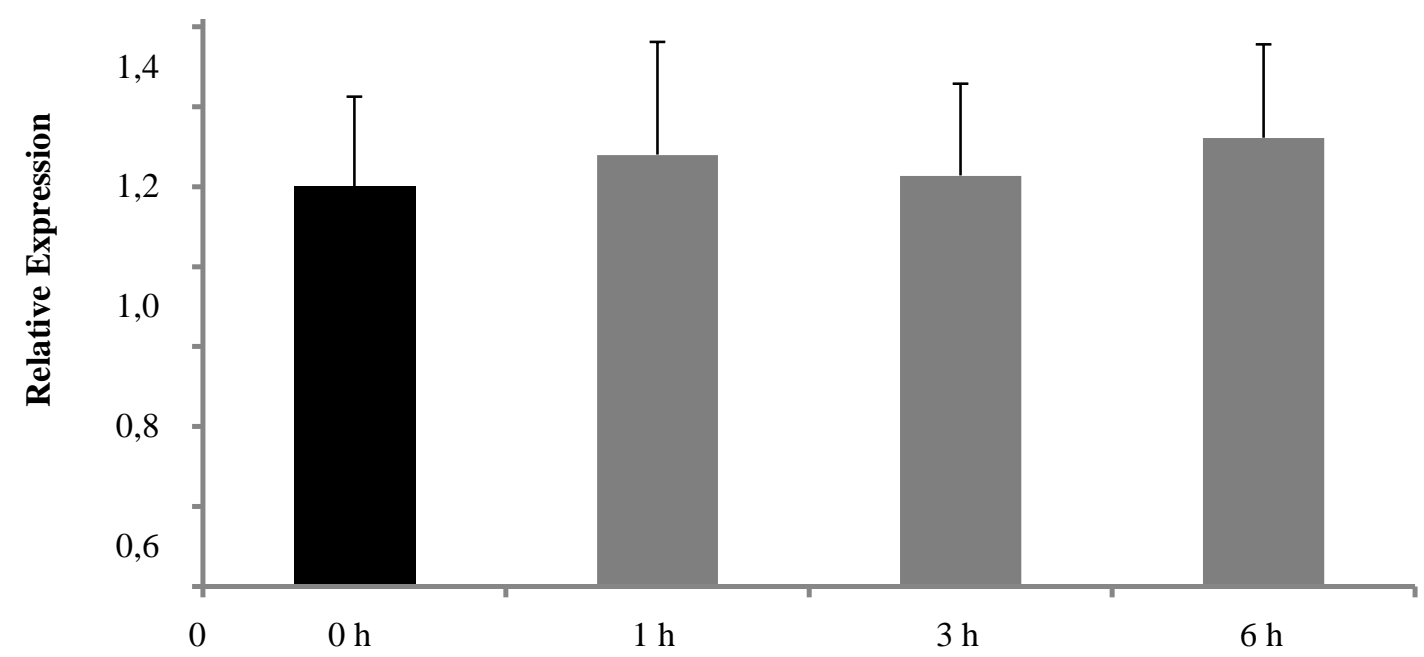

Abb. 19: Zeitreihe der GATA4-Proteinexpression im ventrikulären Myokard. Es kommt zu keiner signifikanten Expressionsabnahme gegenüber der Kontrolle. 
Anders als im Ventrikel kommt es auf Vorhofebene $(\mathrm{n}=17)$ im Verlauf zu einer stetigen und signifikanten Abnahme von GATA4. Nach einer Stunde sinkt die Proteinexpression auf $51 \pm$ $8 \%$ ab. Sie fällt zu drei Stunden weiter ab auf $42 \pm 8 \%$ und erreicht nach sechs Stunden $41 \pm$ $11 \%$. Abbildung 20 stellt diesen Expressionsverlauf von GATA4 im unbelasteten atrialen Myokard dar.

A

Start Start $0,5 \mathrm{~h} \quad 0.5 \mathrm{~h} \quad$ 1h $\quad$ 1h $\quad 6 h \quad 6 h$

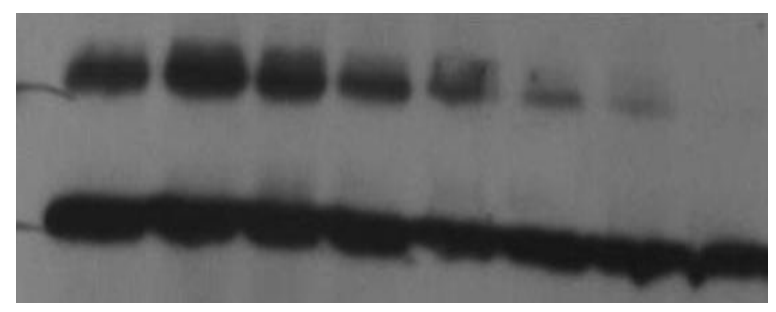

GATA4

B

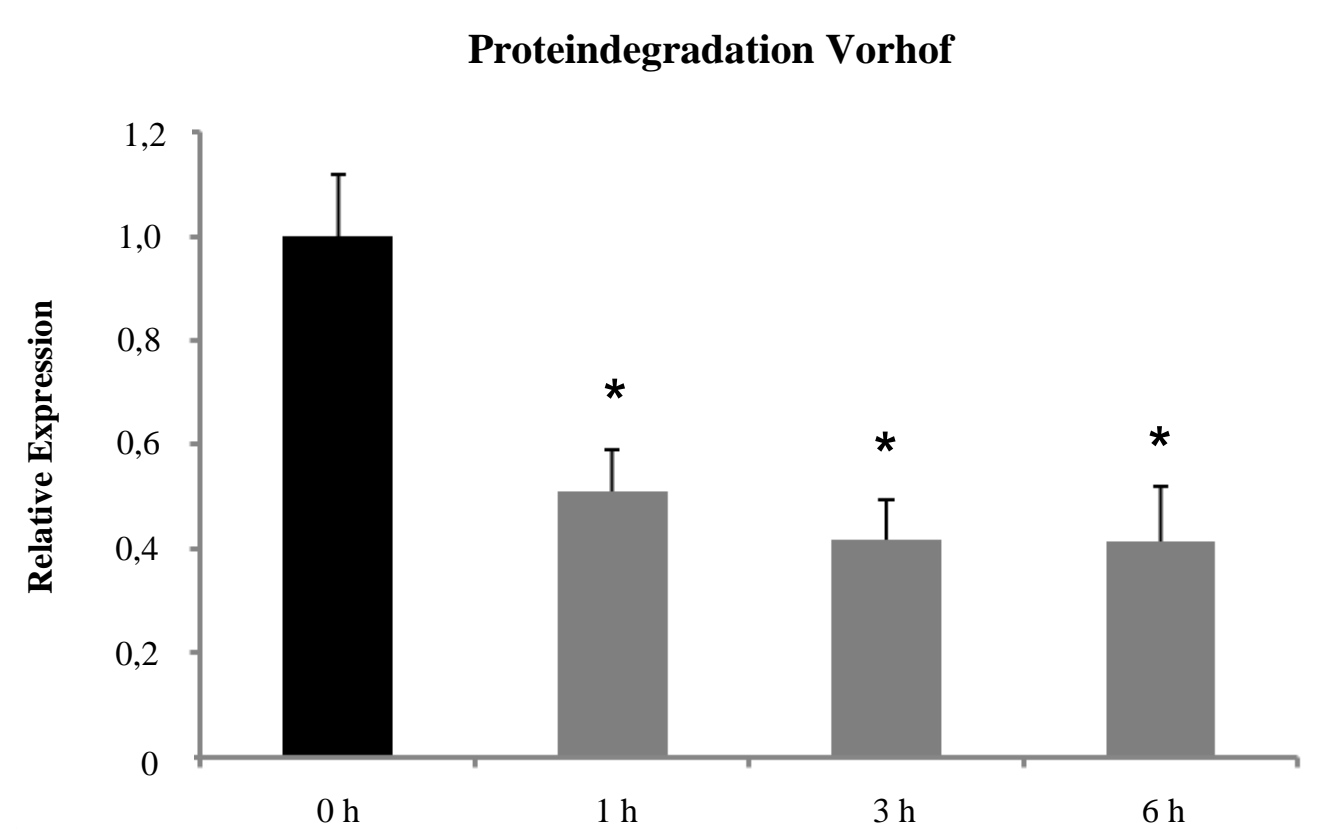

Abb. 20: Teil A zeigt einen exemplarischen Western Blot. Teil B zeigt die statistische Zusammenfassung des Expressionsverlauf in atrialem Myokard. Es kommt zu einer deutlichen, zeitabhängigen Abnahme gegenüber der Kontrolle. 


\section{III.3.2 Abhängigkeit der GATA4-Proteindegradation von der Ubiquitin-Isopeptidase}

Eine mögliche Ursache für die zeitabhängige Degeneration von GATA4 könnte eine Aktivierung des Ubiquitin-Proteasom-Systems sein. Um dies $\mathrm{zu}$ testen, wurde das Prostaglandin $\triangle 12-P G J 2$ als Inhibitor der Ubiquitin-Isopeptidase eingesetzt. Abbildung 21 stellt vergleichend die Degradation von GATA4 im ventrikulären Myokard $(n=2)$ ohne und unter Behandlung mit $\Delta 12-\mathrm{PGJ} 2$ dar. Der Gehalt an GATA4 bleibt in beiden Versuchsgruppen stabil über den gesamten Versuchszeitraum ohne statistisch signifikanten Unterschied zwischen den Gruppen.

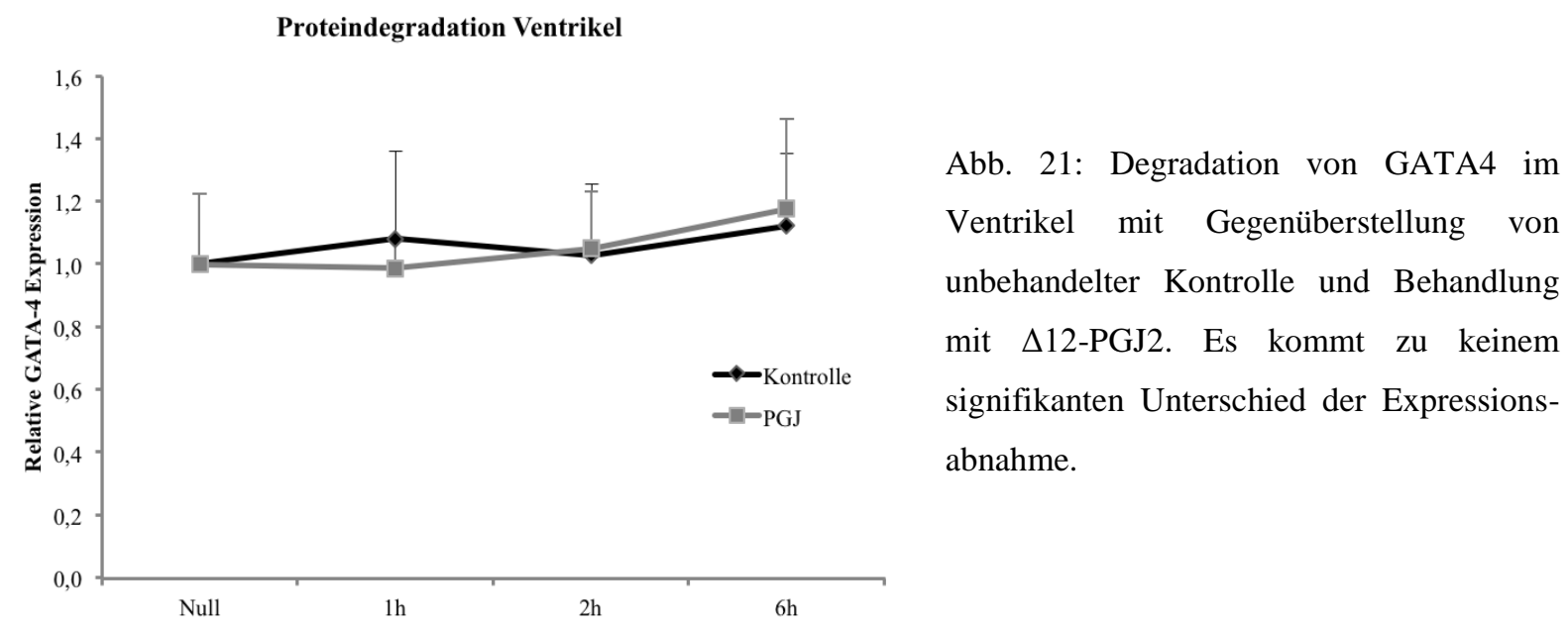

Konträr zum Ventrikel sinkt der Gehalt an GATA4 im Vorhofmyokard $(n=17)$ über den Versuchszeitraum linear ab. Ab dem Zeitpunkt $1 \mathrm{~h}$ ist eine signifikante Abnahme gegenüber dem Ausgangswert zum Zeitpunkt Null zu verzeichnen. Diese Abnahme fällt unter Inkubation mit PGJ vor allem ab dem Zeitpunkt 3 h geringer aus: Nach drei Stunden $80 \pm 36$ $\%$ versus $59 \pm 35 \%$, nach 6 h $74 \pm 35 \%$ versus $58 \pm 33 \%$. Aufgrund der Streuung wird hierbei jedoch nicht das Signifikanzniveau erreicht. Abbildung 22 stellt die genannten Befunde graphisch dar.

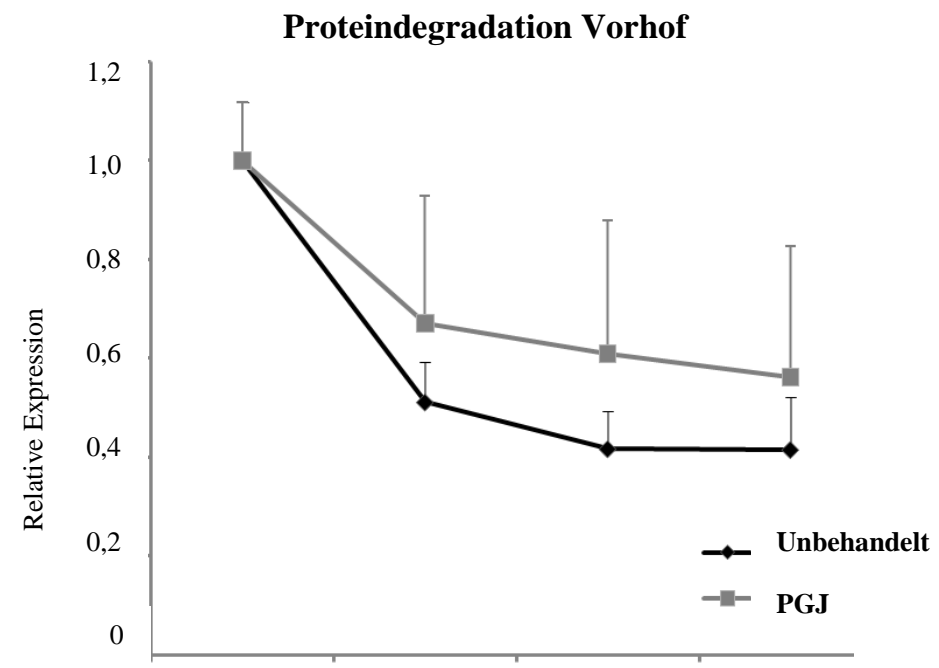

Abb. 22: Degradation von GATA4 im atrialen Myokard. In den PGJ-behandelten Proben sinkt die Expression im Vergleich zur unbehandelten Kontrolle geringer ab. 


\section{Diskussion}

\section{IV.1 Chronische Last}

\section{IV.1.1 Chronische Nachlasterhöhung durch eine Aortenstenose}

Das Ziel des ersten Teils der vorliegenden Arbeit war, den Einfluss einer chronischen Lasterhöhung auf die Expression von GATA4 zu untersuchen. Hierzu dienten Myokardproben von Patienten mit hochgradiger Aortenstenose, die im Rahmen eines operativen Aortenklappenersatzes (AKE) durch eine Morrow-Resektion entnommen wurden. Bei der Morrow-Resektion handelt es sich um die therapeutische Entfernung eines kleinen Stücks hypertrophierten Myokards in Höhe des linksventrikulären Ausflusstraktes, um so einer möglichen subvalvulären Obstruktion entgegenzuwirken.

Grundsätzlich wären für die genannte Fragestellung aber auch andere Lastzustände von Interesse gewesen, sowohl andere Arten der Nachlasterhöhung, z.B. arterielle Hypertonie, als auch Formen der Volumenbelastung, wie z.B. Aorteninsuffizienz und exzentrische Hypertrophie. Die Probengewinnung kardialen Materials bei diesen Grunderkrankungen ist jedoch mit höheren Risiken verbunden und wird daher selten durchgeführt.

Die arterielle Hypertonie, die mit einer Prävalenz von $44 \%$ in Europa die häufigste Form einer chronischen Lasterhöhung repräsentiert, bietet lediglich in Studien die Indikation zur Entnahme von Myokardproben (Wolf-Maier et al. 2003). Herzklappenerkrankungen weisen mit 3 - $5 \%$ zwar eine weitaus geringere Prävalenz auf, eignen sich aber besser zur perioperativen Probengewinnung. Eine Analyse der „Euro Heart Survey“ Studie, die 5.000 Personen mit Klappenveränderungen in 25 europäischen Nationen einschloss, ergab für die Aortenstenose eine Häufigkeit von 43,1 \% unter den degenerativen Klappenerkrankungen (Iung et al. 2003). Damit ist sie die häufigste Form von Herzklappenerkrankungen überhaupt. Für die Aorteninsuffizienz ergab die Studie hingegen eine Häufigkeit von 13,3 \% (Iung et al. 2003). Aufgrund der höheren Prävalenz der Aortenstenose und besseren Verfügbarkeit von Proben humanen Myokards stellte die Aortenstenose das am besten geeignete Korrelat eines chronischen Lastzustandes für diese Arbeit dar.

\section{IV.1.2 Expression von GATA4}

Der Einflusses eines chronischen Lastzustandes, wie er in der vorliegenden Arbeit in Form der chronischen Aortenstenose untersucht wurde, führte sowohl auf Ebene der RNAExpression als auch der Protein-Expression zu einer signifikanten Expressionssteigerung von 
GATA4. Ein signifikanter Unterschied zwischen Patientengruppen mit kompensierter und dekompensierter Ventrikelfunktion konnte in der vorliegenden Arbeit nicht nachgewiesen werden. Jedoch korrelierte die Proteinexpression von GATA4 in signifikant positivem Maße mit dem Lastparameter dPmax. Dieser gibt den maximalen Druckgradienten über der Aortenklappe an und stellt damit eine Größe für erhöhte Nachlast des linken Ventrikels dar.

Diese Daten implizieren eine lastabhängige Regulation der Expression von GATA4 im menschlichen Herzen. Passend dazu haben Hall et al. auch eine ausgeprägte Expressionssteigerung von GATA4 bei Patienten mit dekompensierter Ventrikelfunktion vor Entlastung durch einen LVAD nachgewiesen (Hall et al. 2004). Diedrichs et al. wiesen analog einen Anstieg der Expression von GATA4 in Herzen von Patienten mit dilatativer Kardiomyopathie nach (Diedrichs et al. 2004).

In mehreren Tiermodellen der Druckbelastung konnte hingegen eine gesteigerte Aktivität bei unveränderter Expression von GATA4 nachgewiesen werden (Hautala et al. 2001; Liang et al. 2001b; Liang et al. 2001a; Morimoto et al. 2000). Lediglich Kira et al. und Colston et al. fanden im Mausmodell neben einer Aktivitätssteigerung von GATA4 auch eine Hochregulation der Expression (Colston et al. 2007; Kira et al. 1984). Die gesteigerte Expression von GATA4 ist dabei assoziiert mit einer verminderten nukleären Lokalisation von GSK-3- $\beta$ (Chandrasekar et al. 2005). Dieses Protein phosphoryliert GATA4 an seiner Nterminalen Domäne im Bereich der Aminosäuren 2 - 205 und steigert so seinen nukleären Export und vermutlich auch seinen Abbau (Morisco et al. 2001).

Als weitere Mechanismen zur Regulation der Expression von GATA4 scheinen reaktive Sauerstoffverbindungen ( $\mathrm{ROS}=$ reactive oxygen species) von großer Bedeutung: ROS werden insbesondere in der Stoffwechsellage des oxidativen Stresses erzeugt. Dann fallen vermehrt anaerobe Stoffwechselprodukte, wie z.B. Laktat im Herzmuskel, an, die die zellulären Schutzmechanismen, welche aus enzymatischen und nicht-enzymatischen Antioxidantien sowie Radikalfängern bestehen, nicht mehr puffern können. Ein solcher Zustand kann sowohl durch überproportional gesteigerte mechanische Belastung als auch durch schwere septisch verlaufende Infektionen, aber auch im Rahmen einer chronischen Herzinsuffizienz vorkommen (Belch et al. 1991; Hill und Singal 1996, 1997). Entsprechend führt eine Sepsis (Macdonald et al. 2003) und das Chemotherapeutikum Doxorubicin (Kim et al. 2003; Kobayashi et al. 2010) über vermehrte Generierung von ROS zu einer Suppression der Expression von GATA4. Auch Mangel an Vitamin A (Retinol) führt, wie in Wachtel- und Hühnerembryonen nachgewiesen, zu einer verminderten GATA4-Expression, vermutlich über die fehlende antioxidative Wirkung und damit vermehrten Anfall von ROS (Ghatpande 
et al. 2000), wohingegen die Behandlung von F9-Zellen (embryonale Karzinomzellen) mit Retinsäure (Retinol) eine Induktion der Expression von GATA4 hervorruft (Arceci et al. 1993). Auch das nukleophile Lösungsmittels DMSO (Dimethylsulfoxid) kann als Antioxidationsmittel fungieren und so, wie z.B. in P19-Zellen (embryonale Karzinomzellen) nachgewiesen, die Expression von GATA4 steigern (Macdonald et al. 2003; McCord 2000; Ohara et al. 2006).

Ein weiterer positiver Regulator von GATA4 ist sein Verwandter GATA6. Die Defizienz von GATA6 in Mausmutanten resultiert in einer verminderten Expression von GATA4 und damit in einer gestörten Entwicklung des Herzens (Jiang et al. 2008; Morrisey et al. 1998).

\section{IV.1.3 Phosphorylierung von GATA4}

Hautala et al. beschrieben im Rattenmodell eine gesteigerte DNA-Bindungsaktivität von GATA4 als Folge akuter Nachlasterhöhung in Form gesteigerten Blutdrucks (Hautala et al. 2001). Die gesteigerte DNA-Bindungsaktivität von GATA4 beruht dabei auf einer Zunahme des Phosphorylierungsgrades (Liang et al. 2001a). Van Berlo et al. konnten hierzu zeigen, dass die GATA4 Aktivierung über eine Phosphorylierung an Serin 105 essentiell für die Hypertrophieantwort ist (van Berlo et al. 2011).

Unter chronischer Nachlasterhöhung erwies sich in der vorliegenden Arbeit die Phosphorylierung von GATA4 bei Aortenstenose als signifikant gesteigert gegenüber der Kontrolle. Patienten mit dekompensierter Ventrikelfunktion zeigten tendenziell eine stärker gesteigerte Phosphorylierung. Passend dazu war für die Phospho-Ratio von GATA4 nur in der $\mathrm{AS}_{\text {dekomp}}-$ Gruppe eine signifikante Zunahme zu sehen.

In Bezug zum Lastparameter dPmax wiesen sowohl die absolute als auch relative Phosphorylierung keine positive Korrelation auf. Waren die Drücke über der Aortenklappe erhöht, so blieb der Grad der absoluten Phosphorylierung stabil, die Phospho-Ratio nahm sogar geringfügig ab. Somit scheint eine chronische Nachlasterhöhung allein kein ausreichender Trigger zur Phosphorylierung und damit Aktivitätssteigerung von GATA4 zu sein.

Stattdessen lag eine signifikante Assoziation mit Parametern der kardialen Pumpfunktion vor. Die Ejektionsfraktion (EF) und der Cardiac Index (CI) stellen zwei Parameter zur Evaluierung der kardialen Pumpfunktion dar. Sie sinken bei Abnahme der Kontraktilität mit einhergehender Verschlechterung der Pumpfunktion. Für diese Situation konnte sowohl eine Zunahme des Grads der absoluten als auch der relativen Phosphorylierung von GATA4 in Korrelation gestellt werden. Allerdings konnte für das Verhältnis CI und 
Phosphorylierungsgrad nur eine limitierte Anzahl von Vergleichswerten generiert werden, da von vielen Patienten der untersuchten Gruppen keine Werte zur Verfügung standen. Die Daten legen insgesamt nahe, dass eine eingeschränkte ventrikuläre Pumpfunktion einen geeigneten Stimulus zur Phosphorylierung von GATA4 und damit gesteigerter DNABindungsaktivität im menschlichen Herzen darstellt.

Unterstützt wird dies dadurch, dass auch die MAPK-Signalwege, die auf GATA4 als Ziel hypertropher Signalinduktion konvergieren und GATA4 an der Aminosäure Serin-105 aktivierend phosphorylieren, eine Steigerung ihrer Aktivität bei kardialer Insuffizienz erfahren, jedoch noch nicht im Stadium der kompensierten Hypertrophie (Haq et al. 2001). Chronisch gesteigerte Nachlast allein reicht offensichtlich nicht aus, um die Phosphorylierung von GATA4 in nachhaltiger Form zu steigern, sondern erst die Kombination mit einer myokardialen Dysfunktion. Die Messungen der vorliegenden Arbeit schließen jedoch nicht aus, dass es bei einer Aortenstenose generell $\mathrm{zu}$ einer transienten Steigerung des Phosphorylierungsgrades von GATA4 kommt, die sich langfristig aber wieder normalisiert. Der Effekt akuter Last auf die Phosphorylierung wäre zur Untersuchung dieser Fragestellung daher von großem Interesse gewesen. Dies war aber leider aus methodischen Gründen nicht möglich, worauf unter anderem im folgenden Absatz eingegangen wird. 


\section{IV.2 Akute Last}

\section{IV.2.1 Lastmodell und verwendete Materialien}

Um den Einfluss akuter Lastzustände auf die Expression und Phosphorylierung von GATA4 zu untersuchen, wurde eine Langzeit-Stimulationsanlage der Firma SI Heidelberg verwendet. Diese ermöglichte es, gedehnte Muskelproben im Zustand maximaler Vor- und Nachlast im Vergleich zu lastfrei kontrahierenden, ungedehnten Proben zu untersuchen (Janssen et al. 1998). Dass Dehnung einen Einfluss auf die Expression bzw. Aktivität kardialer Proteine hat, zeigten Kögler et al. sowie Schott et al. sowohl für Kaninchen- als auch für menschliches Myokard (Kogler et al. 2006; Schott et al. 2008).

Gemäß verwendetem Versuchsaufbau kontrahierten die gedehnten Muskelstreifen isometrisch, die ungedehnten Trabekel hingegen isotonisch. Somit ermöglichte der Aufbau einen Paarvergleich zwischen einem gänzlich lastfreien Zustand und einem Zustand maximaler Vor- und Nachlast. Auxotone Kontraktion mit Muskelverkürzung und gleichzeitiger Spannungszunahme als Mischform eines isometrischen und eines isotonischen Kontraktionszustandes stellte kein geeignetes Korrelat des Lastmodells dar, da dieser Kombinationszustand keine geeignete Diskrimination zwischen lastabhängigen und lastunabhängigen Effekten zuließ. Diesen Ansatz bestätigten Bupha-Intr et al., indem sie eine eindeutige Steigerung der Expression kardialer Proteine durch isometrische Kontraktion gegenüber lastfrei kontrahierenden Trabekeln nachwiesen (Bupha-Intr et al. 2007).

Verwendet wurde zur Untersuchung lastabhängiger Veränderungen sowohl insuffizientes ventrikuläres als auch nicht-insuffizientes atriales Myokard. Das insuffiziente Ventrikelmyokard stammte von Patienten, die sich einer orthotopen Herztransplantation unterziehen mussten. Als Korrelat gesunden Myokards wurde atrialer Herzmuskel untersucht, der von Patienten stammte, die sich einer Herzoperation unter Einsatz einer Herz-LungenMaschine unterziehen mussten. Nicht-insuffizientes humanes Ventrikelmyokard erschien hingegen nicht praktikabel, da aufgrund der geringen Zahl technisch nicht durchführbarer Herztransplantationen keine geeignete Anzahl Proben hätte generiert werden können. Der Einsatz ventrikulären Gewebes von Kaninchen wurde ebenfalls im Ansatz verfolgt, aber aufgrund von Kreuzreaktionen der GATA4-Antikörper, die zur Western Blot-Analyse notwendig waren, fallengelassen. Vorhofmyokard hingegen bot diese Kreuzreaktionen nicht und stellte zudem aufgrund seiner hohen Grundexpression von GATA4 (1,6-fach höher als im Ventrikel gemäß eigenen Daten) ein interessantes Gewebe dar.

Untersucht wurden unter akuter Last die Expressionsänderungen von GATA4 sowohl auf RNA- als auch auf Proteinebene. Der Phosphorylierungsgrad hingegen konnte nicht 
untersucht werden, da sich bei den ersten Messreihen und auch Kontrollexperimenten mit dem GATA-Aktivator Phenylephrin herausgestellt hatte, dass die für verwertbare Ergebnisse benötigte Proteinmenge über der eines durchschnittlichen Trabekels lag. Phenylephrin hatte in diesen Kontrollexperimenten einen eindeutigen positiv inotropen Effekt, zu dessen PeakWirkung die Muskeln eingefroren und nachfolgend hinsichtlich ihres Phosphorylierungsgrads untersucht wurden. Es ließ sich jedoch keine gesteigerte Phosphorylierung von GATA4 mit den verwendeten Antikörpern nachweisen und die pGATA4-Messwerte zeigten eine hohe Streuung. Kontrollexperimente an kultivierten Kardiomyozyten unter Verwendung der identischen Antikörper aber Nutzung größerer Proteinmengen zeigten hingegen einen eindeutigen Phosphorylierungseffekt durch Phenylephrin, sodass hieraus gefolgert werden muss, dass das Messverfahren grundsätzlich funktionstüchtig ist, aber eine Abhängigkeit von der Menge des Ausgangsmaterials besteht. Die für die Experimente verwendeten Muskelstreifen durften aufgrund des Versuchsaufbaus einen Diameter von $900 \mu \mathrm{m}$ nicht überschreiten. Insofern war die Messung der Phosphorylierung in Vorhofmyokard unter akuter Last nicht möglich.

\section{IV.2.2 Expression im Vorhofmyokard}

In atrialem Gewebe fiel im Gegensatz zum ventrikulären Myokard sowohl die mRNA- als auch die Proteinexpression zeitabhängig ab. Dabei wiesen die gedehnten Trabekel im Vergleich zu den lastfrei kontrahierenden Muskeln eine geringere zeitabhängige Abnahme und dadurch signifikant höhere GATA4-Expression auf. Anzunehmen ist, dass es sich um einen Dehnungseffekt handelt, da es sich hierbei gemäß dem Versuchsprotokoll um den einzigen Unterschied zwischen den beiden Muskelgruppen handelte. Angesichts der Daten zur mRNA scheint der Effekt dabei nicht auf eine vermehrte Neusynthese, sondern vielmehr auf einer Verringerung des Abbaus von GATA4-Protein in den gedehnten Präparaten zurückzuführen zu sein. Die Mechanismen der Degradation von GATA4 wurden daher gezielt untersucht.

\section{IV.2.3 Expression im ventrikulären Myokard}

Die Untersuchungen zum Einfluss eines akuten Lastzustandes auf die RNA-Expression von GATA4 zeigten in ventrikulärem Myokard eine signifikante zeitabhängige Abnahme der RNA-Expression gegenüber der Referenzprobe zum Zeitpunkt Null. Die Expression nahm nach sechs Stunden um bis zu $50 \%$ ab. Ein signifikanter Unterschied zwischen den geprüften Lastzuständen wurde dabei nicht nachgewiesen. Dies bedeutet, dass im Gegensatz zum 
Referenzgen GAPDH die mRNA von GATA4 rasch degradiert wird. Passend hierzu konnten Kim et al. in isolierten Myozyten in Zellkultur zeigen, dass nach Inhibition der Transkription und damit Inhibition der Neusynthese von RNA, die GATA4-mRNA innerhalb von 6 Stunden komplett degradiert wird (Kim et al. 2003)

Auf Proteinebene machte sich diese Degradation in der vorliegenden Arbeit jedoch nicht akut bemerkbar. Die Halbwertszeit des GATA4-Proteins liegt demnach höher als die der mRNA, sodass hier nach 6 Stunden immer noch eine stabile Expression vorliegt. Ungedehnte und gedehnte Präparate wiesen in der vorliegenden Arbeit keinen Unterschied in der Expression auf, woraus gefolgert werden kann, dass akute Last in ventrikulärem Myokard kein geeigneter Trigger zur Expressionssteigerung von GATA4 zu sein scheint.

\section{IV.2.4 Degradation von GATA4}

Die Familie der GATA-Transkriptionsfaktoren zeigt in den unterschiedlichen Geweben, in denen sie exprimiert werden, deutlich unterschiedliche Eliminations-Halbwertszeiten sowohl auf Protein- als auch auf RNA-Ebene. GATA2-Protein besitzt in hämatopoetischen Stammzellen eine Halbwertszeit zwischen einer halben Stunde und einer Stunde, während diese bei GATA1 ca. vier bis sechs Stunden beträgt (Bresnick et al. 2010; Lurie et al. 2008; Minegishi et al. 2005). Über GATA6 ist bekannt, dass die Halbwertszeit der mRNA in Thekazellen des Hodens ca. 55 Minuten beträgt (Ho et al. 2005). Die Protein-Halbwertszeit beträgt ca. 4 Stunden (Nakagawa et al. 1997). Über GATA4 gibt es diesbezüglich keine Informationen.

Der Abbau von GATA4 Protein im menschlichen Herzen unterliegt einer Gewebespezifizität, wie die Daten der vorliegenden Arbeit zeigen: Im Ventrikelmyokard zeigte sich zu den untersuchten Zeitpunkten eine weitgehend stabile GATA4-Expression ohne signifikante Unterschiede. Im Atrium hingegen sank schon nach einer Stunde die Expression im Vergleich zur Kontrolle ab und erreichte ihre maximale Abnahme nach sechs Stunden.

Ein Grund für diesen deutlichen Unterschied in der Expression über die Zeit innerhalb der beiden Gewebe könnte in zwei Dingen liegen: Zum einen lässt die im atrialen gegenüber ventrikulärem Myokard deutlich erhöhte Grundexpression von GATA4 auf ein stoffwechselaktiveres Gewebe schließen, sodass der Abbau von GATA4 von diesem erhöhten Expressionslevel aus deutlicher im Vergleich zum Ventrikel ausfällt. Zum anderen unterscheidet die Tatsache, dass das Ventrikelmyokard von herzinsuffizienten Patienten gewonnen wurde, dies zusätzlich von dem Vorhofmyokard, welches von Patienten stammte, deren Myokard nicht durch ein muskuläres Remodeling bei kardialer Insuffizienz angepasst 
war. Gesteigerter oxidativer Stress, wie er im Organbad bei zunehmender Versuchsdauer vorliegen kann, führt über die Generierung von ROS zu einer verminderten Expression von GATA4 (Macdonald et al. 2003). An diese Vorgänge könnte das insuffiziente Ventrikelmyokard bei chronischer Herzinsuffizienz bereits adaptiert sein, wodurch die ROSabhängigen Effekte wesentlich geringer ausfallen als im atrialen gesunden Myokard.

\section{IV.2.5 Einfluss der Ubiquitin-Isopeptidase}

Für mehrere Mitglieder der Familie der GATA-Transkriptionsfaktoren konnte nachgewiesen werden, dass deren Abbau cAMP-vermittelt durch das Ubiquitin-Proteasom-System erfolgt (Bresnick et al. 2010; Hernandez-Hernandez et al. 2006; Ishida et al. 2005; Nakagawa et al. 1997). Das Proteasom ist ein Proteinkomplex von $1.700 \mathrm{kDa}$, der im Zytoplasma und im Zellkern Proteine zu Fragmenten abbaut, die durch Poly-Ubiquitin-Ketten markiert wurden. Ubiquitine sind kleine Proteine von $8,5 \mathrm{kDa}$, die sich ubiquitär in jeder Zelle vorfinden. Ihre Anzahl in Form von Ketten an zu degradierenden Proteinen beeinflusst deren Halbwertszeit, Funktion oder Verteilung innerhalb des Zytosols.

Der Abbau des Transkriptionsfaktors GATA6 durch das Ubiquitin-Proteasom-System kann durch Inhibitoren der Ubiquitin-Isopeptidase $\Delta 12-P G J 2$ gehemmt werden (Ishida et al. 2005). Die Inhibition von Serinproteasen oder Lysozymen führt hingegen nicht zu einer Reduktion des Abbaus von GATA6 (Nakagawa et al. 1997). Auf diesen Aussagen basierend wurde $\Delta 12$ PGJ2 in der vorliegenden Arbeit zur Inhibition des Abbaus von GATA4 angewandt.

Im Vorhofmyokard kam es zu einer signifikanten Abnahme der Gesamtexpression von GATA4 in unbehandelten Muskeln gegenüber der Kontrolle. Durch den Einsatz von $\Delta 12-$ PGJ2 konnte diese Abnahme über die Zeit abgeschwächt werden. Die Abnahme der Expression war zwar schwächer, aber immer noch vorhanden. Das legt nahe, dass die Ubiquitin-Isopeptidase an der Degradation von GATA4 beteiligt ist, es zugleich aber noch weitere beteiligte Mechanismen geben muss. Das wird auch für andere Gewebe diskutiert, in denen GATA4 nicht cAMP-vermittelt abgebaut wird (Nakagawa et al. 2001).

Auf Ebene des Ventrikelmyokards wurde eine stabile Expression von GATA4-Protein über die Zeit von bis zu sechs Stunden gemessen (siehe oben IV.2.3). Dementsprechend konnte kein Expressionsunterschied durch den Einsatz von $\Delta 12-\mathrm{PGJ} 2$ ermittelt werden. Sowohl mit als auch ohne den Ubiquitin-Isopeptidase-Inhibitor lag die GATA4-Proteinexpression im Versuchszeitraum stabil auf dem Niveau der Kontrolle. Wahrscheinlich spielt der Dehnungsreiz, wie er in den Versuchen zur akuten Last auf das Myokard einwirkte, eine zentrale Rolle in der Regulation des GATA4-Abbaus durch das Ubiquitin-Proteasom-System. 
Diese Daten legen nahe, dass die Funktion des Proteasoms in den untersuchten Muskeln von Patienten mit insuffizienter Ventrikelfunktion supprimiert war.

Gesteigerte ventrikuläre Druckbelastung inhibiert nachweislich den intrazellulären Abbau von Proteinen und im Rahmen einer chronischen Herzinsuffizienz vermindert sich unter gesteigerter Druckbelastung die Aktivität des Ubiquitin-Proteasom-Systems (Gordon et al. 1987; Morgan et al. 1987; Tsukamoto et al. 2006). Außerdem konnte eine pathologische Ansammlung ubiquitinierter Proteine nachgewiesen werden, was eine verminderte UbiquitinProteasom-Funktion impliziert (Weekes et al. 2003).

Dies könnte erklären, warum in unbelasteten atrialen Proben ein deutlich dehnungsabhängiger Effekt sichtbar war, welcher im insuffizienten ventrikulären Myokard nicht zu finden war, da durch die Vorbelastung bereits eine Hemmung des Ubiquitin-Proteasom-Systems bestand, sodass akute Last keinen zusätzlichen Effekt entfalten konnte.

Als möglicher Mechanismus des Dehnungseffektes kommt Folgendes in Betracht: CHIP (Carboxy-Terminus des Hsp70-Bindungsproteins), ein Co-Chaperon und Ubiquitin-Ligase, vermittelt den Abbau von p53 durch Ubiquitinierung und nachfolgenden Abbau durch das Proteasom (Naito et al. 2010). Eine gesteigerte Expression von CHIP führt bei kultivierten Ratten-Kardiomyozyten, die zellulärem Stress in Form einer Hyperglykämie ausgesetzt sind, zur verstärkten Degradation von GATA4 mittels des Ubiquitin-Proteasom-Systems (Kobayashi et al. 2007). Morgan und Mitarbeiter beschrieben jedoch eine Verminderung der Proteindegradation unter mechanischer Belastung (Morgan et al. 1987). Es ist anzunehmen, dass mechanische Belastung den CHIP-vermittelten Abbau von GATA4 inhibiert und somit $\mathrm{zu}$ einer relativ gesteigerten Expression von GATA4 in gedehnten gegenüber ungedehnten Muskeln führt. 


\section{IV.3 Klinische Relevanz}

Das Verständnis der molekularen und zellulären Adaptationsvorgänge, die an der Anpassung an pathologische Last (Remodeling) beteiligt sind, ist essentiell, um künftig eventuell in diese Prozesse therapeutisch eingreifen zu können. Aufgrund der pleotropen Wirkung als Transkriptionsfaktor kommt der Rolle von GATA4 in diesem Zusammenhang eine besondere Bedeutung zu.

Die Ergebnisse der durchgeführten Untersuchungen legen nahe, dass Last in der Regulation von Aktivität und Expression von GATA4 im humanen Myokard eine Rolle spielt, diese aber nicht direkt und nicht allein lastvermittelt reguliert werden. Sowohl im ventrikulären als auch atrialen Myokard konnte sich akut gesteigerte Last innerhalb von sechs Stunden nicht als suffizienter Trigger zur Steigerung der Gesamtexpression von GATA4 beweisen. Die Untersuchungen zum Einfluss chronischer Lastzustände konnten aber eine eindeutige Korrelation von gesteigerter Last und Gesamtproteinexpression zeigen. Dementsprechend ist anzunehmen, dass eher dauerhaft gesteigerte Lastzustände und neurohumerale Prozesse die entscheidende Rolle in der Regulation von GATA4 spielen, jedoch nicht allein der Dehnungsreiz, also die akut gesteigerte Last.

Die Phosphorylierung von GATA4 zeigte in vivo eine Abhängigkeit von der ventrikulären Funktion und weniger von gesteigerter Last. Die messbare Aktivitätssteigerung durch Phosphorylierung unterstützt dabei die Idee von GATA4 als Mediator ventrikulärer Hypertrophie zum Erhalt der kardialen Pumpfunktion. 


\section{Zusammenfassung}

Die Rolle von GATA4 für die Entwicklung einer Hypertrophie und seine Regulation in Abhängigkeit von der Last sind im menschlichen Herzen im Gegensatz zu den zahlreichen tierexperimentellen Ansätzen bislang nicht gezielt untersucht worden.

Die vorliegende Arbeit sollte zeigen, wie biomechanische Last im menschlichen Herzen die Expression von GATA4 und seine Phosphorylierung an einer aktivierenden Phosphorylierungsstelle (Serin-105) reguliert. Hierfür wurde der Einfluss eines chronischen Lastzustandes, hervorgerufen durch eine Aortenstenose, ebenso wie der eines akuten Lastzustandes durch Steigerung der Vor- und Nachlast von Muskelstreifen im Organbad auf die Expression von GATA4 untersucht. Die Muskelstreifen stammten dabei sowohl aus gesundem Myokard (Vorhofmyokard bei normaler Pumpfunktion) als auch aus vorgeschädigtem Myokard (insuffizientes Ventrikelmyokard).

Im ersten Teil wurde dargestellt, dass eine chronische Nachlasterhöhung zu einer signifikanten Zunahme der mRNA- und Proteinexpression sowie der Phosphorylierung von GATA4 führte. Während die mRNA- und Proteinexpression in vivo lastabhängig reguliert zu sein scheinen, zeigte die GATA4-Phosphorylierung eine signifikante Korrelation mit der kardialen Pumpfunktion. Die messbare Aktivitätssteigerung durch Phosphorylierung unterstützt dabei die Idee von GATA4 als Mediator ventrikulärer Hypertrophie zum Erhalt der kardialen Pumpfunktion.

Unter der Auswirkung akuter Last stellte sich hingegen ein heterogenes Bild dar. Eine Steigerung der Gesamtexpression war nicht nachzuweisen, aber ein signifikanter Dehnungseffekt im suffizienten atrialen Myokard, welcher offensichtlich durch eine Abschwächung einer zeitabhängigen Proteindegradation zu Stande kommt. Die Abnahme der GATA4-Expression über die Zeit war unter Einwirkung akuter Last deutlich vermindert aber noch vorhanden. Das Ubiquitin-Proteasom-System ist daran eindeutig beteiligt, da durch den Ubiquitin-Isopeptidase-Inhibitor $\Delta 12-\mathrm{PGJ} 2$ der Abbau von GATA4 vermindert werden konnte. 


\section{Literaturverzeichnis}

Akazawa H, Komuro I (2003): "Roles of cardiac transcription factors in cardiac hypertrophy." Circ Res 92(10),1079-1088

Arceci RJ, King AA, Simon MC, Orkin SH, Wilson DB (1993): "Mouse GATA-4: a retinoic acid-inducible GATA-binding transcription factor expressed in endodermally derived tissues and heart." Mol Cell Biol 13(4), 2235-2246

Baba HA, Stypmann J, Grabellus F, Kirchhof P, Sokoll A, Schafers M, Takeda A, Wilhelm MJ, Scheld HH, Takeda N et al. (2003): "Dynamic regulation of MEK/Erks and Akt/GSK-3beta in human end-stage heart failure after left ventricular mechanical support: myocardial mechanotransduction-sensitivity as a possible molecular mechanism." Cardiovasc Res 59 (2), 390-399

Belch JJ, Bridges AB, Scott N, Chopra M (1991): "Oxygen free radicals and congestive heart failure." Br Heart J $\underline{65}(5), 245-248$

Bisping E, Ikeda S, Kong SW, Tarnavski O, Bodyak N, McMullen JR, Rajagopal S, Son JK, Ma Q, Springer Z et al. (2006): "Gata4 is required for maintenance of postnatal cardiac function and protection from pressure overload-induced heart failure." Proc Natl Acad Sci U S A $\underline{103(39), ~ 14471-14476 ~}$

Blanchard EM, Smith GL, Allen DG, Alpert NR (1990): "The effects of 2,3-butanedione monoxime on initial heat, tension, and aequorin light output of ferret papillary muscles." Pflugers Arch 416(1-2), 219-221

Bresnick EH, Lee HY, Fujiwara T, Johnson KD, Keles S (2010): "GATA switches as developmental drivers." J Biol Chem 285(41), 31087-31093

Bueno OF, De Windt LJ, Tymitz KM, Witt SA, Kimball TR, Klevitsky R, Hewett TE, Jones SP, Lefer DJ, Peng CF et al. (2000): "The MEK1-ERK1/2 signaling pathway promotes compensated cardiac hypertrophy in transgenic mice." EMBO J $\underline{19}$ (23), 6341-6350

Bupha-Intr T, Holmes JW, Janssen PM (2007): "Induction of hypertrophy in vitro by mechanical loading in adult rabbit myocardium." Am J Physiol Heart Circ Physiol 293(6), H3759-3767

Cannon RO (1987): "Myocardial ischemia in hypertrophic cardiomyopathy." Z Kardiol $\underline{76}$ Suppl 3, 101-104

Chandrasekar B, Mummidi S, Claycomb WC, Mestril R, Nemer M (2005): "Interleukin-18 is a pro-hypertrophic cytokine that acts through a phosphatidylinositol 3-kinasephosphoinositide-dependent kinase-1-Akt-GATA4 signaling pathway in cardiomyocytes." J Biol Chem $\underline{280}(6), 4553-4567$ 
Charron F, Tsimiklis G, Arcand M, Robitaille L, Liang Q, Molkentin JD, Meloche S, Nemer M (2001): "Tissue-specific GATA factors are transcriptional effectors of the small GTPase RhoA." Genes Dev 15(20), 2702-2719

Colston JT, Boylston WH, Feldman MD, Jenkinson CP, de la Rosa SD, Barton A, Trevino RJ, Freeman GL, Chandrasekar B (2007): "Interleukin-18 knockout mice display maladaptive cardiac hypertrophy in response to pressure overload." Biochem Biophys Res Commun $\underline{354}(2), 552-558$

Diedrichs H, Chi M, Boelck B, Mehlhorn U, Schwinger RH (2004): "Increased regulatory activity of the calcineurin/NFAT pathway in human heart failure." Eur J Heart Fail $\underline{6}(1)$, 3-9

Durocher D, Charron F, Warren R, Schwartz RJ, Nemer M (1997): "The cardiac transcription factors Nkx2-5 and GATA-4 are mutual cofactors." EMBO J 16(18), 5687-5696

Fryer MW, Gage PW, Neering IR, Dulhunty AF, Lamb GD (1988): "Paralysis of skeletal muscle by butanedione monoxime, a chemical phosphatase." Pflugers Arch 411(1), 7679

Garrington TP, Johnson GL (1999): "Organization and regulation of mitogen-activated protein kinase signaling pathways." Curr Opin Cell Biol 11(2), 211-218

Ghatpande S, Ghatpande A, Zile M, Evans T (2000): "Anterior endoderm is sufficient to rescue foregut apoptosis and heart tube morphogenesis in an embryo lacking retinoic acid." Dev Biol 219(1), 59-70

Gordon EE, Kira Y, Morgan HE (1987): "Aortic perfusion pressure, protein synthesis, and protein degradation." Circulation $\underline{75}(1 \mathrm{Pt} 2), \mathrm{I78}-80$

Grossman W, Jones D, McLaurin LP (1975): "Wall stress and patterns of hypertrophy in the human left ventricle." J Clin Invest $\underline{56}(1), 56-64$

Gwathmey JK, Hajjar RJ, Solaro RJ (1991): "Contractile deactivation and uncoupling of crossbridges. Effects of 2,3-butanedione monoxime on mammalian myocardium." Circ Res $\underline{69}(5), 1280-1292$

Hall JL, Grindle S, Han X, Fermin D, Park S, Chen Y, Bache RJ, Mariash A, Guan Z, Ormaza S et al. (2004): "Genomic profiling of the human heart before and after mechanical support with a ventricular assist device reveals alterations in vascular signaling networks." Physiol Genomics 17(3), 283-291

Haq S, Choukroun G, Lim H, Tymitz KM, del Monte F, Gwathmey J, Grazette L, Michael A, Hajjar R, Force T et al. (2001): "Differential activation of signal transduction pathways in human hearts with hypertrophy versus advanced heart failure." Circulation 103(5), 
670-677

Hautala N, Tokola H, Luodonpaa M, Puhakka J, Romppanen H, Vuolteenaho O, Ruskoaho H (2001): "Pressure overload increases GATA4 binding activity via endothelin-1." Circulation 103(5), 730-735

Hernandez-Hernandez A, Ray P, Litos G, Ciro M, Ottolenghi S, Beug H, Boyes J (2006): "Acetylation and MAPK phosphorylation cooperate to regulate the degradation of active GATA-1." EMBO J 25(14), 3264-3274

Hill MF, Singal PK (1996): "Antioxidant and oxidative stress changes during heart failure subsequent to myocardial infarction in rats." Am J Pathol 148(1), 291-300.

Hill MF, Singal PK (1997): "Right and left myocardial antioxidant responses during heart failure subsequent to myocardial infarction." Circulation $\underline{96}(7), 2414-2420$

Ho CK, Wood JR, Stewart DR, Ewens K, Ankener W, Wickenheisser J, Nelson-Degrave V, Zhang Z, Legro RS, Dunaif A et al. (2005): "Increased transcription and increased messenger ribonucleic acid (mRNA) stability contribute to increased GATA6 mRNA abundance in polycystic ovary syndrome theca cells." J Clin Endocrinol Metab 90(12), 6596-6602

Ho IC, Vorhees P, Marin N, Oakley BK, Tsai SF, Orkin SH, Leiden JM (1991): "Human GATA-3: a lineage-restricted transcription factor that regulates the expression of the T cell receptor alpha gene." EMBO J $\underline{10}(5), 1187-1192$

Hummel A, Empen K, Dörr M, Felix SB (2015): "De novo acute heart failure and acute decompensated chronic heart failure." Dtsch Arztebl Int 112(17), 298-310

Ishida A, Iijima R, Kobayashi A, Maeda M (2005): "Characterization of cAMP-dependent proteolysis of GATA-6." Biochem Biophys Res Commun 332(4), 976-981

Iung B, Baron G, Butchart EG, Delahaye F, Gohlke-Barwolf C, Levang OW, Tornos P, Vanoverschelde JL, Vermeer F, Boersma E et al. (2003): "A prospective survey of patients with valvular heart disease in Europe: The Euro Heart Survey on Valvular Heart Disease." Eur Heart J 244(13), 1231-1243

Janssen PM, Lehnart SE, Prestle J, Lynker JC, Salfeld P, Just H, Hasenfuss G (1998): "The trabecula culture system: a novel technique to study contractile parameters over a multiday time period." Am J Physiol 274(5 Pt 2), H1481-1488

Jiang SY, Xu M, Zhang YY (2008): "[Role of GATA-4 in cardiac development and remodeling]." Sheng Li Ke Xue Jin Zhan 39(4), 302-306

Joulin V, Bories D, Eleouet JF, Labastie MC, Chretien S, Mattei MG, Romeo PH (1991): "A T-cell specific TCR delta DNA binding protein is a member of the human GATA 
family." EMBO J $\underline{10}(7), 1809-1816$

Kelley C, Blumberg H, Zon LI, Evans T (1993): "GATA-4 is a novel transcription factor expressed in endocardium of the developing heart." Development $\underline{118(3), 817-827}$

Kerkela R, Pikkarainen S, Majalahti-Palviainen T, Tokola H, Ruskoaho H (2002): "Distinct roles of mitogen-activated protein kinase pathways in GATA-4 transcription factormediated regulation of B-type natriuretic peptide gene." J Biol Chem 277(16), 1375213760

Kim Y, Ma AG, Kitta K, Fitch SN, Ikeda T, Ihara Y, Simon AR, Evans T, Suzuki YJ (2003): "Anthracycline-induced suppression of GATA-4 transcription factor: implication in the regulation of cardiac myocyte apoptosis." Mol Pharmacol 63(2), 368-377

Kira Y, Kochel PJ, Gordon EE, Morgan HE (1984): "Aortic perfusion pressure as a determinant of cardiac protein synthesis." Am J Physiol 246(3 Pt 1), C247-258

Ko LJ, Yamamoto M, Leonard MW, George KM, Ting P, Engel JD (1991): "Murine and human T-lymphocyte GATA-3 factors mediate transcription through a cis-regulatory element within the human T-cell receptor delta gene enhancer." Mol Cell Biol 11(5), $2778-2784$

Kobayashi S, Mao K, Zheng H, Wang X, Patterson C, O'Connell TD, Liang Q (2007): "Diminished GATA4 protein levels contribute to hyperglycemia-induced cardiomyocyte injury." J Biol Chem 282(30), 21945-21952

Kobayashi S, Volden P, Timm D, Mao K, Xu X, Liang Q (2010): "Transcription factor GATA4 inhibits doxorubicin-induced autophagy and cardiomyocyte death." J Biol Chem 285(1), 793-804

Kogler H, Schott P, Toischer K, Milting H, Van PN, Kohlhaas M, Grebe C, Kassner A, Domeier E, Teucher $\mathrm{N}$ et al. (2006): "Relevance of brain natriuretic peptide in preloaddependent regulation of cardiac sarcoplasmic reticulum Ca2+ ATPase expression." Circulation 113(23), 2724-2732

LaMorte VJ, Thorburn J, Absher D, Spiegel A, Brown JH, Chien KR, Feramisco JR, Knowlton KU (1994): "Gq- and ras-dependent pathways mediate hypertrophy of neonatal rat ventricular myocytes following alpha 1-adrenergic stimulation." J Biol Chem $\underline{269}(18), 13490-13496$

Laverriere AC, MacNeill C, Mueller C, Poelmann RE, Burch JB, Evans T (1994): "GATA4/5/6, a subfamily of three transcription factors transcribed in developing heart and gut." J Biol Chem 269(37), 23177-23184

Lee Y, Shioi T, Kasahara H, Jobe SM, Wiese RJ, Markham BE, Izumo S (1998): "The cardiac 
tissue-restricted homeobox protein $\mathrm{Csx} / \mathrm{Nkx} 2.5$ physically associates with the zinc finger protein GATA4 and cooperatively activates atrial natriuretic factor gene expression." Mol Cell Biol $\underline{18}(6), 3120-3129$

Levy D, Wilson PW, Anderson KM, Castelli WP (1990): "Stratifying the patient at risk from coronary disease: new insights from the Framingham Heart Study." Am Heart J 119(3 Pt 2), 712-717

Liang Q, Molkentin JD (2002): "Divergent signaling pathways converge on GATA4 to regulate cardiac hypertrophic gene expression." J Mol Cell Cardiol 34(6), 611-616

Liang Q, De Windt LJ, Witt SA, Kimball TR, Markham BE, Molkentin JD (2001a): "The transcription factors GATA4 and GATA6 regulate cardiomyocyte hypertrophy in vitro and in vivo." J Biol Chem 276(32), 30245-30253

Liang Q, Wiese RJ, Bueno OF, Dai YS, Markham BE, Molkentin JD (2001b): "The transcription factor GATA4 is activated by extracellular signal-regulated kinase 1- and 2-mediated phosphorylation of serine 105 in cardiomyocytes." Mol Cell Biol 21(21), 7460-7469

Linzbach A (1948): "Herzhypertrophie und kritisches Herzgewicht." Klin Wschr 26, 459-463

Lurie LJ, Boyer ME, Grass JA, Bresnick EH (2008): "Differential GATA factor stabilities: implications for chromatin occupancy by structurally similar transcription factors." Biochemistry $\underline{47(3), 859-869}$

Macdonald J, Galley HF, Webster NR (2003): "Oxidative stress and gene expression in sepsis." Br J Anaesth 90(2), 221-232

McCord JM (2000): "The evolution of free radicals and oxidative stress." Am J Med 108(8), 652-659

Minegishi N, Suzuki N, Kawatani Y, Shimizu R, Yamamoto M (2005): "Rapid turnover of GATA-2 via ubiquitin-proteasome protein degradation pathway." Genes Cells $\underline{10}(7)$, 693-704

Molkentin JD, Lu JR, Antos CL, Markham B, Richardson J, Robbins J, Grant SR, Olson EN (1998): "A calcineurin-dependent transcriptional pathway for cardiac hypertrophy." Cell 93(2), 215-228

Morgan HE, Gordon EE, Kira Y, Chua HL, Russo LA, Peterson CJ, McDermott PJ Watson PA (1987): "Biochemical mechanisms of cardiac hypertrophy." Annu Rev Physiol 49: 533-543.

Morimoto T, Hasegawa K, Kaburagi S, Kakita T, Wada H, Yanazume T, Sasayama S (2000): "Phosphorylation of GATA-4 is involved in alpha 1-adrenergic agonist-responsive 


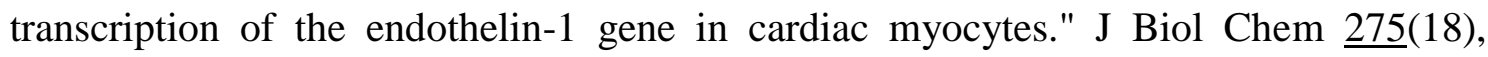
$13721-13726$

Morin S, Charron F, Robitaille L, Nemer M (2000): "GATA-dependent recruitment of MEF2 proteins to target promoters." EMBO J $\underline{19}(9), 2046-2055$

Morisco C, Seta K, Hardt SE, Lee Y, Vatner SF, Sadoshima J (2001): "Glycogen synthase kinase 3beta regulates GATA4 in cardiac myocytes." J Biol Chem 276(30), 2858628597

Morrisey EE, Ip HS, Lu MM, Parmacek MS (1996): "GATA-6: a zinc finger transcription factor that is expressed in multiple cell lineages derived from lateral mesoderm." Dev Biol 177(1), 309-322

Morrisey EE, Ip HS, Tang Z, Parmacek MS (1997): "GATA-4 activates transcription via two novel domains that are conserved within the GATA-4/5/6 subfamily." J Biol Chem $\underline{272}(13), 8515-8524$

Morrisey EE, Tang Z, Sigrist K, Lu MM, Jiang F, Ip HS, Parmacek MS (1998): "GATA6 regulates HNF4 and is required for differentiation of visceral endoderm in the mouse embryo." Genes Dev 12(22), 3579-3590

Mulieri LA, Alpert NR (1984): "Differential effect of 2,3-butanedione monoxime (BDM) on activation and contraction " Biophys $\mathrm{J} \underline{45}, 47 \mathrm{~A}$

Mulieri LA, Hasenfuss G, Ittleman F, Blanchard EM, Alpert NR (1989): "Protection of human left ventricular myocardium from cutting injury with 2,3-butanedione monoxime." Circ Res $\underline{65}$ (5), 1441-1449

Mullally JE, Moos PJ, Edes K, Fitzpatrick FA (2001): "Cyclopentenone prostaglandins of the $\mathrm{J}$ series inhibit the ubiquitin isopeptidase activity of the proteasome pathway." J Biol Chem $\underline{276}(32)$, 30366-30373

Mullis KB, Faloona FA (1987): "Specific synthesis of DNA in vitro via a polymerasecatalyzed chain reaction." Methods Enzymol 155, 335-350

Naito AT, Okada S, Minamino T, Iwanaga K, Liu ML, Sumida T, Nomura S, Sahara N, Mizoroki T, Takashima A et al. (2010): "Promotion of CHIP-mediated p53 degradation protects the heart from ischemic injury." Circ Res 106(11), 1692-1702

Nakagawa R, Sakai Y, Takashima A, Terada T, Kobayashi A, Maeda M (2001): "GATA DNA-binding protein expressed in mouse I-10 Leydig testicular tumor cells." Biochem Biophys Res Commun 283(2), 412-416

Nakagawa R, Sato R, Futai M, Yokosawa H, Maeda M (1997): "Gastric GATA-6 DNAbinding protein: proteolysis induced by cAMP." FEBS Lett $\underline{408(3), 301-305}$ 
Ohara Y, Atarashi T, Ishibashi T, Ohashi-Kobayashi A, Maeda M (2006): "GATA-4 gene organization and analysis of its promoter." Biol Pharm Bull 29(3), 410-419

Oka T, Maillet M, Watt AJ, Schwartz RJ, Aronow BJ, Duncan SA, Molkentin JD (2006): "Cardiac-specific deletion of Gata4 reveals its requirement for hypertrophy,

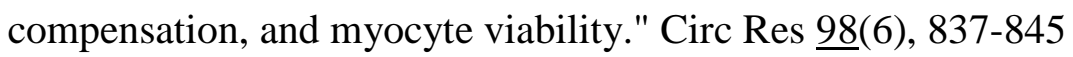

Perreault CL, Mulieri LA, Alpert NR, Ransil BJ, Allen PD, Morgan JP (1992): "Cellular basis of negative inotropic effect of 2,3-butanedione monoxime in human myocardium." Am J Physiol 263(2 Pt 2), H503-510

Phillips RM, Altschuld RA (1996): "2,3-Butanedione 2-monoxime (BDM) induces calcium release from canine cardiac sarcoplasmic reticulum." Biochem Biophys Res Commun $\underline{229}(1), 154-157$

Pikkarainen S, Tokola H, Majalahti-Palviainen T, Kerkela R, Hautala N, Bhalla SS, Charron F, Nemer M, Vuolteenaho O, Ruskoaho H (2003): "GATA-4 is a nuclear mediator of mechanical stretch-activated hypertrophic program." J Biol Chem $\underline{278(26), 23807-}$ 23816

Pikkarainen S, Tokola H, Kerkela R, Ruskoaho H (2004): "GATA transcription factors in the developing and adult heart." Cardiovasc Res $\underline{63}(2), 196-207$

Rockman HA, Koch WJ, Lefkowitz RJ (2002): "Seven-transmembrane-spanning receptors and heart function." Nature $\underline{415}(6868), 206-212$

Ross RS, Borg TK (2001): "Integrins and the myocardium." Circ Res $\underline{88}(11), 1112-1119$

Schoendube FA, Klues HG, Reith S, Flachskampf FA, Hanrath P, Messmer BJ (1995): "Long-term clinical and echocardiographic follow-up after surgical correction of hypertrophic obstructive cardiomyopathy with extended myectomy and reconstruction of the subvalvular mitral apparatus." Circulation 92(9 Suppl), II122-127

Schott P, Asif AR, Graf C, Toischer K, Hasenfuss G, Kogler H (2008): "Myocardial adaptation of energy metabolism to elevated preload depends on calcineurin activity : A proteomic approach." Basic Res Cardiol 103(3), 232-243

Shiojima I, Komuro I, Oka T, Hiroi Y, Mizuno T, Takimoto E, Monzen K, Aikawa R, Akazawa H, Yamazaki T et al. (1999): "Context-dependent transcriptional cooperation mediated by cardiac transcription factors Csx/Nkx-2.5 and GATA-4." J Biol Chem $\underline{274}(12), 8231-8239$

Sugden PH, Clerk A (1998): "Cellular mechanisms of cardiac hypertrophy." J Mol Med 76(11), 725-746

Suzuki E, Evans T, Lowry J, Truong L, Bell DW, Testa JR, Walsh K (1996): "The human 
GATA-6 gene: structure, chromosomal location, and regulation of expression by tissuespecific and mitogen-responsive signals." Genomics $\underline{38}$ (3), 283-290

Suzuki YJ, Shi SS, Blumberg JB (1999): "Modulation of angiotensin II signaling for GATA4 activation by homocysteine." Antioxid Redox Signal 1(2), 233-238

Tremblay JJ, Viger RS (2003): "Transcription factor GATA-4 is activated by phosphorylation of serine 261 via the cAMP/protein kinase a signaling pathway in gonadal cells." J Biol Chem 278(24), 22128-22135

Tsukamoto O, Minamino T, Okada K, Shintani Y, Takashima S, Kato H, Liao Y, Okazaki H, Asai M, Hirata A et al. (2006): "Depression of proteasome activities during the progression of cardiac dysfunction in pressure-overloaded heart of mice." Biochem Biophys Res Commun 340(4), 1125-1133

van Berlo J, Elrod J, Aronow B, Pu W, Molkentin J (2011): "Serine 105 phosphorylation of transcription factor GATA4 is necessary for stress-induced cardiac hypertrophy in vivo." Proc Natl Acad Sci 108(30), 12331-12336

Weekes J, Morrison K, Mullen A, Wait R, Barton P, Dunn MJ (2003): "Hyperubiquitination of proteins in dilated cardiomyopathy." Proteomics $\underline{3}(2), 208-216$

Wettschureck N, Rutten H, Zywietz A, Gehring D, Wilkie TM, Chen J, Chien KR, Offermanns S (2001): "Absence of pressure overload induced myocardial hypertrophy after conditional inactivation of Galphaq/Galpha11 in cardiomyocytes." Nat Med $\underline{7}(11)$, $1236-1240$

Wolf-Maier K, Cooper RS, Banegas JR, Giampaoli S, Hense HW, Joffres M, Kastarinen M, Poulter N, Primatesta P, Rodriguez-Artalejo F et al. (2003): "Hypertension prevalence and blood pressure levels in 6 European countries, Canada, and the United States." JAMA $\underline{289}(18)$, 2363-2369

Yamamoto M, Ko LJ, Leonard MW, Beug H, Orkin SH, Engel JD (1990): "Activity and tissue-specific expression of the transcription factor NF-E1 multigene family." Genes Dev $\underline{4}(10), 1650-1662$

Yamazaki T, Komuro I, Shiojima I, Yazaki Y (1999): "The molecular mechanism of cardiac hypertrophy and failure." Ann N Y Acad Sci $\underline{874}$, 38-48

Yang HY, Evans T (1992): "Distinct roles for the two cGATA-1 finger domains." Mol Cell Biol $\underline{12}(10), 4562-4570$

Zon LI, Gurish MF, Stevens RL, Mather C, Reynolds DS, Austen KF, Orkin SH (1991): "GATA-binding transcription factors in mast cells regulate the promoter of the mast cell carboxypeptidase A gene." J Biol Chem 266(34), 22948-22953 


\section{Danksagung}

Mein ganz großer Dank geht an PD Dr. med. Egbert Bisping, Oberarzt der Klinik für Kardiologie an der medizinischen Universität Graz, der mich in seiner Zeit an der Universität Göttingen für das Thema begeistert und mir viele Aspekte wissenschaftlicher Medizin und universitärer Forschung beigebracht hat. Mit seinem Enthusiasmus, Engagement und Geduld über all die Jahre hat er mir sehr bei der Fertigstellung dieser Arbeit geholfen.

Herzlich danken möchte ich außerdem Prof. Dr. med. Rolf Wachter, Leitender Oberarzt der Klinik für Kardiologie und Pneumologie an der Universitätsmedizin Göttingen, für die Möglichkeit, diese Arbeit erfolgreich abschließen zu können.

Vielen Dank an Esther und Brigitte für die tatkräftige Unterstützung bei der Arbeit im Labor. 


\section{Lebenslauf}

Mein Name ist Andre Wilken. Ich wurde am 13.10.1982 in Damme geboren. Meine Eltern sind der Diplom-Ingenieur Josef Wilken und die Fremdsprachenkorrespondentin Martina Wilken. Ich habe einen Bruder.

Meine schulische Ausbildung absolvierte ich in Lohne und konnte diese im Jahre 2002 mit dem Abitur und Erlangung der Hochschulreife abschließen.

Nach meinem Zivildienst im St. Franziskus Hospital in Lohne trat ich im April 2003 das Studium der Humanmedizin in Göttingen an. Das Studium konnte ich im Mai 2009 mit dem Staatsexamen erfolgreich beenden.

Mit Erlangung der ärztlichen Approbation begann ich meine ärztliche Tätigkeit als Assistenzarzt am St. Vincenz Krankenhaus Paderborn in der Klinik für Kinder- und Jugendmedizin.

Im April 2014 wechselte ich an das Evangelische Krankenhaus in Bielefeld. Seit der Anerkennung als Facharzt für Kinder- und Jugendmedizin im Oktober 2014 absolviere ich in der Abteilung für pädiatrische Intensivmedizin und Neonatologie meine Weiterbildung zum Intensivmediziner und Neonatologen. 